\title{
ANÁliSE DA COMPETIÇÃO ENTRE OS PORTOS DE PARANAGUÁ E SANTOS PARA A MOVIMENTAÇÃO DE SOJA: APLICAÇÃO DE UM MODELO DE EQUILÍBRIO ESPACIAL
}

\section{RONALDO BULHÕES}

Economista

Dissertação apresentada à Escola Superior de Agricultura "Luiz de Queiroz", Universidade de São Paulo, para obtenção do título de Mestre em Ciências, Área de Concentração: Economia Aplicada.

P I R A C I C A B A

Estado de São Paulo - Brasil

Outubro - 1998 
Dados Internacionais de Catalogaçāo na Publicaçāo (CIP)

DIVISÃO DE BIBLIOTECA E DOCUMENTAÇÃO - Campus "Luiz de Queiroz"/USP

Bulhỏes, Ronaldo

Análise da competição entre os portos de Paranaguá e Santos para a

movimentação de soja: aplicação de um modelo de equilibrio espacial / Ronaldo

Bulhōes. - Piracicaba, 1998.

$108 \mathrm{p}$.

Dissertaçāo (mestrado) - E Escola Superior de Agricultura Luiz de Queiroz, 1998.

Bibliografia.

1. Competição econônica 2. Custo 3. Porto de Paranaguá 4. Porto de Santos 5. Soja 6. Transporte rodoviário I. Título 
À minha esposa Adenise pelo amor, compreensão e apoio. À Gabriela pela alegria de sua existência. Aos meus pais Pedro (in memoriam) e Geny pela educação e respeito. 


\section{AGRADECIMENTOS}

Agradeço em especial ao meu orientador, professor José Vicente Caixeta Filho pelo exemplo de dedicação, incentivo e confiança os quais foram determinantes em todas as etapas do curso.

Aos professores do Departamento de Economia da ESALQ Joaquim Bento de Souza Ferreira Filho e Pedro Valentim Marques, pela importante contribuição e valiosas sugestões oferecidas durante o processo de elaboração deste trabalho.

Ao professor da UNIOESTE Ricardo Silveira Martins pela disposição em participar da avaliação final deste estudo.

Aos verdadeiros amigos do curso, Antonio Carlos, Edson, Júlio, Luís Araújo, Márcia, Maurício e Nancy, com os quais compartilhei os sonhos, as angústias, as alegrias e emoções dessa caminhada.

A todos os funcionários do Departamento de Economia da ESALQ, pela simpatia, carinho e amizade, em especial a Cris, Elenice, Helena, Lú, Maiele, Márcia, Pedro e Valdecir.

Ao Ambulatório Médico e Serviço Social da ESALQ, pela profissionalidade e carinho dispensado no momento marcante de minha vida, nascimento da minha primeira filha.

A todos aqueles que em diferentes momentos tiveram uma participação significativa durante minha jornada, por razões intelectuais e afetivas, ficarão sempre na lembrança.

Ao Departamento de Economia, Programa de Pós-Graduação e Capacitação Docente da UNIOESTE e a CAPES pelo incentivo e apoio financeiro. 


\section{S U M Á R I O}

Página

LISTA DE FIGURAS........................................................................ vii

LISTA DE TABELAS............................................................................ vii

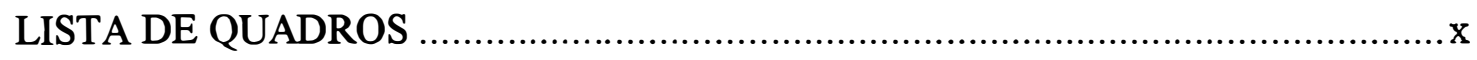

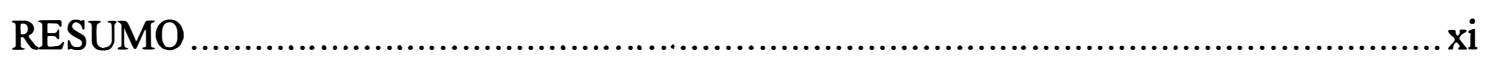

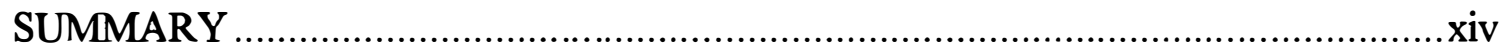

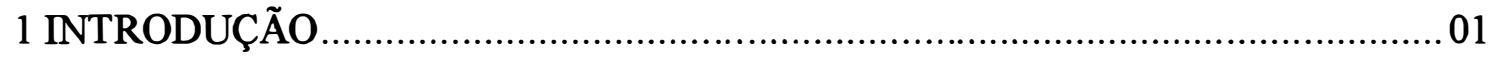

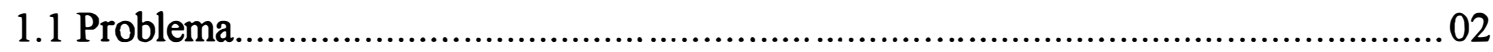

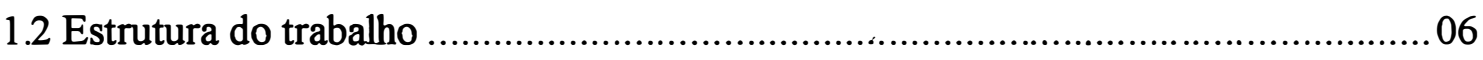

2 A MOVIMENTAÇÃO DE SOJA POR PORTOS MARÍTIMOS …........................ 07

2.1 Panorama geral sobre a soja e o sistema de transporte rodoviário ....................... 07

2.20 Sistema portuário nacional.................................................................... 12

2.2.1 Principais características do porto de Paranaguá ......................................... 19

2.2.2 Principais características do porto de Santos............................................. 23

2.2.3 Análise comparativa entre o porto de Paranaguá e Santos quanto à

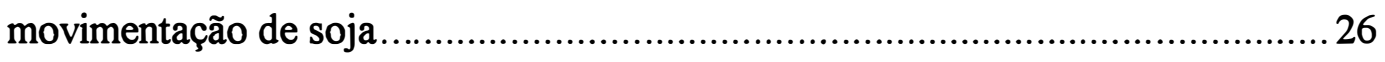

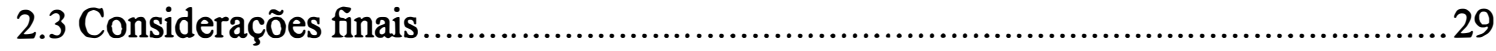

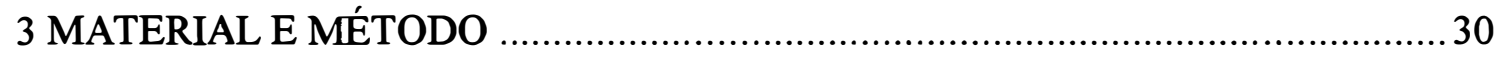

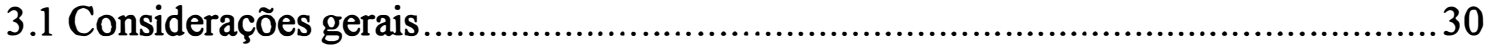

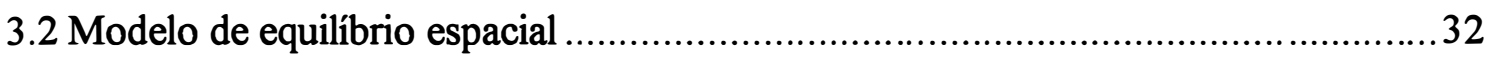




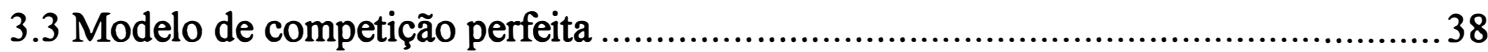

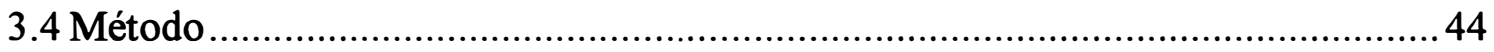

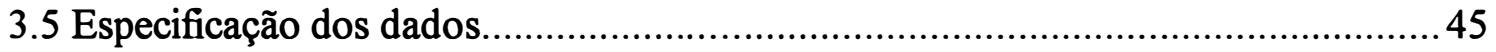

3.5.1 Zoneamento da área de produção da soja ......................................................... 46

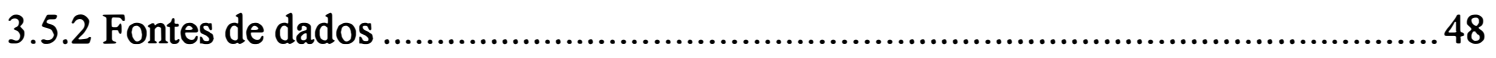

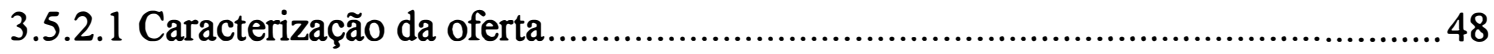

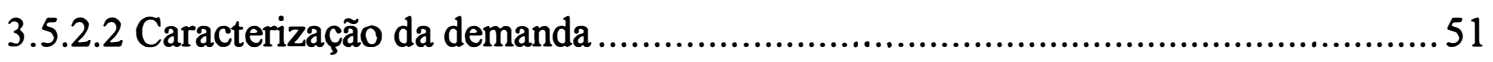

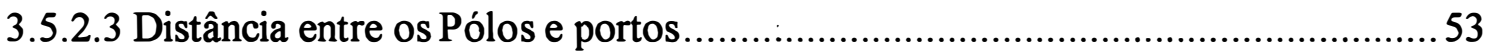

3.5.2.4 Obtenção dos custos de transportes entre os Pólos e portos............................. 55

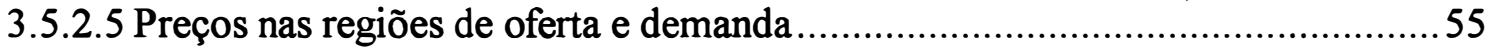

3.5.2.6 Elasticidades preço de oferta e demanda ......................................................58

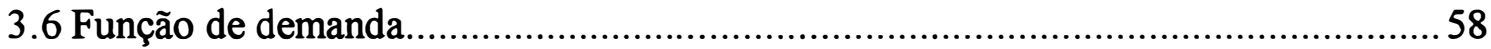

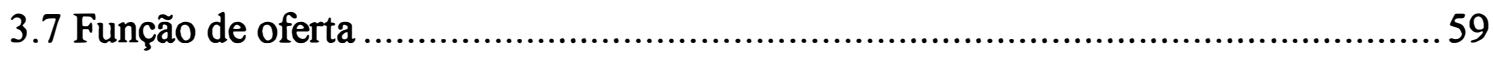

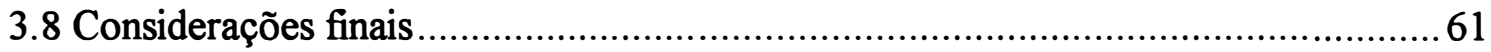

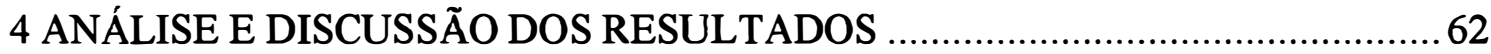

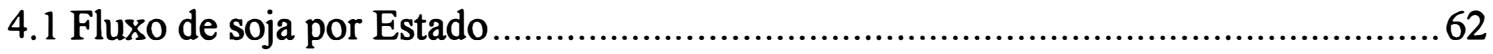

4.2 Fluxo de soja destinado aos portos de Paranaguá e Santos ...................................67

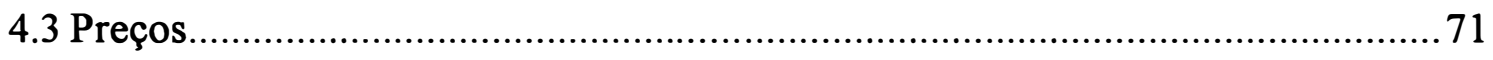

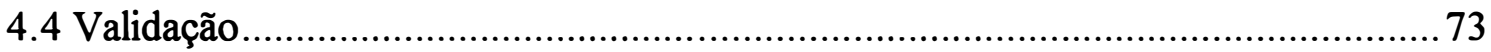

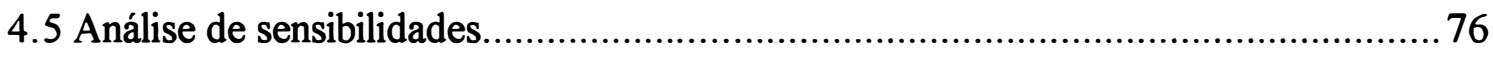

4.5.1 Análise de sensibilidades das elasticidades-preço .............................................77

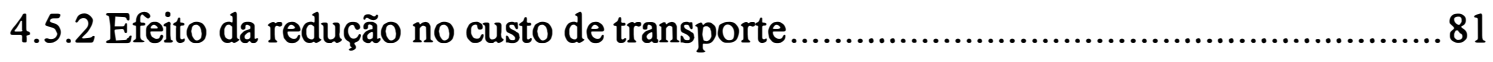

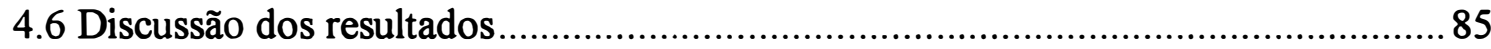

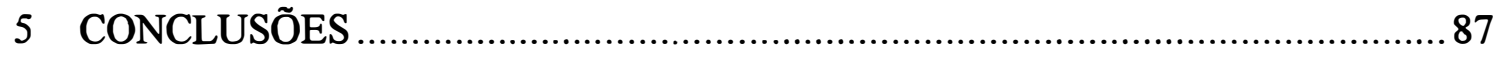

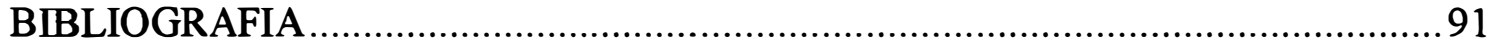

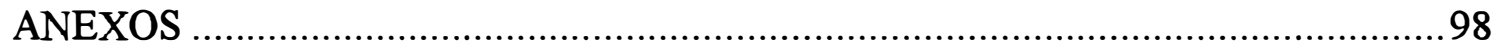




\section{LISTA DE FIGURAS}

Página

Figura 1 Representação esquemática dos canais de comercialização da soja brasileira. 09

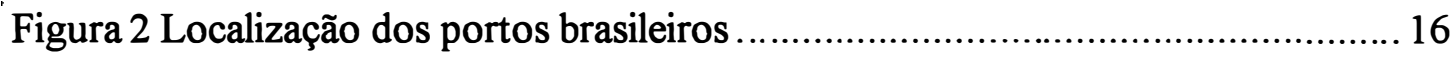

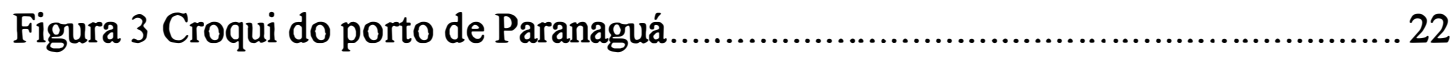

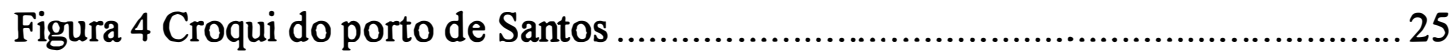

Figura 5 Modelo de equilíbrio espacial sem custos de transportes ...........................33

Figura 6 Modelo de equilibrio espacial com custos de transportes ............................35

Figura 7 Modelo de equilíbrio espacial com custos de transportes fixos...................36

Figura 8 Principais rotas utilizadas para movimentação de grãos em 1995 ................54 


\section{LISTA DE TABELAS}

Página

Tabela 2.1 Capacidade instalada de processamento de soja no Brasil 10

Tabela 2.2 Movimentação dos portos brasileiros por tipo de carga - 1995

Tabela 2.3 Principais portos brasileiros em movimentação de Granéis Alimentares $-1995$

Tabela 2.4 Principais portos brasileiros de exportaçãode soja em gão e as respectivas quantidades e porcentagens exportadas no ano de 1995

Tabela 2.5 Características dos pontos de embarque de grãos e farelo no porto de Paranaguá

Tabela 2.6 Principais Estados brasileiros produtores de grãos em 1995 (em 1000 t) 26

Tabela 2.7 Distâncias em quilômetros entre os principais Pólos de produção e os portos de Santos e Paranaguá - 1995

Tabela 2.8 Estrutura de custos de transportes por rotas selecionadas (utilizadas em 1995) para soja em grão

Tabela 3.1 Produção de soja por Estado na região em estudo - 1995 (1000 t) 48

Tabela 3.2 Movimentação de soja por ferrovia para os portos de Paranaguá, Santos e Vitória para o ano de 1995 (em 1000 t)

Tabela 3.3 Preços médio de mercado por Pólo para a soja no ano de 1995 
Tabela 3.4 Coeficientes utilizados nas funções de demanda de soja em grão, 1995... 59

Tabela 3.5 Coeficientes utilizados nas funções de oferta de soja em grão, 1995 ........60

Tabela 4.1 Comparação do fluxo de soja por origem para o Estado de Santa

Catarina em 1995, (1000 t)

Tabela 4.2 Comparação do fluxo de soja por origem para o Estado do Paraná, em 1995, (1000 t).

Tabela 4.3 Comparação do fluxo de soja por origem para o Estado de Minas Gerais em 1995, (1000 t).

Tabela 4.4 Comparação do fluxo de soja por origem para o Estado de São Paulo em 1995, (1000 t)

Tabela 4.5 Comparação do fluxo de soja por origem para o Estado de Goiás em 1995, (1000 t)

Tabela 4.6 Comparação do fluxo de soja por origem para o Estado de Mato Grosso do Sul em 1995, (1000 t).

Tabela 4.7 Comparação do fluxo de soja por origem para o Estado de Mato Grosso em 1995, (1000 t) 65

Tabela 4.8 Fluxo de soja para os portos de Paranaguá e Santos em 1995 (1000 t) ... 68

Tabela 4.9 Preço de mercado para a soja (atual e fornecido pelo modelo) para o ano de 1995 , em US\$/t . 72

Tabela 4.10 Resultados obtidos pelos testes estatísticos não-paramétricos. 76

Tabela 4.11 Fluxo de soja real, simulado e com custos de transportes reduzidos em $20 \%$

Tabela 4.12 Comportamento dos preços da soja com a redução em $20 \%$ nos custos de transportes, em US\$ por toneladas, para o ano de 1995. 


\section{LISTAS DE QUADROS}

\section{Página}

Quadro 3.1 Principais Pólos de produção agrícola

Quadro 3.2 Quantidades de soja produzidas por Pólos em 1995 (em 1000 t)

Quadro 3.3 Quantidades de soja ofertada por Pólo menos a quantidade transportada por ferrovia em 1995 (em 1000 t). .51

Quadro 3.4 Quantidade de soja demandada por Pólo e portos em 1995 (em 1000 t) 52 


\section{ANÁLISE DA COMPETIÇÃO ENTRE OS PORTOS DE PARANAGUÁ E SANTOS PARA A MOVIMENTAÇÃO DE SOJA: APLICAÇÃO DE UM MODELO DE EQUILÍBRIO ESPACIAL}

Autor: Ronaldo Bulhões

Orientador: Prof. Dr. José Vicente Caixeta Filho

\section{RESUMO}

Este trabalho teve como objetivo fazer uma análise da competição entre os portos de Paranaguá e Santos para a movimentação de soja em grão, utilizando-se, como instrumento analítico, um modelo de equilíbrio espacial, o qual determinou quais as rotas de menor custo, as quantidades a serem transportadas e os preços nas regiões de oferta e demanda.

Os resultados fornecidos pelo modelo para a exportação da soja mostraram que os fluxos devem ser originados naquelas regiões cujas necessidades internas foram satisfeitas e que possuam uma certa proximidade com os portos de exportação. No caso do porto de Paranaguá, a soja por ele escoada teve origem nos Estados do Paraná e Santa Catarina, com fluxos similares aos ocorridos na situação real, porém com volumes diferentes.

Com relação ao porto de Santos, o fluxo de soja simulado pelo modelo para exportação não apresentou o mesmo comportamento da situação real, onde praticamente todos os Pólos do Estado de São Paulo exportavam a soja produzida por este porto. Os 
resultados mostraram que é mais viável os Pólos do Estado de São Paulo consumirem a produção local, de acordo com sua capacidade de industrialização, que exportar, uma vez que se destinar sua produção ao mercado externo, terá que importar de outros Estados para suprir suas necessidades de processamento, o que por sinal vem sendo observado ultimamente. Assim, a soja destinada ao porto de Santos, de acordo com a solução ótima, deve ter origem nos Estados de Minas Gerais, Goiás e Mato Grosso.

As simulações realizadas com as variáveis exógenas do modelo (elasticidadepreço de oferta, elasticidade-preço de demanda e custos de transportes), demonstraram que a soja poderá tornar-se mais competitiva, principalmente no caso de melhorias no setor de infra-estrutura de transportes.

Para melhor poder de análise da competição entre os portos de Paranaguá e Santos, a pesquisa abordou também outros aspectos relevantes, tais como vias de acesso e infra-estrutura fisica dos mesmos. No caso do acesso por rodovia, os dois portos enfrentam problemas com relação à transposição das cidades de Curitiba e São Paulo, onde há conflito de tráfego de caminhões com o tráfego urbano. Contudo, a transposição de Curitiba é menos congestionada que a de São Paulo. Por outro lado, com relação ao modal ferroviário, o porto de Santos possui uma melhor infra-estrutura nas vias de acesso que o porto de Paranaguá.

No caso da infra-estrutura física, o porto de Paranaguá apresenta maior capacidade de recepção, armazenamento e embarque, sendo que sua capacidade total de embarque é duas vezes maior que o porto de Santos, o qual apresenta ainda limitações nos setores de recepção e armazenamento, além de uma tarifa portuária superior à tarifa portuária praticada em Paranaguá.

De acordo com as análises sobre os resultados do modelo, pode-se inferir que para a soja originada nas regiões mais próximas aos portos (no caso Santa Catarina e 
Paraná com destino ao porto de Paranaguá e São Paulo e Minas Gerais com destino ao porto de Santos) praticamente não existe competição. Contudo, as limitações de infraestrutura e os altos custos portuários, somados aos elevados custos de transportes, acabam por diminuir a vantagem que o porto de Santos possui sobre o porto de Paranaguá em relação à região Centro-Oeste e, até mesmo, para o Sul e Sudoeste de São Paulo, o que contribui para tornar o porto de Paranaguá mais competitivo que o porto de Santos no que diz respeito à soja oriunda dessa região, mesmo possuindo maior distância em relação ao porto de Santos. 


\title{
ANALYSIS OF THE COMPETITION BETWEEN THE PORTS OF PARANAGUÁ AND SANTOS FOR SOYBEAN MOVEMENTS: THE APPLICATION OF A SPATIAL EQUILIBRIUM MODEL
}

\author{
Author: Ronaldo Bulhões
}

Adviser: Prof. Dr. José Vicente Caixeta Filho

\section{SUMMARY}

The purpose of this paper was to analyse the competition between the Ports of Paranaguá and Santos for the movement of soybean grains, through the use of a spatial equilibrium as an analytical instrument, which determinted which were the least costly routes, the quantities to be transported and the prices in the supply and demand regions.

The results provided by the model for exporting soybean showed that flows should be originated in those regions where internal needs have been satisfied and that were within a certain proximity from the exporting ports. In the case of the Port of Paranaguá, the soybean flowing through it was originated in the States of Paraná and Santa Catarina, similarly to those that occurred in the real situation, however in different quantities. 
With regard to the Port of Santos, the flow of soybean simulated by the model did not show the same behaviour as in the real situation, where practically all the Points in the State of São Paulo exported the produced soybean through this Port. The results showed that it would be more feasible for the Points in the State of São Paulo to consume their production in accordance to their capacity for industrial processessing instead of exporting it. If it were destined to the overseas market, soybean would have to be imported from other states to meet local processing requirements, which is what in fact has been observed in recent times. Thus, soybean destined for the Port of Santos, according to an optimum solution, should be originated from the States of Minas Gerais, Goiás and Mato Grosso.

The simulations carried out with the variations of exogenous variables of the model (elasticity-price of supply, elasticity-price of demand and transport costs) demonstrated that soybean could become more competitive, mainly in the case of improving the conditions of the transport infra-structure sector.

To enable a better analysis of the competition between the Ports of Paranaguá and Santos, the research also approached other relevant aspects, such as access ways and their physical infra-structure. In the case of access by highways, the two ports face problems with regard to traversing the cities of Curitiba and São Paulo, where there is conflict between truck and urban traffic. Nonetheless, in traversing Curitiba there is less congestion than in São Paulo. On the other hand, with regard to the railway mode, the Port of Santos has a better access way infra-structure than the Port of Paranaguá.

As far as physical infra-structure is concerned, the Port of Paranaguá shows greater reception, storage and shipping capacity, its total shipping capacity being twice as large as that of the Port of Santos which, moreover, has limitations in the reception and storage sectors, apart from applying a higher port tariff than that applied in Paranaguá. 
According to the analysis of the model's results, it may be inferred that for soybean originating in the regions closest to the Ports (in the case of Santa Catarina and Paraná destined for the Port of Paranaguá and São Paulo and Minas Gerais destined for the Port of Santos) there is practically no competiton. Even so, the infra-structure limitations and high port costs, added to the high cost of transport, end up lessening the advantage which the Port of Santos has over the Port of Paranaguá in the Midwestern region and even for the South and Southwest of São Paulo, which contribute toward making the Port of Paranagua more competitive than the Port of Santos with respect to soybean originating from this region, despite the greater distance in relation to that of the Port of Santos. 


\section{INTRODUÇÃO}

A soja, apesar de ser cultivada no Brasil há aproximadamente 100 anos, é somente a partir da década de 1970 que sua produção torna-se expressiva, levando o Brasil a conquistar, em um curto espaço de tempo, a segunda posição na produção e exportação mundial da soja in natura. Seu cultivo inicial deu-se na região Sul do País, expandindo-se, num segundo momento, para a região Centro-Oeste.

A transferência espacial da produção implicou um aumento considerável na distância média a ser percorrida entre as zonas de produção e os portos de exportação, principalmente em relação aos portos de Paranaguá e Santos, tornando-se comum referirse aos altos custos de transportes e portuários como sendo fatores que contribuem negativamente na competição da soja brasileira no mercado internacional.

Esse panorama de competição internacional exige a crescente busca de vantagens competitivas por parte dos produtores e comerciantes participantes da cadeia da soja brasileira.

Sendo assim, de acordo com Magano (1995a, p.6) "o porto deve contribuir no sentido de garantir condições básicas propiciadoras do estabelecimento de vantagem competitiva, destacadamente para os produtos de interesse da sociedade, inserindo-se nos planos estratégicos da agricultura e da indústria". 
Nesse contexto, uma distribuição logística eficiente torna-se necessária para que os agentes envolvidos no processo de produção e comercialização da soja, principalmente os da região Centro-Oeste brasileira, possam auferir maiores ganhos no momento da opção pela utilização do porto de Paranaguá ou do porto de Santos.

\subsection{Problema}

A grande maioria das exportações brasileiras é escoada através da rede portuária. Segundo Moreira (1997), em 1995, dos US\$ 46,5 bilhões exportados, US\$ 37,5 bilhões deixaram o País via mar, isto é, $81 \%$ do valor total exportado. Nesse mesmo ano, foram enviados ao exterior 387,7 milhões de toneladas de cargas a partir dos portos brasileiros.

O sistema portuário nacional conta com cerca de 46 portos, sendo 34 de navegação marítima e 12 de navegação interior (Anuário Estatístico Portuário, 1995). Dentre os portos de navegação marítima destaca-se o porto de Paranaguá, no Estado do Paraná.

O volume total de cargas movimentadas pelo porto de Paranaguá em 1995 foi de aproximadamente 17,2 milhões de toneladas. A movimentação de granéis sólidos (soja, farelo de soja, trigo, milho, cítricos, açúcar, entre outros) constitui a principal fatia de cargas movimentada pelo porto $(62,3 \%)$, vindo em segundo lugar os granéis líquidos (derivados de petróleo, óleo vegetal, produtos químicos, entre outros), com $20,5 \%$, e, por fim, a chamada carga geral (mercadorias acondicionadas em volume: madeira, algodão, congelados, tratores, entre outros), com 17,2\%. Dentre os granéis sólidos movimentados pelo porto de Paranaguá, aproximadamente 1,3 milhões de toneladas $(12,2 \%)$ corresponderam à soja em grão (Anuário Estatístico Portuário, 1995). 
A área de influência do porto de Paranaguá, segundo GEIPOT ${ }^{1}$ (1994a), compreende o Estado do Paraná, Santa Catarina, Sul de São Paulo, Mato Grosso do Sul, Mato Grosso e Paraguai. Movimenta, ainda, cargas provenientes de Rondônia e parte do Rio Grande do Sul e Argentina.

A soja chega ao porto de Paranaguá através do corredor de transporte ${ }^{2}$ do Paraná/Santa Catarina, constituído pelos modais rodoviário e ferroviário. A área de influência desse corredor engloba os Estados do Paraná, Santa Catarina, Mato Grosso do Sul, Mato Grosso e Paraguai.

$\mathrm{Na}$ área de influência do porto de Paranaguá, como meio alternativo para o escoamento de soja, encontra-se o porto de Santos, porto de navegação marítima, no Estado de São Paulo. O volume total de cargas movimentadas pelo porto de Santos atingiu aproximadamente 35,1 milhões de toneladas no ano de 1995 , sendo que deste montante, $42,6 \%$ corresponderam a granéis sólidos; $21,6 \%$ a granéis líquidos e $35,8 \%$ a carga geral. Dentre os granéis sólidos movimentados pelo porto de Santos, aproximadamente 1,2 milhões de toneladas $(8,0 \%)$ corresponderam à soja em grão (Anuário Estatístico Portuário, 1995).

A área de influência do porto de Santos compreende, de acordo com o GEIPOT (1994b), os Estados de São Paulo, Norte do Paraná, Mato Grosso do Sul, Mato Grosso, Goiás e Minas Gerais (Triângulo Mineiro). O porto de Santos é suprido pelo corredor de transporte que leva o seu próprio nome, isto é, o corredor de transporte de Santos, cuja área de influência é a mesma do porto. Os meios de transporte utilizados neste corredor envolvem os modais rodoviário, ferroviário e hidroviário.

\footnotetext{
${ }^{1}$ Empresa Brasileira de Planejamento de Transportes - GEIPOT.

${ }^{2}$ Define-se corredor de transporte como um conjunto coordenado de meios e facilidades que, ao longo de determinados eixos de circulação, viabilizam a movimentação de cargas em escala econômica (GEIPOT, 1995).
} 
A soja produzida no Mato Grosso e Mato Grosso do Sul e exportada via porto de Paranaguá percorre aproximadamente 100 quilômetros a mais do que se fosse exportada via porto de Santos, o que implica em um custo de transporte mais elevado. Segundo Lício \& Corbucci (1996), o custo final da soja originada da Chapada dos Parecis, no Mato Grosso, e movimentada aos portos de Paranaguá e Santos, utilizando o transporte rodoviário, fica entre $35 \%$ a $45 \%$ mais elevado do que seu preço de oferta na Chapada dos Parecis.

A elevação no custo final da soja tem sido motivo de preocupação por parte dos empresários e produtores agrícolas, uma vez que o grão é um produto homogêneo, produzido na área de influência dos dois portos, sendo que a diferença entre os preços de oferta e demanda é basicamente devida aos custos de transporte e armazenagem.

A movimentação de soja, assim como de qualquer outra carga, através de diversos meios de transporte, ocorre sem qualquer tipo de restrição dentro do território brasileiro. Isto significa que a soja pode se movimentar livremente de uma região para outra, de acordo com a opção que envolve um menor custo de transporte, uma maior rapidez e confiabilidade na entrega da carga e um serviço portuário mais eficiente.

A movimentação de soja de uma região para outra é prática comum no Brasil. Porém, o sistema de transporte da mesma não tem ocorrido de forma integrada, devido a falta de corredores de transportes multimodais, que ofereçam alternativas de transportes menos custosas.

O meio de transporte mais utilizado no Brasil é o rodoviário. Segundo Caixeta Filho (1996a), citando dados do GEIPOT, nos últimos dez anos, a modalidade de transporte rodoviário vem sendo responsável por algo em torno de $60 \%$ do transporte de carga no Brasil, contra $20 \%$ do sistema ferroviário, e outros quase $20 \%$ do sistema hidroviário. Para o caso de granéis sólidos agrícolas, observou-se que, em alguns anos, 
mais de $80 \%$ da produção agrícola nacional era transportada por caminhões.

O modal rodoviário apresenta-se como o meio de transporte mais compatível com a movimentação' de soja entre as duas áreas de atuação dos portos, devido à sua maior flexibilidade, comparada aos modais ferroviário e hidroviário. Isso se explica pelo fato dos caminhões se deslocarem de uma região para outra com maior facilidade e por rotas alternativas, ao passo que as ferrovias ligam áreas isoladas de produção aos portos, sem interligação regional. No caso das hidrovias (a Tietê-Paraná, por exemplo), estas normalmente não têm acesso direto aos portos, limitando-se a movimentar os grãos de terminal a terminal, necessitando, com isso, complementação de outros meios de transportes.

Neste sentido, visando oferecer elementos que possam contribuir para uma melhor compreensão sobre a movimentação de soja até o porto de Paranaguá, em função da disponibilidade alternativa pelo porto de Santos, pretende-se avaliar e comparar os desempenhos dos portos de Paranaguá e Santos quanto à movimentação de soja. Especificamente pretende-se: caracterizar os portos de Paranaguá e Santos quanto à movimentação de soja; identificar os principais fatores de competitividade que tornam os portos de Paranaguá e Santos os principais portos na movimentação de soja da região em estudo; e, identificar e analisar o fluxo de soja destinado ao porto de Paranaguá e Santos.

Diante deste cenário, um Modelo de Equilíbrio Espacial, citado e desenvolvido por diversos autores (Bressler \& King, 1970; Takayama \& Judge, 1971; Tomek \& Robinson, 1972; Barros, 1987; Caixeta Filho, 1989; Marques \& Aguiar, 1993), fornece considerações que podem ser incorporadas na análise da movimentação de soja entre várias regiões, tais como as de influência do porto de Paranaguá (Santa Catarina, Paraná, Sul de São Paulo, Mato Grosso do Sul, Mato Grosso e Paraguai) e do porto de Santos (São Paulo, Norte do Paraná, Mato Grosso do Sul, Mato Grosso, Goiás e Minas Gerais). 


\subsection{Estrutura do trabalho}

Este trabalho, além deste capítulo introdutório, conta com mais quatro capítulos, conforme descrito a seguir.

No capítulo 2 apresenta-se a caracterização na movimentação de soja nos portos nacionais, onde se procura realçar a competição entre os portos de Paranaguá e Santos.

No capítulo 3 apresenta-se o Modelo de Equilíbrio Espacial discutido por Bressler \& King, 1970; Takayama \& Judge, 1971; Tomek \& Robinson, 1972; Barros, 1987; Caixeta Filho, 1989 e Marques \& Aguiar, 1993. Em seguida são apresentados os dados estatísticos sobre a distribuição espacial da produção de soja da área em estudo; quantidades ofertadas e demandadas por região e portos; distâncias entre as regiões de oferta e demanda, preços de mercado nas regiões de oferta e demanda e as elasticidades preços de oferta e demanda, os quais serão analisados de acordo com a metodologia proposta.

No capítulo 4, num primeiro momento são apresentados os resultados obtidos; em seguida é procedida a validação do modelo; na terceira etapa são realizadas as análises de sensibilidade do modelo; e por fim, é feita a discussão dos resultados.

O capítulo 5 resume os resultados e apresenta as principais conclusões deste estudo. 


\section{A MOVIMENTAÇÃO DE SOJA POR PORTOS MARÍTIMOS}

Neste capítulo será apresentado um panorama geral relacionando a soja e o sistema de transporte rodoviário. Posteriormente serão apresentados os principais portos nacionais que atuam na movimentação de soja e, finalmente, serão apresentadas as principais características e comparações sobre os portos de Paranaguá e Santos quanto à movimentação de soja.

\subsection{Panorama geral sobre a soja e o sistema de transporte rodoviário}

No Brasil, até o início da década de 70, a soja praticamente não tinha importância econômica. Porém, a partir dessa década, a produção brasileira de soja teve um crescimento significativo, passando de 1,5 milhões de toneladas em 1970 para aproximadamente 30 milhões de toneladas em 1998. O desenvolvimento inicial da soja ocorreu na região Sul do Brasil, sendo que, além das condições externas como preços e demandas crescentes, o apoio governamental e as condições edafobioclimáticas contribuíram para tal crescimento.

A área cultivada com soja no Brasil atinge aproximadamente 12,5 milhões de hectares, com uma produção em torno de 30 milhões de toneladas para safra de 
1997/1998. Atualmente o Brasil ocupa a segunda posição na produção mundial de soja, com $18,0 \%$ do total mundial produzido. Os Estados Unidos ocupam a primeira posição, com $50,3 \%$ e a Argentina e a China ocupam a terceira e a quarta posições, com $9,5 \%$ e $9,2 \%$, respectivamente. Juntos, estes países produzem $87,0 \%$ da soja mundial (Roessing, 1998).

De acordo com Silva (1997), o valor das exportações do complexo soja (grão, farelo e óleo), integra a balança comercial com participação superior a $8,0 \%$ nas receitas globais dos últimos anos, ou seja, algo em torno de US\$ 4,5 bilhões, constituindo-se a principal fonte geradora de divisas do setor agropecuário.

Apesar de ter uma participação significativa na balança comercial brasileira, o complexo soja enfrenta problemas de infra-estrutura praticamente em toda sua cadeia, isto é, desde a produção até o consumo final, quer seja para o mercado interno quer seja para o mercado externo, o que geralmente implica perda de competitividade.

No processo de comercialização, o trajeto percorrido pela soja é, basicamente, da área de produção ao armazém ou cooperativa e destes para a fábrica ou porto, ou diretamente da área de produção para a fábrica ou porto (Soares et al., 1997). Da fábrica saem o óleo e o farelo de soja que vão para o mercado interno ou para exportação (Aguiar, 1990). Tal fluxo pode ser visualizado na Figura 1. 


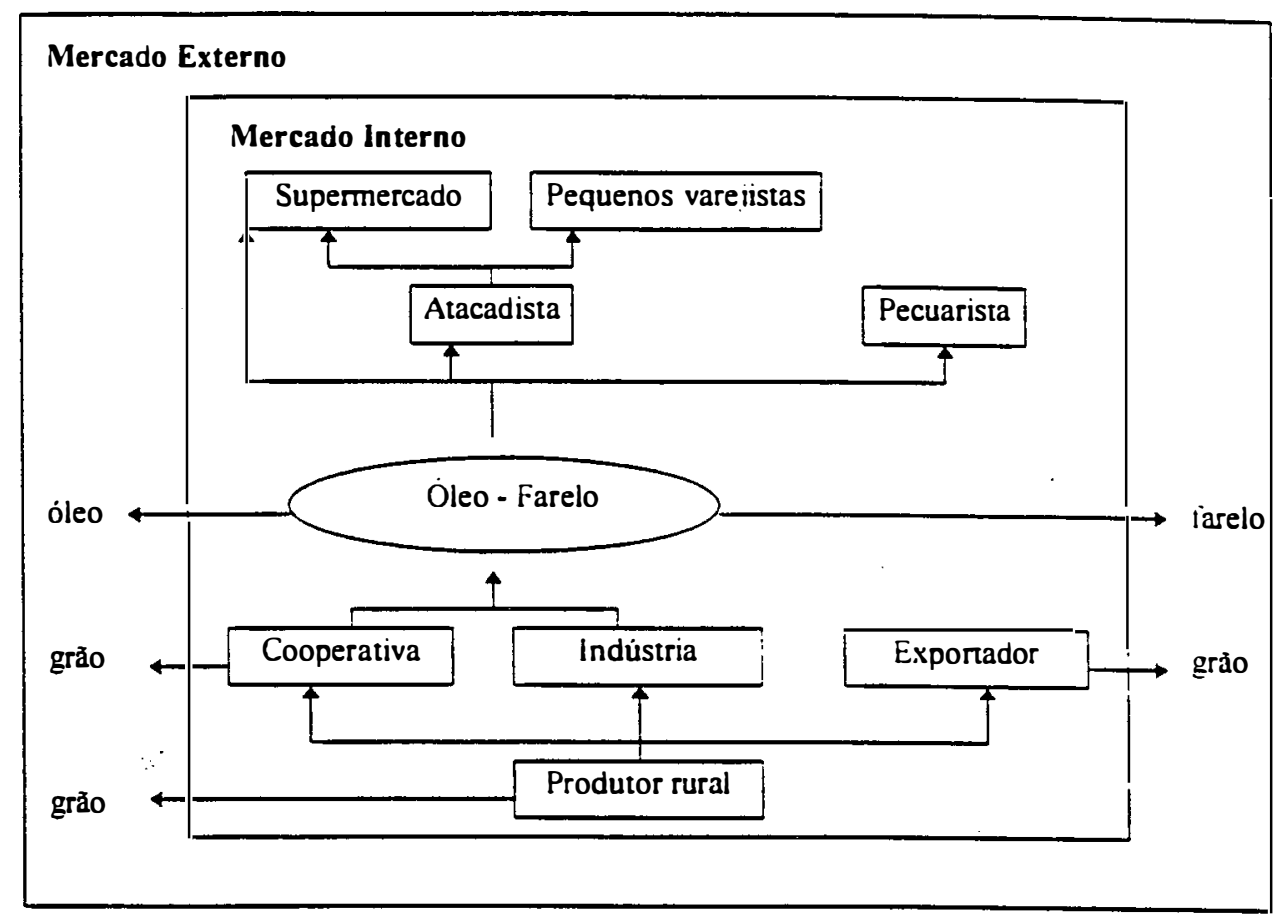

Figura 1 - Representação esquemática dos canais de comercialização da soja brasileira (Fonte: Aguiar, 1990).

As formas processadas são exportadas, geralmente, pelas próprias indústrias de processamento, enquanto a soja em grão é exportada por cooperativas, indústrias ou agentes exportadores. Em termos de processamento a grande maioria das indústrias tem acompanhado o deslocamento da produção de soja. Conforme a Tabela 2.1, observa-se que em $1988,89,9 \%$ da capacidade instalada de processamento de soja encontrava-se na região Sul do País, incluindo o Estado de São Paulo. Já em 1995 essa capacidade reduziu-se para $71,0 \%$. Por outro lado, na região Centro-Oeste a capacidade instalada de processamento de soja passou de 8,7\% em 1988 para 24,9\% em 1995. Nota-se, portanto, uma tendência de deslocamento da indústria da região Sul para a região Centro-Oeste. 
Tabela 2.1 - Capacidade instalada de processamento de soja no Brasil.

\begin{tabular}{lcc}
\hline Estado & \multicolumn{2}{c}{ Capacidade Instalada (\%) } \\
\cline { 2 - 3 } & $\mathbf{1 9 8 8}^{\mathbf{a}}$ & $\mathbf{1 9 9 5}$ \\
\hline Paraná & 30,2 & $\mathbf{2 9 , 8}$ \\
Rio Grande do Sul & 34,1 & 26,9 \\
São Paulo & 17,5 & $\mathbf{9 , 6}$ \\
Mato Grosso & 1,0 & $\mathbf{7 , 7}$ \\
Goiás & 3,1 & 6,9 \\
Mato Grosso do Sul & 2,1 & 6,3 \\
Santa Catarina & 8,1 & 4,7 \\
Minas Gerais & 2,5 & 4,0 \\
Bahia & - & 2,4 \\
Outros & 1,4 & 1,7 \\
\hline Total & $\mathbf{1 0 0}$ & $\mathbf{1 0 0}$ \\
\hline Fonte: a - Sousa (1990). & &
\end{tabular}

O fato de se observar um deslocamento da indústria de processamento de soja para a região Centro-Oeste justifica-se, uma vez que a região de produção de soja tem sofrido modificações no seu perfil locacional ao longo dos últimos 20 anos, onde a zona produtora tradicional, região Sul e São Paulo, cede lugar a uma crescente expansão no Brasil Central (Ferreira et al., 1993), atingindo, nos últimos anos, o Oeste baiano e o Sul do Maranhão (Soares et al., 1997).

A ocupação do espaço geográfico deve orientar-se pela vantagem comparativa de cada região. Contudo, deve-se ressaltar que as distâncias que separam as regiões de produção das regiões consumidoras podem constituir em entraves na competitividade inter-regional da soja, principalmente quando se refere à soja produzida na região tradicional em relação à região de expansão, assim como no que diz respeito à exportação via porto de Paranaguá ou Santos.

Segundo Aguiar (1994), devido aos elevados custos de transporte entre a nova região de produção e o parque processador tradicional, é natural a implantação de indústrias na região fronteiriça para que fossem transportados preferencialmente produtos 
com maior valor agregado. Além do que, evitar-se-ia o fluxo duplo de produtos, ou seja a soja em grão indo do Centro-Oeste para o Sul e Sudeste e derivados voltando para o Centro-Oeste.

Conforme Wright (1980), o aproveitamento do potencial de expansão da produção de grãos depende do estabelecimento de um sistema eficiente de transporte. Tal sistema terá de comportar volumes muito maiores, a custos menores, para permitir que o setor de grãos aumente sua contribuição ao abastecimento interno de alimentos e mantenha sua posição no mercado internacional. Neste sentido, Lício (1995), ressalta que os corredores de transportes multimodais (rodovia, ferrovia, hidrovia, porto) objetivam a integração racional e competitiva entre as áreas de produção e os centros de consumo do País, ou pontos para exportação/importação.

Para o escoamento dos grãos dos diferentes pontos de produção do País, o GEIPOT (1995) apresenta os corredores de transportes do Rio Grande, Paraná/Santa Catarina, Santos, Centro-Leste, Rio de Janeiro, Nordeste e Norte. O sistema de transporte utilizado em todos esses corredores envolve os modais rodoviário, ferroviário e hidroviário. No entanto, apesar da existência dos corredores de transportes com estas diferentes modalidades, a forma unimodal de transporte rodoviário é predominante.

Neste aspecto, Costa (1995), ressalta que o modelo de desenvolvimento do modal rodoviário é o mais compatível com o ritmo de mudanças na estrutura econômica do País, ao passo que os modelos estatais descentralizados das ferrovias e portos, associados ao isolamento histórico dos sistemas regionais, não responderam às exigências da rápida industrialização e deslocamentos das fronteiras econômicas. Costa (1995) afirma ainda que o caminhão não é a melhor alternativa, mas é a alternativa que tem sido mais usada e tem resolvido, de uma certa maneira, o problema de transportes no Brasil. 
Para Caixeta Filho (1996a), a predominância do modo rodoviário é explicada pelas dificuldades enfrentadas por outros sistemas de transportes em atender, de forma eficiente, a demanda em áreas mais afastadas do País, as quais não dispõem de ferrovias e hidrovias. Contudo, isso não quer dizer que o sistema rodoviário brasileiro tenha um desempenho eficiente.

O transporte de grãos no Brasil está associado a grandes distâncias, o que implica altos custos dos fretes. De acordo com Ferreira et al. (1993), na região Sul, para uma distância média de $600 \mathrm{~km}$, há ùm custo representando pouco mais de $10 \%$ da cotação da soja no porto. Para uma distância média de $1.100 \mathrm{~km}$, região Central até o porto de Paranaguá, o custo eleva-se para cerca de $30 \%$ da cotação no porto.

Os altos custos dos fretes rodoviários e das tarifas portuárias têm levado autoridades governamentais e grupos de empresários a buscarem soluções alternativas, visando reduzir tais custos. De um lado, têm-se o investimento na construção de ferrovias (FERROESTE, no Paraná e FERRONORTE, no Mato Grosso, por exemplo), assim como reativação e privatização das linhas ferroviárias já existentes, hidrovias (TietêParaná, em São Paulo e Paraná, e do Madeira, em Rondônia e Amazonas) e rodovias (Anel de integração no Paraná e construção de duas pontes ligando o Paraná à região Centro-Oeste, além de duplicação e privatização de uma grande parte da malha rodoviária existente no Brasil). Por outro lado, tem-se a Lei 8930/93, de Modernização dos Portos, que prevê, entre outros, a privatização e redução nas tarifas portuárias.

\subsection{O sistema portuário nacional}

Os portos constituem um forte elo entre o Brasil e o comércio exterior, por onde é escoada anualmente a grande maioria dos produtos brasileiros destinada ao mercado 
externo, bem como, por onde entram os produtos importados pelo País.

Os altos custos portuários têm sido motivo de preocupação das autoridades e empresários brasileiros. De acordo com Almeida et al. (1996), a ineficiência dos portos, somada aos custos operacionais elevados, contribui para o chamado "Custo Brasil", que repercute no comércio exterior através da diminuição da competitividade dos produtos nacionais.

Segundo Moreira (1997), o Brasil deixa de receber US\$ 5 bilhões ao ano devido aos altos custos da rede portuária, seja porque as tarifas cobradas são elevadas, seja porque o manuseio das cargas é lento e caro demais. De acordo com Pavan (1998, p.29), "no caso da soja, os custos portuários no Brasil respondem por 3\% a $5 \%$ do valor de exportação, enquanto nos Estados Unidos e Argentina chegam no máximo a 1\% e 1,5\%".

Em 1995, trabalho realizado pelo GEIPOT (1995) apontava que os elevados custos de movimentação nos portos nacionais eram basicamente função de: falta de áreas no pátio que antecede ao porto, equipadas com instalações e recursos de armazenagem que permitam regular melhor o fluxo da carga destinada à faixa portuária; excessivo tempo de permanência dos navios no aguardo de atracação e nas operações de carga e descarga.

Sendo assim, Lima \& Velasco (1996) realçam que os portos devem ser analisados enquanto um dos elos de uma matriz de transporte, que deve ter abrangência nacional e integração global.

\footnotetext{
${ }^{3}$ Custo Brasil, de acordo com a Confederação Nacional da Indústria (1995), é um conjunto de ineficiências e distorções acumuladas nos últimos anos no sistema tributário, na legislação trabalhista, na precariedade da educação e saúde, na obsolescência da infra-estrutura de transportes, nos elevados custos portuários, na deterioração das comunicações, no estrangulamento do sistema energético, no elevado custo de financiamento e de rancaçôes.
} 
$\mathrm{Na}$ realidade, o que se verifica é uma certa deficiência em todos os elos da matriz de transportes. Estudos realizados por Wright (1980) apontavam pontos de estrangulamento na infra-estrutura de transporte e armazenamento de grãos no corredor de Paranaguá, onde a falta de integração entre rodovia e ferrovia provocava congestionamento, com filas de até 26 quilômetros na época de pico de safra, aguardando o descarregamento no porto. Hoje, 18 anos após a realização do trabalho de Wright, a situação continua praticamente a mesma pois, em março de 1998, a fila aumentou para 30 quilômetros.

Com relação ao porto de Santos, pesquisa realizada em 1990 pela EPUSP/FEA ${ }^{4}$, citado por Magano (1995a), demonstrou que a valorização de uma opção portuária, de maneira geral, por importadores e exportadores, está associada à sua localização geográfica e à proximidade dos principais centros de produção e consumo. Constatou-se também que as maiores críticas eram originadas do desempenho das operações portuárias, tais como, baixa qualidade de serviços, baixa velocidade na manutenção das cargas e falta de flexibilidade.

O resultado decorrente diz respeito aos preços elevados dos serviços portuários, provocados pela elevada taxa de ocupação dos berços de atracação nos embarcadouros, o que provoca um encarecimento das exportações e constitui-se em um entrave ao seu crescimento.

Neste aspecto, Magano (1995a), afirma que o desempenho e a avaliação da eficácia do sistema portuário, assim como a de qualquer outro setor da atividade humana, estão associadas à perfeita caracterização dos objetivos do sistema e à capacidade de seus agentes em persegui-los de maneira obstinada, sistemática e duradoura.

\footnotetext{
${ }^{4}$ Estudo do Potencial Mercadológico e Elaboração de Plano de Ação Comercial para o Porto de Santos. Convênio CODESP - USP PRES/44.01 - Trabalho não publicado.
} 
No entanto, os dados estatísticos disponíveis referentes ao setor portuário, assim como aos demais setores da economia brasileira, apresentam uma certa debilidade, dificultando uma análise mais profunda em termos de movimentação dos portos.

Isto pode ser verificado no trabalho realizado por Lima \& Velasco (1996), onde são ressaltadas as deficiências em termos de estatísticas disponíveis, associadas à quantificação da especialização de cada porto, à área de influência, às características gerais das cargas e dos seus demandantes para o conjunto de portos. Os principais trabalhos realizados restringem-se aos grandes agregados, tais como movimentações de granéis sólidos, granéis líquidos e carga geral.

Apesar da existência de 46 portos no complexo portuário brasileiro (vide Figura 2), são poucos os que atuam na movimentação de grãos. Isto em parte justifica-se, pois, segundo Magano (1995b), cada porto trata sistemas e produtos de maneira diversa. Por sua vez, cada produto tem seu sistema de operação próprio, com atuação comercial e operacional distintas. 


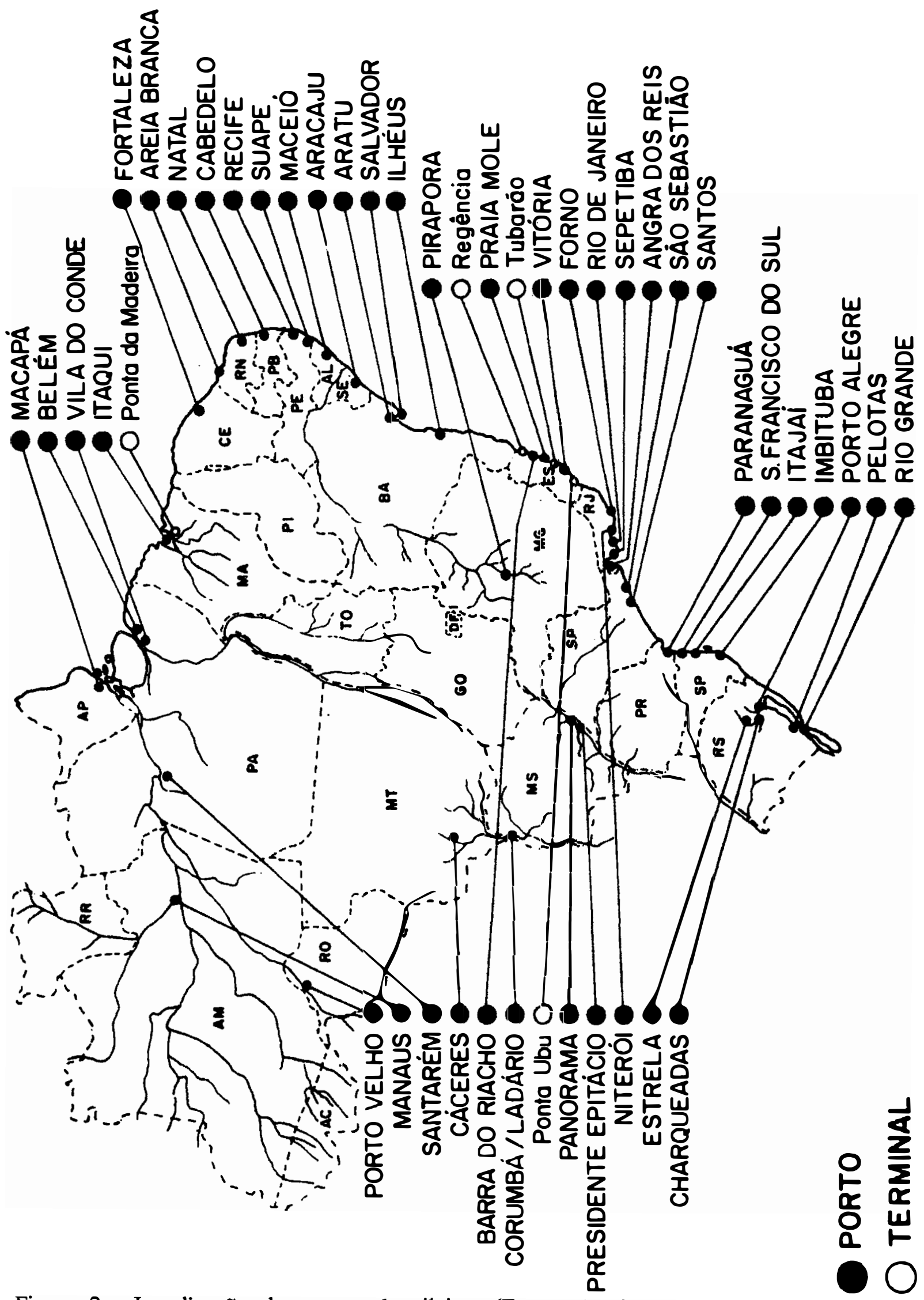

Figura 2 - Localização dos portos brasileiros (Fonte: Anuário Estatístico Portuário, 1995). 
Os portos marítimos brasileiros movimentaram 387,7 milhões de toneladas em 1995, sendo que 222,5 milhões $(57,4 \%)$ referem-se a operações com granéis sólidos, 122,7 milhões $(31,6 \%)$ a granéis líquidos e 42,5 milhões $(11,0 \%)$ a carga geral (Tabela 2.2). Dos 222,5 milhões de toneladas dos granéis sólidos, 27,4 milhões de toneladas $(12,3 \%)$ corresponderam aos granéis alimentares (soja e derivados, sal, açúcar, cítricos, trigo, milho e outros), conforme apresentado na Tabela 2.3. Dentre os principais portos na movimentação de granéis alimentares, destacam-se o porto de Paranaguá, que vem ocupando a primeira posição com $37,8 \%$ do total movimentado e, em segundo e terceiro lugar, vêm os portos de Santos e Rio Grande, com 30,1\% e 20,8\% respectivamente.

Tabela 2.2 - Movimentação dos portos brasileiros por tipo de carga - 1995.

\begin{tabular}{lccc}
\hline Tipo de carga & $\begin{array}{c}\text { Movimentação } \\
\text { Total (t) }\end{array}$ & $\begin{array}{c}\text { Embarques } \\
(\mathbf{t})\end{array}$ & $\begin{array}{c}\text { Desembarques } \\
(\mathbf{t})\end{array}$ \\
\hline Granéis Sólidos & 222.539 .904 & 174.363 .404 & 48.176 .500 \\
Granéis Líquidos & 122.657 .844 & 39.909 .996 & $\mathbf{8 2 . 7 4 7 . 8 4 8}$ \\
Carga Geral & 42.491 .240 & 30.853 .766 & 11.637 .474 \\
\hline Total & $\mathbf{3 8 7 . 6 8 8 . 9 8 8}$ & $\mathbf{2 4 5 . 1 2 7 . 1 6 6}$ & $\mathbf{1 4 2 . 5 6 1 . 8 2 2}$ \\
\hline
\end{tabular}

Fonte: Anuário Estatístico Portuário (1995).

Tabela 2.3 - Principais portos brasileiros em movimentação de Granéis Alimentares 1995.

\begin{tabular}{lccc}
\hline Porto & $\begin{array}{c}\text { Embarque } \\
\text { (em toneladas) }\end{array}$ & $\begin{array}{c}\text { Desembarque } \\
\text { (em toneladas) }\end{array}$ & $\begin{array}{c}\text { Total } \\
\text { (em toneladas) }\end{array}$ \\
\hline Paranaguá & 9.671 .811 & 689.823 & 10.361 .634 \\
Santos & 6.679 .901 & 1.800 .993 & 8.480 .894 \\
Rio Grande & 4.173 .767 & 1.520 .235 & 5.694 .002 \\
São Francisco do Sul & 1.309 .625 & 378.937 & 1.688 .562 \\
Porto Alegre & 162.003 & 402.590 & 564.593 \\
Outros & 378.973 & 277.017 & 655.990 \\
\hline Total & $\mathbf{2 2 . 3 7 6 . 0 8 0}$ & $\mathbf{5 . 0 6 9 . 5 9 5}$ & $\mathbf{2 7 . 4 4 5 . 6 7 5}$ \\
\hline
\end{tabular}

Fonte: elaborado a partir de dados do Anuário Estatístico Portuário (1995). 
O porto de Porto Alegre apresenta movimentação predominantemente no sentido do desembarque (71,3\%). Segundo Lima \& Velasco (1996), a produção vem do interior do Estado do Rio Grande do Sul, por hidrovia, para ser processada nas indústrias locais. Porém, nos demais portos citados, há a predominância dos movimentos de embarque (72,0\% em média), caracterizando-os como portos exportadores.

Os portos localizados na região Sul são os maiores exportadores de soja e derivados, sendo que estes respondem por aproximadamente $68,9 \%$ de sua movimentação, onde cerca de 89,0\% são exportados na forma de granel sólido e $11,0 \%$ na forma de granel líquido. Dentre os sólidos, $79,3 \%$ são representados por farelos e $20,7 \%$ in natura.

A modificação no perfil locacional da região de produção de grãos ampliou o raio de atendimento dos portos (Paranaguá e Santos, principalmente) que atuam na movimentação de produtos agrícolas, assim como novos portos passaram a operar com movimento de grãos, como por exemplo, os portos de Vitória no Espírito Santo e Itaqui no Maranhão, até então especializados em granéis sólidos minerais. Segundo Lima \& Velasco (1996), os portos de Itaqui e Vitória realizam pequenas movimentações de soja originadas da região do cerrado maranhense e da região Centro-Oeste (Minas Gerais e Goiás), respectivamente. Segundo a Administração ${ }^{5}$ do porto de Vitória, o modo de transporte predominante para escoar os grãos por este porto é o ferroviário.

Na Tabela 2.4 são apresentados os principais portos brasileiros responsáveis pela movimentação de aproximadamente 3,5 milhões de toneladas de soja em grãos para o ano de 1995. De acordo com os dados observa-se que os portos de Paranaguá e Santos exportaram praticamente a mesma quantidade de soja, 1.342 e 1.224 milhões de toneladas, respectivamente, enquanto que os demais portos exportaram juntos 896 mil toneladas.

\footnotetext{
${ }^{5}$ Comunicação verbal em 25 de novembro de 1997.
} 
Tabela 2.4 - Principais portos brasileiros de exportação de soja em grão e as respectivas quantidades e porcentagens exportadas no ano de 1995.

\begin{tabular}{lcc}
\hline \multicolumn{1}{c}{ Porto } & \multicolumn{2}{c}{ Soja em grão } \\
& $\mathbf{1 . 0 0 0 ~ t}$ & (\%) \\
\hline Paranaguá - PR & $1.342,1$ & 38,8 \\
Santos - SP & $1.223,8$ & 35,4 \\
Rio Grande - RS & 361,9 & 10,5 \\
Vitória - ES & 292,5 & $\mathbf{8 , 4}$ \\
Itaqui - MA & 139,8 & 4,0 \\
São Francisco - SC & 101,7 & 2,9 \\
\hline Total & $\mathbf{3 . 4 6 1 , 8}$ & $\mathbf{1 0 0}$ \\
\hline
\end{tabular}

Fonte: elaborado a partir de dados do Anuário Estatístico Portuário (1995).

\subsubsection{Principais características do porto de Paranaguá}

O Porto de Paranaguá, operado pela Administração dos Portos de Paranaguá e Antonina (APPA), localiza-se numa posição estratégica em relação às regiões Sudeste e Sul do País. A sua área de influência compreende o Estado do Paraná, Santa Catarina, Sul de São Paulo, Mato Grosso do Sul, Mato Grosso e Paraguai, além de parte do Rio Grande do Sul e Argentina (GEIPOT, 1994a e Anuário Estatístico Portuário, 1995).

O porto, a partir de Curitiba, tem acesso rodoviário pela BR-277, duplicada no trecho Curitiba-Paranaguá, e ferroviário pelas linhas em bitola métrica da antiga Superintendência Regional 5 (SR-5) da Rede Ferroviária Federal (hoje Ferrovia Sul Atlântica - FSA), e acesso marítimo pelo canal de Galheta, com cerca de $15 \mathrm{~km}$ de extensão, largura variando entre $150 \mathrm{~m}$ e $200 \mathrm{~m}$ e profundidade média de $15 \mathrm{~m}$, permitindo a navegação de graneleiros de até 78 mil toneladas (GEIPOT, 1994a). 
Antes de chegarem ao porto, os caminhões passam por um centro de triagem rodoviário, com capacidade de estacionamento para 1.000 caminhões dotado de infraestrutura de atendimento, de onde são destinados para os diversos terminais de descarga. Com relação à ferrovia, a cerca de $5 \mathrm{~km}$ do porto, há um pátio de triagem sendo que a movimentação de vagões entre esse pátio e a área portuária é feita pela agora FSA e, dentro da área portuária, por locomotivas pertencentes ao porto (GEIPOT, 1995).

As instalações de acostagem do porto consistem em um cais comercial, com $2.616 \mathrm{~m}$ de comprimento, contendo 12 berços de atracação (vide Figura 3 - a qual apresenta um croqui do porto Paranaguá com os respectivos berços de atracação e armazéns, dando uma noção de suas dimensões), com profundidade variando de 8 a 13 $\mathrm{m}$, dos quais $650 \mathrm{~m}$ ( 3 berços - 12, 13 e 14 - com $12 \mathrm{~m}$ de profundidade) abrangem $\mathrm{o}$ chamado complexo do corredor de exportação, constituído por cinco pontos de embarque de grãos e farelos. $O$ porte médio de navios que freqüentam o porto situa-se entre 27.000 e 35.000 mil Toneladas de Porte Bruto (TPB), com instalações previstas para atender navios de 40 a 50 mil TPB (GEIPOT, 1995 e Anuário Estatístico Portuário, 1995).

Os cinco pontos do complexo de embarque de grãos e farelos são subdivididos em três grandes grupos, sendo que o principal deles é formado pelo complexo graneleiro da APPA, interligado a outros sete terminais privados (CARGILL, COTRIGUAÇU, COAMO, CENTRO SUL, SAGEL, V. MOREL e PARAGUAI). Os outros dois grupos são formados pelos terminais privados da SOCEPPAR e SANBRA, conectados diretamente com a faixa portuária.

De acordo com o GEIPOT (1995), o terminal particular da SOCEPPAR está localizado no extremo oeste do cais comercial, possuindo instalações de acostagem com $150 \mathrm{~m}$ de comprimento e $10 \mathrm{~m}$ de profundidade, dispondo de $330 \mathrm{~m}$ de correia transportadora para expedição de granéis com capacidade de embarque de $1.000 \mathrm{t} / \mathrm{h}$. Já o 
terminal da SANBRA está localizado no trecho central do cais comercial, com $200 \mathrm{~m}$ de comprimento e $8 \mathrm{~m}$ de profundidade, dotado de correias transportadoras com $700 \mathrm{~m}$ de comprimento e capacidade de embarque de $800 \mathrm{t} / \mathrm{h}$. Na Tabela 2.5 são apresentadas as características dos pontos de embarques.

Tabela 2.5 - Características dos pontos de embarque de grãos e farelo no porto de Paranaguá.

\begin{tabular}{llccc}
\hline $\begin{array}{l}\text { Pontos de } \\
\text { Embarque }\end{array}$ & Operação & & Capacidade & \\
\cline { 2 - 5 } & SOCEPPAR & $\begin{array}{c}\text { Recepção } \\
\text { (Toneladas/hora) }\end{array}$ & $\begin{array}{c}\text { Ensilagem } \\
\text { (Toneladas) }\end{array}$ & $\begin{array}{c}\text { Embarque } \\
\text { (Toneladas/hora) }\end{array}$ \\
\hline $\mathrm{N}^{\circ} 1$ & SANBRA & 7.450 & 184.500 & 1.000 \\
\hline $\mathrm{N}^{\circ} 2$ & APPA & 1.600 & 88.000 & 800 \\
\hline \multirow{2}{*}{$\mathrm{N}^{\circ} 3,4$ e 5 } & CARGILL & 500 & 160.000 & 75.000 \\
& COTRIGUAÇU & 900 & 168.000 & \\
$($ Corredor & COAMO & 450 & 60.000 & 7.500 \\
\multicolumn{1}{c}{ de } & CENTRO SUL & 600 & 72.000 & \\
Exportação) & SAGEL & 1.000 & 60.000 & \\
& V. MOREL & 1.000 & 56.000 & \\
& PARAGUAI & 1.000 & 182.000 & \\
\hline Total & & 10.250 & 1.105 .500 & \\
\hline
\end{tabular}

Fonte: dados coletados na APPA, através da Internet no endereço http://www.pr.gov.br/ports, no dia 06/03/1997.

O complexo graneleiro da APPA, através do sistema de carregamento por correias transportadoras, com o auxilio de cinco embarcadores, que levam os cereais dos silos diretamente aos porões dos navios, é capaz de carregar, ao mesmo tempo, três embarcações, com uma velocidade de $7.500 \mathrm{t} / \mathrm{h}$.

Para que estes resultados sejam observados no corredor de exportação, o porto, além da capacidade de estacionamento para 1.000 caminhões, conta ainda com um silo vertical para 100 mil t, com recepção rodoferroviária e operações por comando 
eletrônico, comunicando ao porão do navio, além de quatro baterias de silos horizontais, totalizando $68.000 \mathrm{t}$, todas elas interligadas por correias transportadoras.

Toda esta infra-estrutura, torna o porto de Paranaguá o maior complexo graneleiro público/privado do Brasil, com uma capacidade estática de 1 milhão e 100 mil toneladas e uma capacidade de embarque de $9.300 \mathrm{t} / \mathrm{h}$.

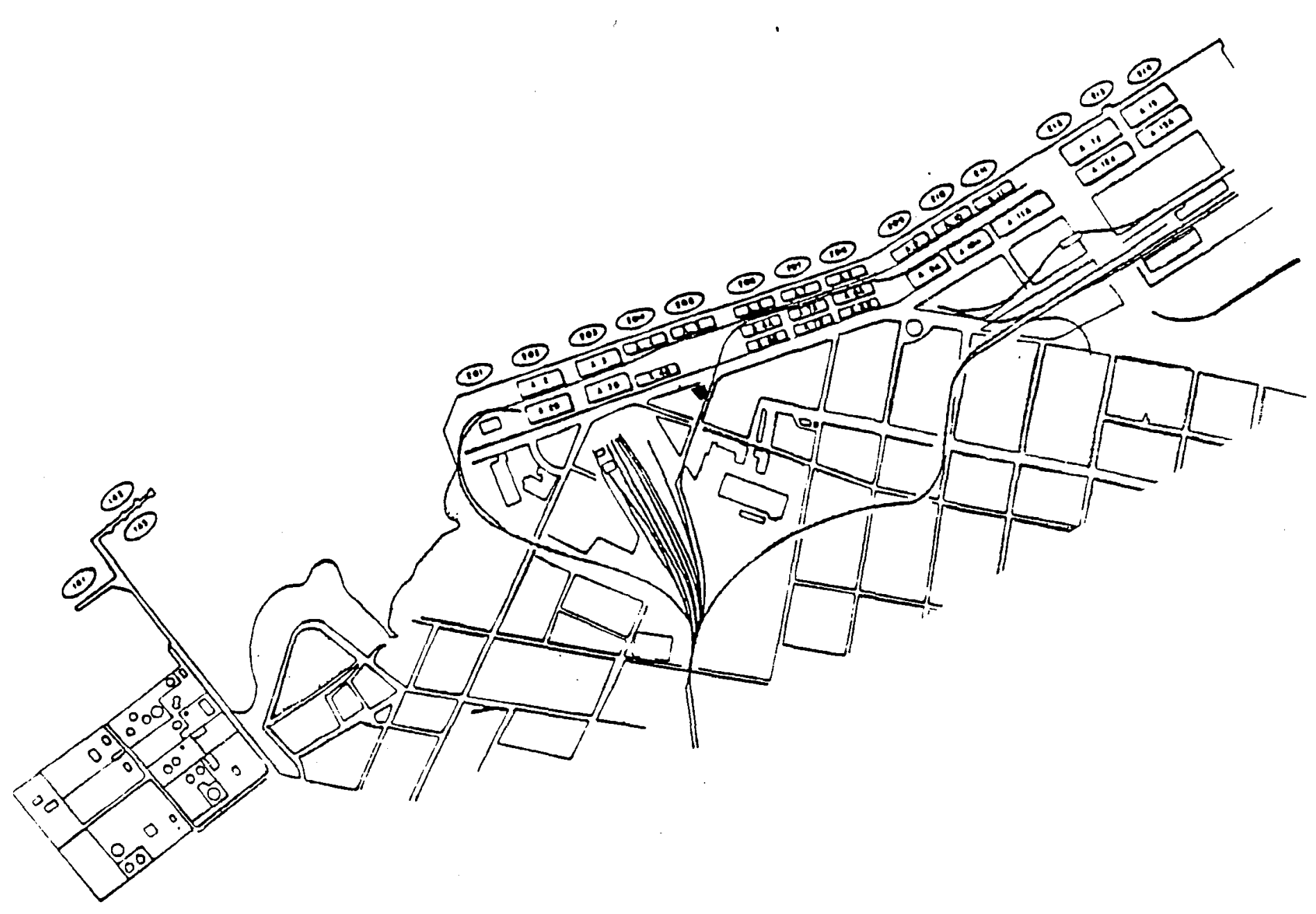

Figura 3 - Croqui do porto de Paranaguá (Fonte: Pavan, 1997). 


\subsubsection{Principais características do porto de Santos}

O porto de Santos, administrado pela Companhia Docas do Estado de São Paulo (CODESP), está situado no centro do litoral do Estado de São Paulo. Sua área de influência é constituída pelos Estados de São Paulo, Goiás, Mato Grosso, Mato Grosso do Sul, Minas Gerais (Triângulo Mineiro) e Norte do Paraná (GEIPOT, 1994b e Anuário Estatístico Portuário, 1995).

O acesso rodoviário ao porto é feito pelas rodovias SP-160 (Imigrantes), SP-150 (Anchieta), SP-055 (Cubatão-Guarujá), BR-101 (Rio-Santos), BR-116/SP-165/BR-101 (Curitiba-Santos). $\mathrm{O}$ acesso ferroviário é realizado pela antiga SR-4 da Rede Ferroviária Federal (com exploração transferida ao consórcio MRS Logística), em bitola larga e pela Ferrovia Paulista S.A. (Fepasa), em bitola métrica e mista. $\mathrm{O}$ acesso marítimo se dá pela entrada da Barra, cujo canal possui profundidade mínima de $12 \mathrm{~m}$ e largura variando de 300 a 700 m (GEIPOT, 1995).

A extensão total do cais da CODESP conta com aproximadamente $13.406 \mathrm{~m}$, incluindo os terminais privativos da COSIPA, DOW QUÍMICA, CARGILL, CUTRALE S/A e ULTRAFÉRTIL (vide Figura 4 - a qual apresenta um croqui do porto de Santos com seus berços de atracação e armazéns). A margem direita do porto possui 11.400 metros de extensão, sendo que a margem esquerda possui 2.006 metros de extensão (GEIPOT, 1994b e Anuário Estatístico Portuário, 1995).

O porto conta ainda com 62 berços de atracação, sendo quatro para grãos e pellets com $280 \mathrm{~m}$ de extensão de cais, $13 \mathrm{~m}$ de profundidade e cinco armazéns com capacidade total de 170.000 t ? Os armazéns estão ligados ao cais por conjuntos de esteiras transportadoras com capacidade total de $3.000 \mathrm{t} / \mathrm{h}$, que alimentam, na faixa fora do cais, dois embarcadores com capacidade nominal de $1.500 \mathrm{t} / \mathrm{h}$ / cada um. Estes, por sua 
vez, são providos de três moegas rodoferroviárias com capacidade de $2.300 \mathrm{t} / \mathrm{h}$ e duas moegas rodoviárias com capacidade de 500 e $800 \mathrm{t} / \mathrm{h}$, respectivamente (GEIPOT, 1994b, Anuário Estatístico Portuário, 1995 e Pavan, 1997).

Dos quatro berços para soja dois são administrados pela CODESP (Eixo de Exportação e Armazéns Convencionais), sendo que os outros dois pertencem à CUTRALE, com $286 \mathrm{~m}$ de extensão e $13 \mathrm{~m}$ de profundidade, e à CARGLL, com $250 \mathrm{~m}$ de extensão e 13 m de profundidade (Pavan, 1997 e Anuário Estatístico Portuário, 1995). 


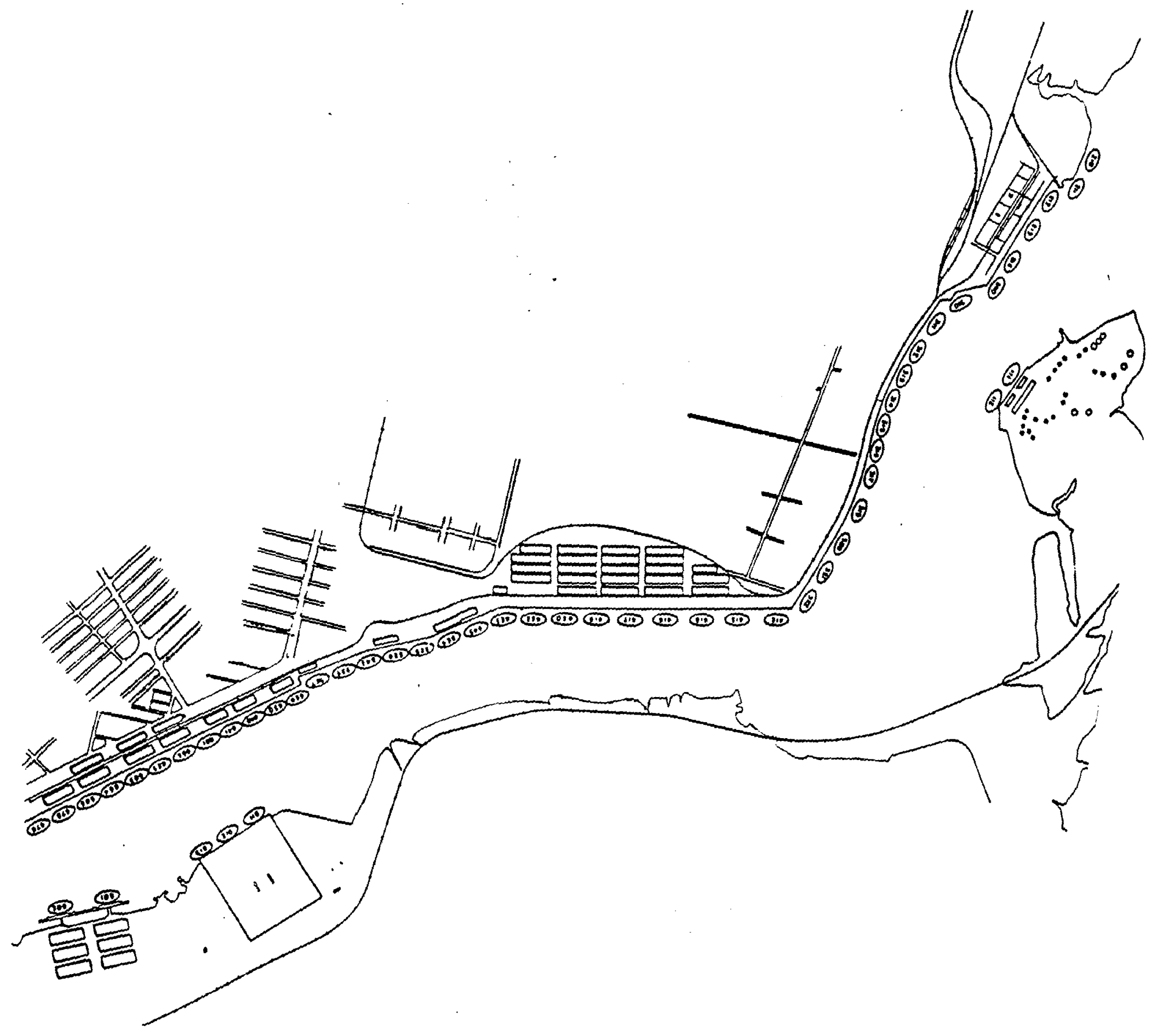

Figura 4 - Croqui do porto de Santos (Fonte: Pavan, 1997). 


\subsubsection{Análise comparativa entre o porto de Paranaguá e Santos quanto à movimentação de so ja}

A região que compõe a área de influência dos portos de Paranaguá e Santos é a maior produtora de grãos do Brasil, possuindo, também, o maior parque moageiro do País, absorvendo grande parte da produção de soja da região, gerando farelo e óleo para o mercado interno e exportação.

A produção brasileira de soja atingiu aproximadamente 25,5 milhões de toneladas em 1995. Dentre os 25,5 milhões de toneladas produzidas no Brasil, aproximadamente $72,2 \%$ corresponderam à produção da área de influência dos portos de Paranaguá e Santos, ficando o Estado do Rio Grande do Sul com 22,9\% e os Estados do Maranhão, Bahia e Tocantins com 5,0\%, conforme pode ser observado na Tabela 2.6 .

Tabela 2.6 - Principais Estados produtores de grãos em 1995 (em $1000 \mathrm{t}$ ).

\begin{tabular}{|c|c|c|c|c|c|c|}
\hline Estado & Arroz & $\begin{array}{c}\text { Farelo } \\
\text { de Soja }\end{array}$ & Milho & Soja & Trigo & Total \\
\hline Rio Grande do Sul & $5.038,1$ & $3.813,1$ & $5.935,7$ & $5.848,0$ & 382,3 & $21.017,2$ \\
\hline Santa Catarina & 708,4 & 667,3 & $3.651,2$ & 444,1 & 53,9 & $5.524,9$ \\
\hline Paraná & 225,0 & $4.687,5$ & $9.041,0$ & $5.624,4$ & $1.068,9$ & $20.646,8$ \\
\hline São Paulo & 260,1 & $1.783,6$ & $4.175,2$ & $1.185,5$ & 40,4 & $7.444,8$ \\
\hline Minas Gerais & 387,0 & 563,4 & $2.758,4$ & $1.199,7$ & 9,1 & $4.917,6$ \\
\hline Bahia & 21,3 & 341,9 & 174,5 & $1.072,9$ & - & $1.610,6$ \\
\hline Piauí & 145,2 & 34,2 & 25,5 & & - & 204,9 \\
\hline Maranhão & 152,5 & - & 60,6 & 162,4 & - & 375,5 \\
\hline Tocantins & 417,1 & - & 112,1 & 36,2 & - & 565,4 \\
\hline Rondônia & 262,4 & 0 & 370,2 & - & - & 632,6 \\
\hline Mato Grosso & 757,3 & $1.095,3$ & $1.224,9$ & $5.491,4$ & - & $8.568,9$ \\
\hline Mato Grosso do Sul & 239,2 & 917,8 & $1.435,2$ & $2.283,5$ & 19,9 & $4.895,6$ \\
\hline Goiás & 419,9 & $1.183,4$ & $3.476,9$ & $2.146,9$ & - & $7.227,1$ \\
\hline Total & $\mathbf{9 . 0 3 3 , 5}$ & $\mathbf{1 5 . 0 8 7 , 5}$ & $32.441,4$ & $25.495,0$ & $1.574,5$ & $83.631,9$ \\
\hline
\end{tabular}

Fontes: GEIPOT (1997), elaborado a partir de dados do IBGE e Abiove. 
Observando os dados da Tabela 2.6, verifica-se que os Estados de São Paulo, Minas Gerais e Goiás, juntos, produziram 4,5 milhões de toneladas de soja; os Estados do Paraná e Santa Catarina produziram 6,1 milhões de toneladas e os Estados de Mato Grosso e Mato Grosso do Sul produziram 7,8 milhões de toneladas (estes valores equivalem a $24,7 \%, 33,0 \%$ e $42,3 \%$, respectivamente, da produção total para a região que compõe a área de influência dos portos de Paranaguá e Santos).

Em vista desse quadro e de acordo com a Tabela 2.7, verifica-se que a produção apresenta uma distribuição espacial mais ou menos equilibrada em relação à distância dos portos de Paranaguá e Santos. No entanto, parte da soja produzida no Mato Grosso do Sul, Mato Grosso, Minas Gerais e Goiás, tem percorrido maiores distâncias para serem exportadas via porto de Paranaguá.

Tabela 2.7 - Distâncias em quilômetros entre os principais Pólos de produção e os portos de Santos e Paranaguá - 1995.

\begin{tabular}{lcc}
\hline Origem & Santos & Destino \\
\hline Sorriso-MT & 2.181 & Paranaguá \\
Rondonópolis-MT & 1.544 & 2.285 \\
Dourados-MS & 1.104 & 1.648 \\
Presidente Prudente-SP & 630 & 1.181 \\
\hline
\end{tabular}

Fonte: elaborado a partir de dados do GEIPOT (1997) e Guia Rodoviário Quatro Rodas (1997).

Conforme dados da Tabela 2.7, confirma-se que o custo total de transporte rodoviário é mais elevado para distâncias maiores; no entanto, quando se adiciona aos custos de transportes os preços dos serviços portuários, para distâncias de até 122 quilômetros superiores para o porto de Paranaguá em relação ao porto de Santos, o custo 
total torna-se menor para o porto de Paranaguá. Tal fato deve-se aos custos portuários ${ }^{6}$ praticados em Santos que são $25,0 \%$ superiores aos custos portuários praticados em Paranaguá (US\$10,00 e US\$ 7,50 por tonelada, respectivamente).

Tabela 2.8 - Estrutura de custos de transportes por rotas selecionadas (utilizadas em 1995) para soja em grão.

\begin{tabular}{lcccc}
\hline Origem/Destino & $\begin{array}{c}\text { Distância } \\
(\mathbf{k m})\end{array}$ & $\begin{array}{c}\text { Fretes } \\
\text { Rodoviários } \\
(\mathbf{U S \$} / \mathbf{t})^{\mathbf{1}}\end{array}$ & $\begin{array}{c}\text { Preços dos Serviços } \\
\text { Portuários }^{(\text {US\$/t) }} \mathbf{2}^{2}\end{array}$ & $\begin{array}{c}\text { Custo Total } \\
\text { de } \\
\text { Transportes } \\
\text { (US\$/t) }\end{array}$ \\
\hline Dourados-Santos & 1.104 & 33,02 & 10,00 & 43,02 \\
Dourados-Paranaguá & 1.181 & 34,79 & 7,50 & 42,29 \\
Rondonópolis-Santos & 1.544 & 42,49 & 10,00 & 52,49 \\
Rondonópolis-Paranaguá & 1.648 & 44,50 & 7,50 & 52,00 \\
Presidente Prudente-Santos & 630 & 21,06 & 10,00 & 31,06 \\
Presidente Prudente-Paranaguá & 707 & 23,13 & 7,50 & 30,63 \\
\hline
\end{tabular}

Fonte: (1) elaborado a partir da equação estimada po r Oliveira (1996).

(2) GEIPOT (1997).

Finalmente, segundo o GEIPOT (1993b), o fato dos serviços portuários em Santos atingirem um valor superior ao de Paranaguá se justifica pela maior flexibilidade tarifária existente no porto de Paranaguá, que conta com uma estrutura menos complexa. Pode-se citar como exemplo o excessivo número de trabalhadores portuários. De acordo com a CNI (1998), em fevereiro de 1998 o porto de Santos contava com 12.927 trabalhadores contra 4.429 trabalhadores no porto de Paranaguá. No entanto, de acordo com as dimensões do porto de Santos em relação ao porto de Paranaguá, a proporção de trabalhadores por extensão de cais no segundo é mais elevada.

\footnotetext{
${ }^{6}$ Os custos portuários considerados são os custos diretos, despesas com administração do porto (tarifias e taxas), exceto custos com suprimento de água, energia, comunicações e armazenagem e os custos de estiva, despesas com serviços de movimentação de cargas no porão dos navios, conferentes, vigias, consertadores e trabalhadores de bloco (GEIPOT, 1993b, p.27).
} 


\subsection{Considerações finais}

Neste capítulo foi caracterizado o sistema portuário nacional quanto à movimentação de soja, tendo como enfoque principal a comparação entre os portos de Paranaguá e Santos em vários aspectos, tais como: características portuárias, área de influência com as respectivas quantidades produzidas de soja, quantidades de soja movimentadas nos portos e algumas distâncias por rotas selecionadas juntamente com os custos de transportes e portuários. Diante deste quadro e com o propósito de fornecer uma análise sobre os preços e fluxos de soja entre as regiões produtoras e os portos de Paranaguá e Santos, no próximo capítulo será apresentada a teoria referente ao modelo de equilíbrio espacial. 


\section{MATERIAL E MÉTODO}

Neste capítulo será apresentado primeiramente o modelo de equilíbrio espacial, assim como sua estrutura matemática e o método adotado para resolução do mesmo. Posteriormente, serão apresentados os dados referentes às variáveis definidas para o modelo apresentado.

\subsection{Considerações gerais}

A soja, à medida que é transportada, armazenada e processada, vai tendo seu preço alterado, sendo que os custos de transportes constituem a principal diferença entre os preços nas regiões de oferta e de demanda pelo grão. De acordo com Enke ${ }^{7}$ (1951), citado por Takayama \& Judge (1971, p.129), se

“...Há duas (originalmente três) ou mais regiões comercializando um produto homogêneo. Cada região constitui um único e distinto mercado. Cada possível par de regiões são separadas mas não isoladas por um custo de transporte por unidade fisica, o qual é independente do volume transportado. Não há restrições legais para o limite do lucro esperado através das ações comerciais em cada região. Para cada região funções que relacionam produção local, consumo local e preço local poderão ser derivadas e, consequentemente, a magnitude da diferença

7 Enke, S. Equilibrium Among Spatially Separated Markets: Solution by Eletric Analogue. Econométrica, Vol. 10, 1951, p.40-47. 
entre o preço local e o exportado ou importado poderá também ser derivada. Dadas estas funções comerciais e custos de transportes, nós podemos obter: (1) o preço de equilíbrio em cada) região; (2) a quantidade exportada e importada para cada região; (3) quais regiões exportam, importam ou nenhum dos dois; (4) o volume e a direção do comércio entre cada possível par de regiões..."

Diante destas especificações, o Modelo de Equilíbrio Espacial, discutido por Bressler \& King (1970), Takayama \& Judge (1971), Tomek \& Robinson (1972), Barros (1987), Caixeta Filho (1989) e Marques \& Aguiar (1993), oferece um referencial teórico interessante para explicar o preço de equilíbrio em mercados espacialmente separados.

Segundo Caixeta Filho (1989, p.39), entre as principais características do modelo de equilíbrio espacial, podem ser destacadas:

“(i) é uma generalização do modelo de transporte, no sentido de que os resultados obtidos com um modelo de transporte podem também ser reproduzidos pelo modelo de equilibrio espacial;

(ii) possibilita a inclusão das elasticidades-preço de oferta e demanda.... Isto facilita uma avaliação dos efeitos das mudanças no nível de produção causados pela implementação de políticas agrícolas que venham a afetar o setor;

(iii) o modelo pode ser estendido para permitir a inclusão de funções de custos de transportes baseadas em funções de oferta não perfeitamente elásticas;

(iv) sua estrutura pode ser modificada para imperfeições de mercado, tais como a inclusão de monopólio espacial ou mercados oligopolísticos".

Uma série de aplicações envolvendo modelos de equilíbrio espacial têm sido documentadas na literatura. Mais recentemente, Waquil (1996) utilizou o modelo de 
equilíbrio espacial para análise da alocação ótima de produtos animais e grãos no Mercosul. A solução ótima obtida mostrou que o comércio intra-regional do Brasil com os demais Países do Mercosul é dado principalmente pelas exportações de aves e importações de produtos lácteos, trigo, milho e arroz. $\mathrm{O}$ autor sugere também que o modelo pode ser estendido para outros setores e outras regiões ou simular diferentes cenários políticos, visando avaliar os efeitos na alocação, determinação de preços e no bem-estar dos agentes econômicos envolvidos.

Bivings (1997) fez uma análise sazonal e espacial do mercado de sorgo no México. $\mathrm{O}$ estudo demonstrou a importância que os custos de transporte e armazenagem significam para a tomada de decisão quanto à política de liberalização de preço no mercado agrícola mexicano.

Mwanaumo et al. (1997) fizeram uma análise espacial sobre o mercado de milho na Zâmbia, com o objetivo de examinar os efeitos intra e interregional provocados pela mudança no sistema de transporte, devido à reforma política realizada pelo governo daquele País. Já Kawaguchi et al. (1997) utilizaram o modelo de equilíbrio espacial para analisar o movimento interregional do leite no Japão.

\subsection{Modelo de Equilíbrio Espacial ${ }^{8}$}

Conforme Sugai et al. (1994), se duas regiões separadas, mas não isoladas entre si, produzem e consomem o mesmo produto, é possível que uma venha a comprar o produto da outra. A condição necessária para que exista comércio entre as regiões é que os preços praticados em ambas sejam diferentes e que a diferença entre os preços seja

\footnotetext{
${ }^{8}$ Modelo baseado em Bressler \& King (1970), Takayama \& Judge (1971), Tomek \& Robinson (1972), Barros (1987), Caixeta Filho (1989) e Marques \& Aguiar (1993).
} 
suficiente para cobrir os custos de transferência de uma região para outra.

A Figura 5 apresenta o caso hipotético da soja produzida e consumida nas regiões 1 e 2, respectivamente. Os três diagramas da Figura 5 apresentam nos eixos das abcissas as quantidades de soja demandada $\left(\mathrm{Y}_{\mathrm{j}}\right)$ e ofertada $\left(\mathrm{X}_{\mathrm{i}}\right)$ e nos eixos das ordenadas os preços praticados $\left(P_{j}=\right.$ preço na região de demanda e $P_{i}=$ preço na região de oferta). $A$ região 1 tem o preço de equilíbrio $P_{1}$ e a região 2 tem o preço de equilíbrio $P_{2}$, determinados em função das curvas de oferta ( $S_{1}$ para a região 1 e $S_{2}$ para a região 2$)$ e demanda ( $D_{1}$ para a região 1 e $D_{2}$ para a região 2$)$.

\section{Região $1 \quad$ Região 2}

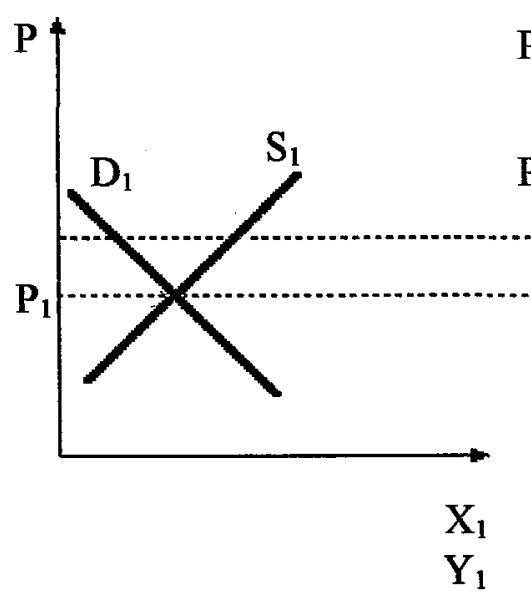

(a)

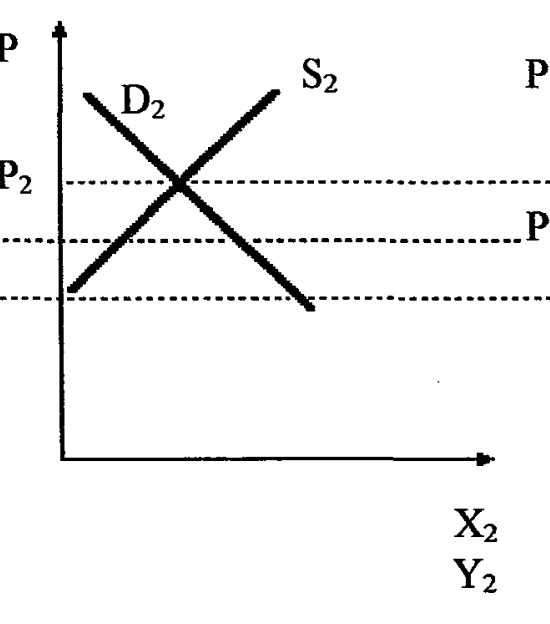

(b) (c)

Figura 5 - Modelo de Equilíbrio Espacial sem Custos de Transportes (Extraído de Caixeta Filho, 1989, p.29).

Segundo Barros (1987), supondo a existência de comércio entre as duas regiões, sem levar em consideração os custos de transportes, será vantajoso transferir a soja da região 1 para 2, uma vez que $P_{2}$ é maior do que $P_{1}$. A tendência será de que o fluxo de soja da região 1 para 2 ocorra até que o suprimento do produto em 2 aumente o suficiente para que os preços em ambas as regiões se igualem, gerando um novo preço de 
equilíbrio $\mathrm{P}^{*}$. O novo preço de equilíbrio $\mathrm{P}^{*}$ é determinado pela intersecção das curvas de excesso de oferta $\mathrm{ES}_{1}$ e excesso de demanda $\mathrm{ED}_{2}$, respectivamente (vide diagrama (c) da Figura 5).

Conforme Tomek \& Robinson (1972), a curva do excesso de oferta é baseada na diferença horizontal entre as curvas de oferta e demanda na região 1, acima do preço de equilíbrio $P_{1}$ e representa $o$ montante pelo qual a quantidade ofertada excede a quantidade demandada em vários níveis de preços. Devido à diferença entre a oferta e demanda aumentar à medida que o preço se eleva, a curva de excesso de oferta é positivamente inclinada, semelhantemente à curva de oferta convencional. Por outro lado, a curva de excesso de demanda é baseada na diferença horizontal entre as curvas de oferta e demanda na região 2 , abaixo do preço de equilíbrio $P_{2}$. A curva é negativamente inclinada já que a diferença entre as curvas de oferta e demanda aumenta à medida que o preço diminui.

Pelo método empregado e ilustrado na Figura 5, na ausência de comércio entre as duas regiões, as quantidades do excesso de oferta e demanda será zero. Por outro lado, a existência de comércio entre as duas regiões, sem considerar os custos de transportes, resulta na igualdade entre o excesso de oferta da região 1 e o excesso de demanda na região 2 , resultando na comercialização de $\mathrm{X}_{12}$ unidades a um preço de equilíbrio $\mathrm{P}^{*}$.

Segundo Barros (1987, p.99), "a projeção à esquerda desse nível de preço $\mathrm{P}$ ", de modo a alcançar os dois gráficos correspondentes a cada região, determinará nas curvas de oferta regional a quantidade produzida em cada região e nas curvas de demanda regional a quantidade demandada em cada região".

Considerando agora a existência de custos unitários de transportes entre as duas regiões (Figura 6), de acordo com Barros (1987), a transferência da soja da região 1 para a região 2 não prosseguiria até o ponto de igualdade entre $P_{1}$ e $P_{2}$, mas sim, enquanto a 
diferença entre esses preços for maior ou igual ao custo de transporte.

Conforme Caixeta Filho (1989), a principal conseqüência originada pela introdução dos custos de transportes é a redução do montante do produto comercializada entre as regiões 1 e 2; a redução do preço do produto na região 1; e o aumento do preço do produto na região 2. Segundo Marques \& Aguiar (1993, p.85), "se o custo de transporte aumentar muito, a quantidade de mercadoria a ser comercializada entre as regiões 1 e 2 diminuirá e eventualmente poderá chegar a zero".

$\mathrm{Na}$ Figura 6 pode ser visualizado o caso de um produto comercializado entre duas regiões envolvendo os custos de transportes. No diagrama (c) $T_{12}$ significa o custo de transporte de um unidade transportada da região 1 para a região 2 .

Região $1 \quad$ Região 2

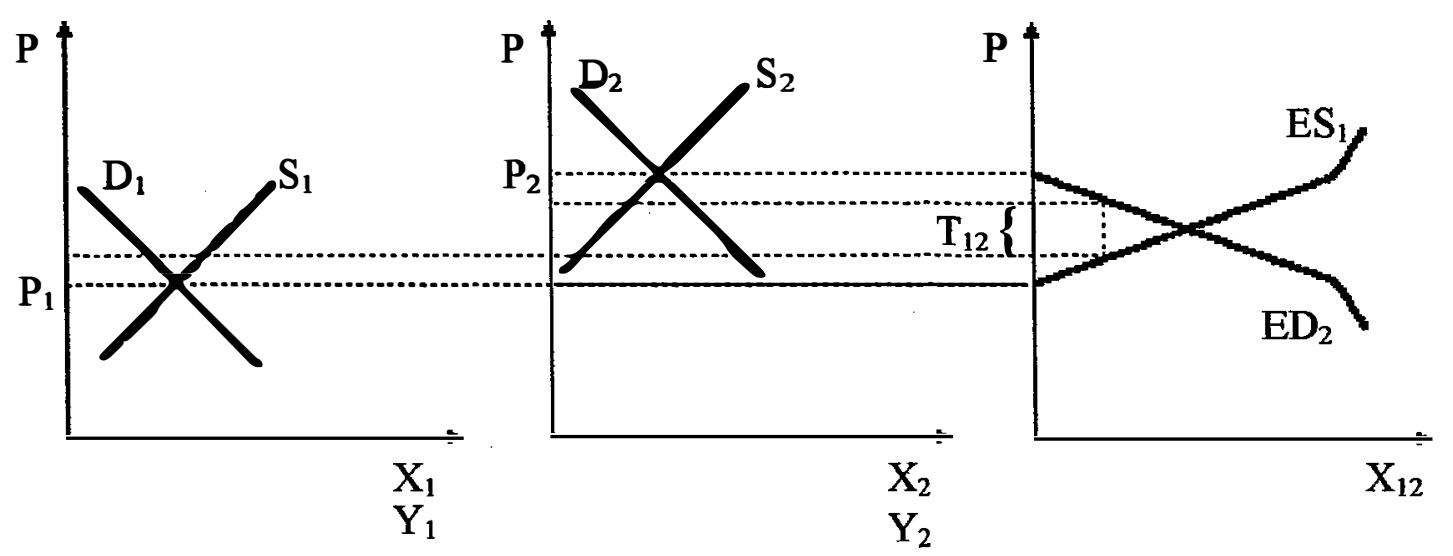

(a)

(b)

(c)

Figura 6 - Modelo de Equilíbrio Espacial com Custos de Transportes (Extraído de Caixeta Filho, 1989, p.29).

Uma maneira de analisar o efeito dos custos de transportes da soja entre as duas regiões pode ser observada na Figura 7, onde no diagrama (a) as curvas de excesso de oferta e demanda são as mesmas do diagrama (c) da Figura 6. 


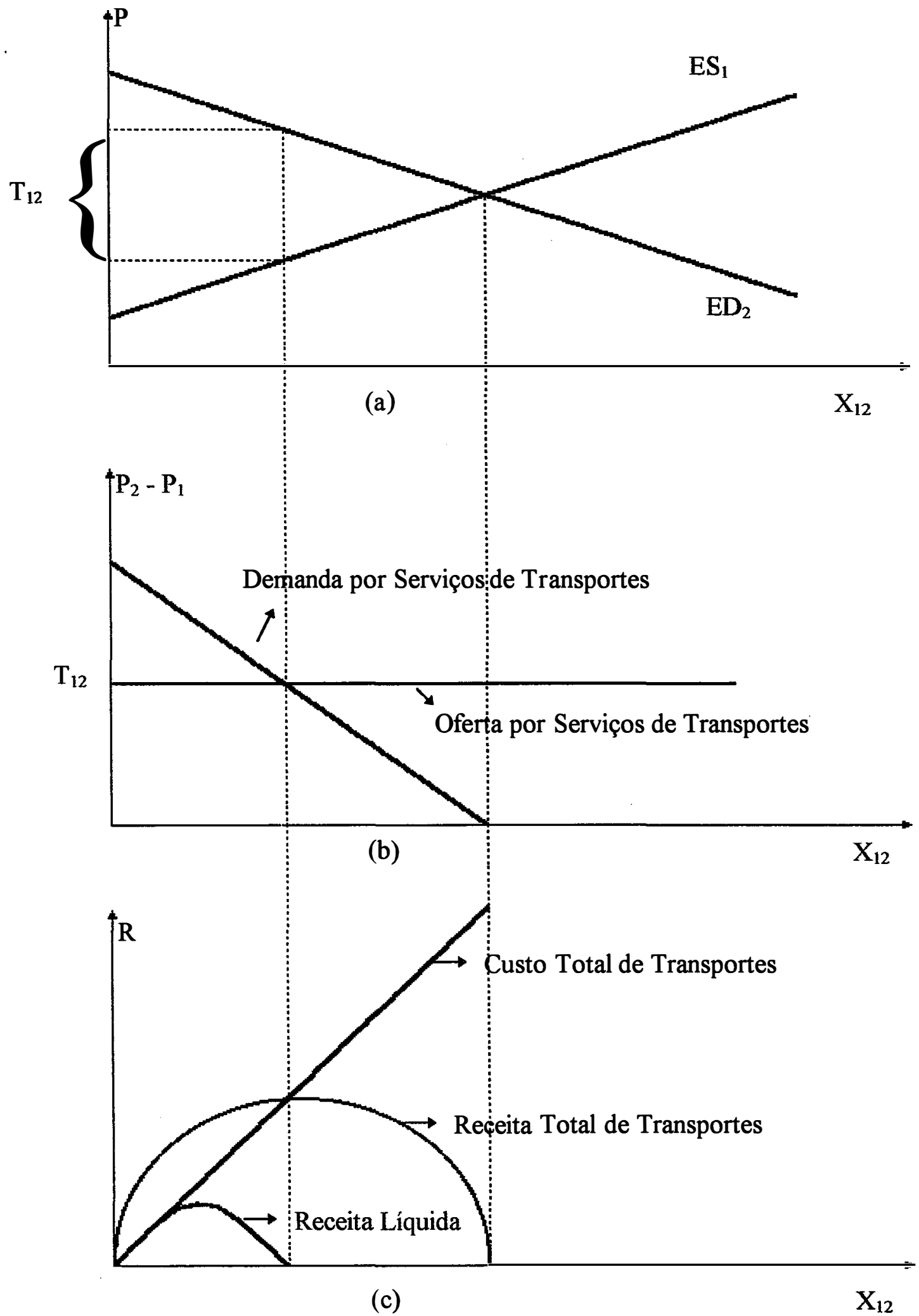

Figura 7 - Modelo de Equilíbrio Espacial com Custos de Transportes Fixos (Extraído de Caixeta Filho, 1989, p.31). 
De acordo com Caixeta Filho (1989), a diferença vertical entre as curvas de excesso de oferta e demanda é dada pela curva conhecida como demanda por serviços de transportes, que relaciona a quantidade de soja que pode ser comercializada entre as regiões 1 e 2. Em função da oferta por serviços de transportes ser assumida como perfeitamente elástica, esta é igual ao custo de transporte por unidade $T_{12}$. $O$ equilíbrio dá-se no ponto onde a curva de demanda por serviços de transportes intercepta a curva de oferta por serviços de transportes. Ambas as curvas encontram-se representadas no diagrama (b) da Figura 7, onde no eixo das abcissas tem-se a quantidade de soja transportada da região 1 para a região $2\left(\mathrm{X}_{12}\right)$ e no eixo das ordenadas tem-se a diferença entre os preços das regiões 2 e $1\left(P_{2}-P_{1}\right)$.

Segundo Caixeta Filho (1989), o custo total de transporte é calculado multiplicando-se a diferença vertical dos preços entre as curvas de excesso de oferta e demanda pelo nível de comércio representado na curva de oferta por serviços de transportes. A informação obtida através da curva de demanda por serviços de transportes é usada para calcular a curva de receita total de transporte. A subtração do custo total de transportes da receita total de transportes resulta na curva de receita líquida, a qual está representada no diagrama (c) da Figura 7, onde no eixo das abcissas tem-se a quantidade de soja transportada da região 1 para 2 e no eixo das ordenadas a Receita (R).

Analisando ainda a Figura 7, no diagrama (c), observa-se que o equilíbrio ocorre no ponto em que a receita social líquida é igual a zero, que por sinal é onde a curva da receita social líquida intercepta o eixo $X_{12}$. Nesse ponto, no diagrama (b), a demanda por serviços de transportes é igual a oferta por serviços de transportes, o que corresponde à diferença vertical igual a $\mathrm{T}_{12}$ entre as curvas de excesso de oferta e demanda do primeiro diagrama (a). 


\subsection{Modelo de competição perfeita}

A utilização do modelo de equilíbrio espacial apresentado na seção anterior visa a obtenção da solução ótima para produtores e consumidores de soja em regiões espacialmente separadas, cujo relacionamento entre o preço e o fluxo de soja são determinados pelo custo de transferência. Neste caso, o objeto de análise é a relação preço/demanda e a composição do valor da soja dada pela soma dos custos de transportes e portuários (sem levar em consideração outros custos, tais como, custo de produção, impostos, seguros, entre outros). Tal relação é a que prevalece em um mercado de competição perfeita, onde produtores e consumidores expressam suas preferências através do preço.

Segundo Ferguson (1986), quatro importantes condições definem competição

perfeita: grande número de vendedores e compradores, produto homogêneo, livre entrada e saída de produtores no mercado (mobilidade) e perfeito conhecimento pelos produtores das condições de mercado.

Para o caso da soja, a existência de um grande número de vendedores e compradores, se refere ao fato de que, cada vendedor ou comprador, atuando isoladamente, não consegue influenciar o preço do produto. Já a homogeneidade significa que as diversas unidades do produto colocado no mercado pelos produtores são idênticos, ou seja, são substitutos perfeitos entre si. Isto quer dizer que os compradores são indiferentes quanto ao produtor do qual irão adquirir o produto. Quanto à livre entrada e saída de produtores no mercado, inexistem barreiras legais para tal. Isto significa que os produtores poderão passar a produzir no momento em que o mercado para o produto for atrativo, assim como, poderão deixar de produzir quando o mercado para o produto deixar de ser atrativo. Finalmente, existe completa informação e conhecimento sobre o preço do produto (transparência de mercado). Isto significa que 
nenhum comprador estará disporto a adquirir um produto por um preço maior ao de mercado. Por outro lado, nenhum produtor estará disposto a vender seu produto a um preço inferior ao preço de mercado.

De acordo com as hipóteses anteriormente mencionadas, o aspecto mais relevante para os produtores em um mercado de concorrência perfeita é o fato deles serem tomadores de preço, ou seja, aceitam o preço determinado pelas condições de oferta e demanda de mercado.

No caso da soja brasileira, seu preço dá-se no mercado internacional, refletido na Bolsa de Futuros de Chicago, nos Estados Unidos. Segundo Marques \& Mello (1997, p. 47), dos preços da Bolsa de Chicago deriva-se a demanda pelo produto brasileiro, o qual recebe um prêmio positivo ou negativo, e deduzem-se os custos de frete, chegando ao porto. Do preço do porto são deduzidos a comissão do corretor, a corretagem de câmbio, as despesas portuárias, a quebra de transportes, os tributos e o frete, obtendo-se o preço na fábrica. Da fábrica, deduzem-se os custos de frete, chegando-se ao preço que, juntamente com a concorrência em cada região, formará o preço a ser pago ao produtor. De uma forma resumida, a formação de preços na fazenda ocorre da seguinte forma:

Chicago \pm prêmio $=$ FOB estivado - custos de internalização - custos de armazenamento - frete interno - quebra de peso - riscos, juros, etc - benefícios de arbitragem financeira ou venda de performace de exportação \pm outras variáveis (poder da indústria na região, condições locais de oferta e demanda) = preço local na fazenda.

Neste contexto, o modelo de competição perfeita ajusta-se aos propósitos do presente trabalho, uma vez que a soja é considerada como um produto homogêneo, ofertada por um grande número de produtores, os quais possuem um bom nível de conhecimento sobre o funcionamento do mercado, assim como, não há barreiras quanto à entrada ou à saida de produtores no mercado brasileiro. 
Admitindo-se como objetivo principal dos agentes envolvidos no processo de comercialização da soja a maximização da Receita Social Líquida (receita social total menos custo social total menos custo de transporte), esta poderá ser obtida utilizando-se a estrutura matemática básica proposta por Takayama \& Judge (1971), conforme a função objetivo apresentada em (1) ${ }^{9}$.

$R S L=\sum_{j=1}^{n} P_{j} Y_{j}-\sum_{i=1}^{m} P_{i} X_{i}-\sum_{j=1}^{n} \sum_{i=1}^{m} T_{i j} X_{i j}$

onde:

$R S L=$ receita social líquida;

$P_{j}=$ preço na região de demanda da soja;

$P_{i}=$ preço na região de oferta da soja;

$Y_{j}=$ quantidade de soja demandada;

$X_{i}=$ quantidade de soja ofertada;

$T_{i j}=$ custo de transporte entre as regiões $i$ e $j$;

$X_{i j}=$ quantidade transportada da região $i$ para a região $j$.

Tal função objetivo será sujeita às seguintes restrições:

(a) restrições de demanda

A função de demanda para cada uma das $n$ regiões de consumo pode ser

\footnotetext{
${ }^{9}$ A estrutura matemática do modelo de competição perfeita apresentada a seguir, e que será utilizada neste trabalho, foi baseada em Caixeta Filho (1989, p.36-38).
} 
representada como:

$$
Y_{j}=\alpha_{j}-\beta_{j} P_{j}, \quad j=1, \ldots, n
$$

onde:

$\alpha_{j}=$ é um valor positivo, representando o intercepto da curva de demanda para cada uma das $n$ regiões;

$-\beta_{j}=$ é um valor negativo, representando a inclinação da curva de demanda para cada uma das $n$ regiões.

Para garantir que a quantidade de soja demandada seja obtida

$$
Y_{j} \geq \alpha_{j}-\beta_{j} P_{j}, \quad j=1, \ldots, n
$$

Se a soja produzida mais a soja transportada de outras regiões são consideradas para suprir a demanda de uma região, então:

$$
Y_{j}=\sum_{i=1}^{m} X_{i j}, \quad j=1, \ldots, n, \quad i=1, \ldots, m,
$$

substituindo (4) em (3) têm-se:

$$
\sum_{i=1}^{m} X_{i j} \geq \alpha_{j}-\beta_{j} P_{j}, \quad j=1, \ldots, n, \quad i=1, \ldots, m \text {. }
$$

Rearranjando, 
$-\beta_{j} P_{j}-\sum_{i=1}^{m} X_{i j} \leq-\alpha_{j}, \quad j=1, \ldots, n, \quad i=1, \ldots, m$.

Para a formulação das funções de demanda para cada uma das $n$ regiões, o seguinte artificio é sugerido:

- considere a forma genérica da equação de demanda:

$Y=\alpha-\beta P$

- tomando o valor de elasticidade-preço de demanda igual a $E_{\mathrm{d}}$, (um valor supostamente negativo) a seguinte relação poderá ser utilizada:

$\beta=(\partial Y) /(\partial P)=-E_{d}(Y / P)$

onde $(Y / P)$ é a relação entre a quantidade demandada e o preço médio obtido em determinado ano;

- conhecido o coeficiente angular $\beta$, o coeficiente linear $\alpha$ poderá ser obtido a seguinte forma:

$$
\alpha=\beta P+Y
$$

O raciocínio acima é valido para a versão competitiva do modelo de equilíbrio espacial. 
(b) restrições de oferta

A função de oferta para cada uma das $m$ regiões pode ser representada como:

$$
X_{i}=\phi_{i}+\gamma_{i} P_{i}, \quad i=1, \ldots, m,
$$

onde:

$\phi_{i}=$ é um valor positivo, representando o intercepto da curva de oferta para cada uma das $m$ regiões;

$\gamma_{i}=$ é um valor positivo, representando a inclinação da curva de oferta para cada uma das $m$ regiões.

Para garantir que a oferta de soja seja obtida,

$$
X_{i} \leq \phi_{i}+\gamma_{i} P_{i}, \quad i=1, \ldots, m
$$

Como a oferta total disponivel numa região será no mínimo igual à quantidade comercializada com outras regiões, então:

$$
X_{i}=\sum_{j=1}^{n} X_{i j}, \quad j=1, \ldots, n \quad i=1, \ldots, m,
$$

substituindo (12) em (11) tem-se:

$$
\sum_{j=1}^{n} X_{i j} \leq \phi_{i}+\gamma_{i} P_{i}, \quad j=1, \ldots, n, \quad i=1, \ldots, m \text {. }
$$

\section{Rearranjando,}




$$
-\gamma_{i} P_{i}+\sum_{j=1}^{n} X_{i j} \leq \phi_{i}, \quad j=1, \ldots, n, \quad i=1, \ldots, m
$$

Observe-se que o mesmo artificio desenvolvido para a obtenção das equações (8) e (9) pode ser aplicado para as equações de oferta.

(c) restrições de preço

As restrições de preços são as mais importantes para a definição da estrutura de mercado a ser investigada. Num modelo de equilíbrio espacial competitivo, para garantir que os preços entre duas regiões não difiram por mais que seus respectivos custos de distribuição, a seguinte restrição deve ser considerada.

$$
P_{j}-P_{i} \leq T_{i j}, \quad j=1, \ldots, n, \quad i=1, \ldots, m .
$$

A relação expressa em (15) deve ser válida para qualquer possível combinação entre uma das $n$ regiões de demanda e uma das $m$ regiões de oferta.

\subsection{Método}

Primeiramente será feito um zoneamento das regiões de oferta e demanda. Incluise neste zoneamento, tendo como referência o ano de 1995, o levantamento da quantidade ofertada e demandada de soja por região, quantidade de soja transportada 
entre as regiões, rotas utilizadas para a movimentação da soja, distância entre regiões, custos de transportes, preço de mercado nas regiões de oferta e demanda de soja e elasticidades preço de oferta e demanda da soja. Feito o zoneamento e levantados os dados, será utilizado o modelo visando reproduzir a situação atual referente à movimentação de soja.

O processamento das informações será realizado utilizando-se o software GAMS - General Algebraic Modeling System - (Brooke et al., 1992), versão 2.25. O GAMS é um software cuja estruturação do modelo em linguagem computacional obedece à mesma estruturação da linguagem matemática estabelecida. Devido às suas características peculiares o GAMS é largamente utilizado em problemas de programação matemática, principalmente de Programação Linear, Programação Não Linear e Programação Inteira. A programação matemática utilizada no presente trabalho é a Não Linear.

Admitindo-se que essa "situação atual" tenha sido reproduzida, e portanto validado o modelo, o passo seguinte dirá respeito ao processamento de cenários alternativos para movimentação da soja através da análise de sensibilidades dos custos de transportes e elasticidades preços de oferta e demanda. Com isso, poder-se-á inferir sobre a melhor alternativa do fluxo entre as regiões de oferta e os portos de Paranaguá e Santos, de tal maneira que a competição entre os portos possa ser avaliada.

\subsection{Especificação dos dados}

Nesta seção será feita a descrição dos dados associados às variáveis definidas conforme o modelo apresentado na seção 3.3. Primeiro será apresentado o zoneamento das regiões de oferta e demanda da soja, caracterizando os Pólos e as respectivas quantidades ofertadas e demandadas. Em seguida será apresentado o levantamento das 
distâncias entre as regiões produtoras e consumidoras, a partir das quais serão obtidos os custos de transportes entre os Pólos. Finalmente, serão levantados os preços de mercado para cada Pólo e o valor das elasticidades preço de oferta e demanda da soja. A partir dos dados levantados serão estimados os coeficientes das funções de demanda e oferta do modelo.

\subsubsection{Zoneamento da área de produção da soja}

Para o zoneamento das regiões seguiu-se a definição estabelecida pelo GEIPOT, o qual levantou as principais áreas de concentração da produção de soja em cada Estado. De acordo com o GEIPOT (1997), para alcançar este objetivo, foi realizada uma análise da distribuição espacial da produção com base nas microrregiões geográficas do Instituto Brasileiro de Geografia e Estatística (IBGE), elegendo, posteriormente, dentre os municípios de cada microrregião, aquele que pela sua importância como centro produtor, comercial ou pela posição na malha viária, exercesse a condição de Pólo da microrregião.

A relação dos Pólos, por Estado, é apresentada no Quadro 3.1, onde se encontram listados os principais municípios pertencentes a cada Pólo. Entre os Pólos apresentados no Quadro 3.1, encontram-se os Pólos de Santos, Paranaguá e São Francisco do Sul, aos quais correspondem os fluxos portuários propriamente ditos. 
Quadro 3.1 - Principais Pólos de Produção Agrícola.

\begin{tabular}{|c|c|c|}
\hline Estado & Pólo & Microrregiōes \\
\hline \multirow[t]{5}{*}{ Santa Catarina } & Florianópolis & $\begin{array}{l}\text { Araranguá, Criciúma, Tubarão, Tabuleiro, Tijucas, Rio do Sul e } \\
\text { Itupiranga }\end{array}$ \\
\hline & Herval d'Oeste & Concórdia e Joaçaba \\
\hline & Lages & Campos de Lages e Curitibanos \\
\hline & Porto União & Canoinhas, São Bento do Sul, Joinvile, Blumenau e Itajaí \\
\hline & Xanxerê & Chapecó e São Miguel d'Oeste \\
\hline \multirow[t]{5}{*}{ Paraná } & Cascavel & Campo Mourão, Goioerê, Toledo, Umuarama e Foz do Igụacu \\
\hline & Curitiba & Cerro Azul, Lapa, Rio Negro e São Mateus do Sul \\
\hline & Guarapuava & $\begin{array}{l}\text { União da Vitória, Capanema, Francisco Beltrão, Palmas, Pato } \\
\text { Branco e Pitanga }\end{array}$ \\
\hline & Londrina & $\begin{array}{l}\text { Apucarana, Faxinal, Ivaiporã, Comélio Procópio, Ibati, } \\
\text { Jacarezinho, Wenceslau Braz, Maringá, Paranavai, Cianorte, } \\
\text { Astorga, Porecatu e Florai }\end{array}$ \\
\hline & Ponta Grossa & Irati, Jaguariaiva, Prudentópolis e Telêmaco Borba \\
\hline \multirow[t]{7}{*}{ São Paulo } & Bauru & Araraquara, São Carlos, Jaú, Lins, Avaré e Botucatu \\
\hline & Campinas & $\begin{array}{l}\text { Amparo, Bragança Paulista, Jundiai, Mogi-Mirim, São João da } \\
\text { Boa Vista, Itapetininga, Itapeva, Registro, Sorocaba, Tatú, } \\
\text { Limeira, Piracicaba, Pirassununga, Rio Claro, Piedade }\end{array}$ \\
\hline & Ourinhos & Assis, Marília e Tupã \\
\hline & Presidente Prudente & Andradina, Araçatuba, Birigui, Adamantina e Dracena \\
\hline & Ribeirão Preto & Batatais, Jaboticabal, Franca, Ituverava, e São Joaquim da Barra \\
\hline & São José do Rio Preto & $\begin{array}{llll}\text { Barretos, Auriflama, Fernadópolis, Jales, } & \text { Votuporanga, } \\
\text { Catanduva, Nhandeara e Novo Horizonte } & & \\
\end{array}$ \\
\hline & São Paulo & $\begin{array}{l}\text { Bananal, Campos do Jordão, Caraguatatuba, Guaratingueta, São } \\
\text { José dos Campos, Guarulhos, Mogi das Cruzes, Osasco, Itanhaém. }\end{array}$ \\
\hline \multirow[t]{3}{*}{ Minas Gerais } & Patos de Minas & Patrocínio, Paracatu, Unaí e Montes Claros \\
\hline & Uberlândia & Araxá, Frutal, Uberaba e Itumbiara \\
\hline & Varginha & $\begin{array}{l}\text { Campo Belo, Formiga, Oliveira, Piuí, Passos, Poços de Caldas, } \\
\text { Pouso Alegre, Santa Rita do Sapucai, Alferes e São Sebastião do } \\
\text { Paraíso }\end{array}$ \\
\hline \multirow[t]{4}{*}{ Mato Grosso } & Barra do Garças & Médio Araguaia, Canarana e Norte Araguaia \\
\hline & Cuiabá & $\begin{array}{l}\text { Alto Pantanal, Alto Guaporá, Jauru, Rosário Oeste e Tagará da } \\
\text { Serra }\end{array}$ \\
\hline & Rondonópolis & Alto Araguaia, Tesouro, Paranatinga e Primavera do Leste \\
\hline & Sorriso & $\begin{array}{l}\text { Alto Paraguai, Arinos, Parecis, Aripuanã, Alta Floresta, Colider, } \\
\text { Sinop e Alto Teles Pires }\end{array}$ \\
\hline \multirow{3}{*}{$\begin{array}{l}\text { Mato Grosso do } \\
\text { Sul }\end{array}$} & Campo Grande & Aquidauana, Bodoquena, Alto Taquari e Corumbá \\
\hline & Dourados & Iguatemi \\
\hline & Três Lagoas & Nova Andradina, Paranaiba e Cassilândia \\
\hline \multirow[t]{3}{*}{ Goiás } & Brasilia & Entorno de Brasília \\
\hline & Goiânia & $\begin{array}{l}\text { Anápolis, Catalão, Pires do Rio, Ceres, Anicuns, Aragarças, Iporá, } \\
\text { Rio Vermelho, Chapada dos Veadeiros, Vão do Paranã, São } \\
\text { Miguel do Araguaia e Porangatu }\end{array}$ \\
\hline & Rio Verde & $\begin{array}{l}\text { Vale do Rio dos Bois, Meia Ponte, Quininópolis e Sudoeste de } \\
\text { Goiás }\end{array}$ \\
\hline
\end{tabular}

Fonte: GEIPOT (1997). 


\subsubsection{Fontes de dados}

As quantidades ofertadas e demandadas de soja, por Pólo, para o ano de 1995, foram obtidas junto ao GEIPOT (1997), órgão que possui um levantamento sistemático de matrizes origem/destino. O GEIPOT disponibiliza também informações sobre o trajeto percorrido pela soja entre os diversos Pólos e portos, possibilitando assim o levantamento das distâncias entre os centros produtores e consumidores/exportadores.

\subsubsection{Caracterização da oferta}

A produção de soja, na área em estudo, atingiu aproximadamente 18,4 milhões de toneladas em 1995, destacando-se como principais produtores os Estados do Paraná $(30,6 \%)$ e Mato Grosso (29,9\%), conforme pode ser observado na Tabela 3.1. As quantidades de soja produzidas por Pólo, dentro de cada Estado, podem ser observadas no Quadro 3.2.

Tabela 3.1 - Produção de soja por Estado na região em estudo em 1995 (1000 t).

\begin{tabular}{lc}
\hline Estado & Quantidade (1000 t) \\
\hline Santa Catarina & 444,1 \\
Paraná & $5.624,4$ \\
São Paulo & $1.185,5$ \\
Minas Gerais & $1.199,7$ \\
Mato Grosso & $5.491,4$ \\
Mato Grosso do Sul & $2.283,5$ \\
Goiás & $2.146,9$ \\
\hline Total & $\mathbf{1 8 . 3 7 5 , 5}$ \\
\hline Fonte: GEIPOT (1997), elaborado a partir de dados do IBGE e Abiove.
\end{tabular}

Fonte: GEIPOT (1997), elaborado a partir de dados do IBGE e Abiove.

No Quadro 3.2, a coluna “código" corresponde à abreviação do nome de cada 
Pólo. Esta abreviação será utilizada para identificar e representar os respectivos Pólos no momento que os dados forem processados através do programa computacional.

Quadro 3.2 - Quantidades de soja produzidas por Pólo em 1995 (1000 t).

\begin{tabular}{|c|c|c|c|}
\hline Estado & Pólo & Código & Qtde. Ofertada (1000 t) \\
\hline Santa Catarina & $\begin{array}{l}\text { Herval d'Oeste } \\
\text { Lages } \\
\text { Porto União } \\
\text { Xanxerê } \\
\text { Florianópolis } \\
\end{array}$ & $\begin{array}{l}\text { HOSC } \\
\text { LASC } \\
\text { PUSC } \\
\text { XASC } \\
\text { FLSC } \\
\end{array}$ & $\begin{array}{r}22,5 \\
64,3 \\
76,9 \\
279,7 \\
0,7 \\
\end{array}$ \\
\hline Paraná & $\begin{array}{l}\text { Curitiba } \\
\text { Cascavel } \\
\text { Guarapuava } \\
\text { Londrina } \\
\text { Ponta Grossa } \\
\end{array}$ & $\begin{array}{l}\text { CUPR } \\
\text { CAPR } \\
\text { GUPR } \\
\text { LOPR } \\
\text { PGPR }\end{array}$ & $\begin{array}{r}93,6 \\
2.545,4 \\
856,1 \\
1.562,1 \\
567,2 \\
\end{array}$ \\
\hline São Paulo & $\begin{array}{l}\text { Bauru } \\
\text { Ourinhos } \\
\text { Presidente Prudente } \\
\text { Ribeirão Preto } \\
\text { S.J. do Rio Preto } \\
\text { Campinas } \\
\end{array}$ & $\begin{array}{l}\text { BASP } \\
\text { OUSP } \\
\text { PPSP } \\
\text { RPSP } \\
\text { SJSP } \\
\text { CASP } \\
\end{array}$ & $\begin{array}{r}32,2 \\
369,4 \\
16,7 \\
620,2 \\
92,7 \\
54,3 \\
\end{array}$ \\
\hline Minas Gerais & \begin{tabular}{|l} 
Uberlândia \\
Varginha \\
Patos de Minas \\
\end{tabular} & $\begin{array}{l}\text { UBMG } \\
\text { VAMG } \\
\text { PMMG } \\
\end{array}$ & $\begin{array}{r}696,7 \\
12,6 \\
490,4 \\
\end{array}$ \\
\hline Mato Grosso & \begin{tabular}{|l|} 
Rondonópolis \\
Cuiaba-MT \\
Sorriso \\
Barra do Garças \\
\end{tabular} & $\begin{array}{l}\text { ROMT } \\
\text { CUMT } \\
\text { SOMT } \\
\text { BGMT } \\
\end{array}$ & $\begin{array}{r}1.725,6 \\
446,8 \\
2.825,8 \\
493,2 \\
\end{array}$ \\
\hline Mato Grosso do Sul & $\begin{array}{l}\text { Campo Grande } \\
\text { Dourados } \\
\text { Três Lagoas } \\
\end{array}$ & $\begin{array}{l}\text { CGMS } \\
\text { DOMS } \\
\text { TLMS } \\
\end{array}$ & $\begin{array}{r}616,2 \\
1.100,4 \\
566,9 \\
\end{array}$ \\
\hline Goiás & $\begin{array}{l}\text { Goiânia } \\
\text { Brasília } \\
\text { Rio Verde } \\
\end{array}$ & $\begin{array}{l}\text { GOGO } \\
\text { BRGO } \\
\text { RVGO }\end{array}$ & $\begin{array}{r}339,2 \\
257,8 \\
1.549,9 \\
\end{array}$ \\
\hline \multicolumn{3}{|l|}{ Total Produzido } & $18.375,5$ \\
\hline
\end{tabular}

Fonte: elaborado a partir de dados do GEIPOT (1997).

Para os Pólos de Londrina, Bauru, Ourinhos, Ribeirão Preto, Uberlândia, Patos de Minas, Goiânia e Brasília há uma redução na quantidade ofertada em relação à quantidade produzida. A redução no montante ofertado refere-se às quantidades 
transportadas por ferrovia. Estas quantidades não serão consideradas no presente estudo uma vez que o modo de transporte adotado para a análise do fluxo de soja entre os Pólos de oferta e demanda é o rodoviário. Portanto, estes valores serão desconsiderados tanto na oferta quanto na demanda. Os fluxos por ferrovia para os portos podem ser visualizados na Tabela 3.2. Com relação ao porto de Vitória, este não fará parte da análise devido a todo o seu fluxo ter sido realizado por ferrovia.

Tabela 3.2 - Movimentação de soja por ferrovia para os portos de Paranaguá, Santos e Vitória para o ano de 1995 (em $1000 \mathrm{t}$ ).

\begin{tabular}{|c|c|c|c|c|}
\hline Origem & $\begin{array}{l}\text { Quantidade } \\
\text { Produzida (1) }\end{array}$ & Destino & $\begin{array}{l}\text { Quantidade } \\
\text { Demandada (2) }\end{array}$ & Diferença (1 - 2) \\
\hline Londrina & $1.562,1$ & Paranaguá ${ }^{a}$ & 148,8 & $1.413,3$ \\
\hline Bauru & 32,2 & Santos ${ }^{b}$ & 0,4 & 31,8 \\
\hline Ourinhos & 369,4 & Santos & 93,9 & 275,5 \\
\hline Riberão Preto & 620,2 & Santos & 82,4 & 537,8 \\
\hline \multirow[t]{2}{*}{ Uberlândia* } & 696,7 & Santos & 36,4 & \\
\hline & & Vitória $^{\mathrm{c}}$ & 31,3 & 629,0 \\
\hline Patos de Minas & 490,4 & Vitória & 109,3 & 381,1 \\
\hline Goiânia & 339,2 & Vitória & 22,2 & 317,0 \\
\hline Brasília & 257,8 & Vitória & 129,2 & 128,6 \\
\hline
\end{tabular}

* Uberlândia enviou soja para os portos de Santos e Vitória. Logo têm-se: 696,7 - 67,7 $(36,4+31,3)=$ 629,0 .

Fonte: dados primários coletados através da APPA (a), FEPASA (b) e Administração do Porto de de Vitória e GEIPOT (1997) (c).

Outro aspecto que deve ser considerado refere-se à soja procedente do Paraguai. Segundo a matriz de origem/destino do GEIPOT (1997), os portos de Paranaguá e Santos movimentaram 458,4 e 100,7 mil toneladas respectivamente, oriundas do Paraguai via Pólo de Cascavel. Estes valores devem ser incluídos, a exemplo do GEIPOT, na quantidade de soja ofertada pelo Pólo de Cascavel. Tal procedimento justifica-se uma vez que não se tem dados disponíveis sobre as regiões de produção no Paraguai, assim como, preços de oferta e demanda. Portanto, no Quadro 3.3 encontram-se as quantidades ofertadas, já com os valores da Tabela 3.2 deduzidos e com as quantidades $(559,1$ mil 
toneladas, oriundas do Paraguai) adicionadas à quantidade de soja produzida pelo Pólo de Cascavel.

Quadro 3.3 - Quantidades de soja ofertadas por Pólo menos a quantidade transportada por ferrovia em 1995 (em $1000 \mathrm{t}$ ).

\begin{tabular}{|c|c|c|c|}
\hline Estado & Pólo & Código & Qtde. Ofertada (1000 t) \\
\hline Santa Catarina & $\begin{array}{l}\text { Herval d'Oeste } \\
\text { Lages } \\
\text { Porto União } \\
\text { Xanxerê } \\
\text { Florianópolis }\end{array}$ & $\begin{array}{l}\text { HOSC } \\
\text { LASC } \\
\text { PUSC } \\
\text { XASC } \\
\text { FLSC }\end{array}$ & $\begin{array}{r}22,5 \\
64,3 \\
76,9 \\
279,7 \\
0,7\end{array}$ \\
\hline Paraná & $\begin{array}{l}\text { Curitiba } \\
\text { Cascavel } \\
\text { Guarapuava } \\
\text { Londrina } \\
\text { Ponta Grossa } \\
\end{array}$ & $\begin{array}{l}\text { CUPR } \\
\text { CAPR } \\
\text { GUPR } \\
\text { LOPR } \\
\text { PGPR } \\
\end{array}$ & $\begin{array}{r}93,6 \\
3.104,5 \\
856,1 \\
1.413,3 \\
567,2 \\
\end{array}$ \\
\hline São Paulo & $\begin{array}{l}\text { Bauru } \\
\text { Ourinhos } \\
\text { Presidente Prudente } \\
\text { Ribeirão Preto } \\
\text { S.J. do Rio Preto } \\
\text { Campinas } \\
\end{array}$ & $\begin{array}{l}\text { BASP } \\
\text { OUSP } \\
\text { PPSP } \\
\text { RPSP } \\
\text { SJSP } \\
\text { CASP } \\
\end{array}$ & $\begin{array}{r}31,8 \\
275,5 \\
16,7 \\
537,8 \\
92,7 \\
54,3 \\
\end{array}$ \\
\hline Minas Gerais & $\begin{array}{l}\text { Uberlândia } \\
\text { Varginha } \\
\text { Patos de Minas } \\
\end{array}$ & $\begin{array}{l}\text { UBMG } \\
\text { VAMG } \\
\text { PMMG }\end{array}$ & $\begin{array}{r}629,0 \\
12,6 \\
381,1 \\
\end{array}$ \\
\hline Mato Grosso & \begin{tabular}{|l} 
Rondonópolis \\
Cuiabá \\
Sorriso \\
Barra do Garças
\end{tabular} & $\begin{array}{l}\text { ROMT } \\
\text { CUMT } \\
\text { SOMT } \\
\text { BGMT }\end{array}$ & $\begin{array}{r}1.725,6 \\
446,8 \\
2.825,8 \\
493,2 \\
\end{array}$ \\
\hline Mato Grosso do Sul & $\begin{array}{l}\text { Campo Grande } \\
\text { Dourados } \\
\text { Três Lagoas } \\
\end{array}$ & $\begin{array}{l}\text { CGMS } \\
\text { DOMS } \\
\text { TLMS }\end{array}$ & $\begin{array}{r}616,2 \\
1.100,4 \\
566,9 \\
\end{array}$ \\
\hline Goiás & $\begin{array}{l}\text { Goiânia } \\
\text { Brasília } \\
\text { Rio Verde }\end{array}$ & $\begin{array}{l}\text { GOGO } \\
\text { BRGO } \\
\text { RVGO }\end{array}$ & $\begin{array}{r}317,0 \\
128,6 \\
1.549,9\end{array}$ \\
\hline \multicolumn{3}{|l|}{ Total Ofertado } & $18.280,6$ \\
\hline
\end{tabular}

Fonte: elaborado a partir de dados do GEIPOT (1997).

\subsubsection{Caracterização da Demanda}

Segundo o GEIPOT (1997), a demanda de soja em 1995 foi quantificada e 
distribuída em Pólos a partir dos coeficientes de consumo aparente elaborados pela EMBRAPA, IBGE, APINCO, ABIOVE e CONAB, considerando o consumo das indústrias de esmagamento e volumes destinados à exportação.

No Quadro 3.4 observa-se as quantidades de soja demandadas por Pólos tanto para o mercado interno quanto para o mercado externo (portos). Cabe ressaltar que os portos de Paranaguá e Santos possuem suas quantidades reduzidas em 148,8 e 213,1 mil toneladas, respectivamente, devido à movimentação por ferrovia, conforme apresentado na Tabela 3.2.

Quadro 3.4 - Quantidade de soja demandada por Pólo e Portos em 1995 (em 1000 t).

\begin{tabular}{|c|c|c|c|}
\hline Estado & Pólo & Código & Qtde. Demandada (1000 t) \\
\hline Santa Catarina & \begin{tabular}{|l|} 
Xanxerê \\
Florianópolis \\
São Francisco do Sul \\
\end{tabular} & $\begin{array}{l}\text { XASC } \\
\text { FLSC } \\
\text { SFSC }\end{array}$ & $\begin{array}{r}22,51 \\
240,33 \\
94,47\end{array}$ \\
\hline Paraná & \begin{tabular}{|l|} 
Curitiba \\
Londrina \\
Ponta Grossa \\
Paranaguá ${ }^{(1)(2)}$ \\
\end{tabular} & $\begin{array}{l}\text { CUPR } \\
\text { LOPR } \\
\text { PGPR } \\
\text { PGUA } \\
\end{array}$ & $\begin{array}{r}435,63 \\
2.793,31 \\
2.566,74 \\
1.165,30 \\
\end{array}$ \\
\hline São Paulo & $\begin{array}{l}\text { Bauru } \\
\text { Ourinhos } \\
\text { Presidente Prudente } \\
\text { Ribeirão Preto } \\
\text { S.J. do Rio Preto } \\
\text { Campinas } \\
\text { São Paulo } \\
\text { Santos }^{(1)(2)}\end{array}$ & $\begin{array}{l}\text { BASP } \\
\text { OUSP } \\
\text { PPSP } \\
\text { RPSP } \\
\text { SJSP } \\
\text { CASP } \\
\text { SPSP } \\
\text { SANT }\end{array}$ & $\begin{array}{r}137,09 \\
134,62 \\
827,87 \\
708,45 \\
335,97 \\
477,11 \\
9,95 \\
1.014,01\end{array}$ \\
\hline Minas Gerais & Uberlândia & UBMG & 288,08 \\
\hline Mato Grosso & $\begin{array}{l}\text { Cuiabá } \\
\text { Rondonópolis }\end{array}$ & $\begin{array}{l}\text { CUMT } \\
\text { ROMT }\end{array}$ & $\begin{array}{r}1.761,83 \\
783.80\end{array}$ \\
\hline Mato Grosso do Sul & $\begin{array}{l}\text { Campo Grande } \\
\text { Três Lagoas }\end{array}$ & $\begin{array}{l}\text { CGMS } \\
\text { TLMS }\end{array}$ & $\begin{array}{r}1.901,05 \\
502,81 \\
\end{array}$ \\
\hline Goiás & $\begin{array}{l}\text { Goiânia } \\
\text { Brasília } \\
\text { Rio Verde }\end{array}$ & $\begin{array}{l}\text { GOGO } \\
\text { BRGO } \\
\text { RVGO }\end{array}$ & $\begin{array}{r}86,67 \\
29,96 \\
304,87\end{array}$ \\
\hline \multicolumn{3}{|l|}{ Total Demandado } & $16.622,43$ \\
\hline
\end{tabular}

Fonte: elaborado a partir de dados do GEIPOT (1997).

(1) Somente a área portuária.

(2) Entre o total de soja demandada nos portos de Paranaguá e Santos, 458,4 e 100,7 mil toneladas, respectivamente, correspondem ao fluxo oriundo do Paraguai via Pólo de Cascavel. 
Comparando o Quadro 3.3 (oferta) com o Quadro 3.4 (demanda), observa-se que nem todos os Pólos ofertantes de soja são também demandantes (caso dos Pólos de HOSC, LASC, PUSC, CAPR, VAMG, PMMG, DOMS e SOMT). Por outro lado, dos Pólos demandantes somente quatro não são ofertantes (SPSP, SANT, PGUA e SFSC). Observa-se ainda que a quantidade ofertada é superior à quantidade demandada. Este desbalanceamento entre oferta e demanda, entretanto, não implica em problema para a resolução do modelo proposto, uma vez que se pode criar uma região fictícia de demanda, com custo de transporte zero, para alocar este excedente entre oferta e demanda.

\subsubsection{Distância entre os Pólos e Portos}

O GEIPOT classifica as rotas utilizadas para movimentação de soja como sendo o caminho efetivamente percorrido pelos transportadores, em atendimento a seus interesses e a conveniências específicas.

As distâncias associadas às rotas utilizadas para movimentação de soja adotadas neste trabalho foram levantadas através da situação existente, a partir da matriz de origem/destino representativa dos principais fluxos de transporte, utilizada pelo GEIPOT (1997). De acordo com o GEIPOT (1997), a seleção das rotas decorre de uma definição prévia dos grandes Pólos geradores, consumidores, processadores e distribuidores de grãos agrícolas e vinculados aos mercados interno e externo.

A Figura 11 apresenta as principais rotas utilizadas para movimentação de soja no ano de 1995. Através desta Figura e com o auxílio do Guia Rodoviário Quatro Rodas 1997, foram levantadas as distâncias existentes entre cada Pólo e os portos de Paranaguá e Santos. As distâncias (Anexo 1) levantadas servirão como base para calcular os custos 
de transportes entre os Pólos produtores e consumidores/exportadores de soja, os quais serão utilizados para analisar o fluxo de soja entre as regiões de oferta e demanda.

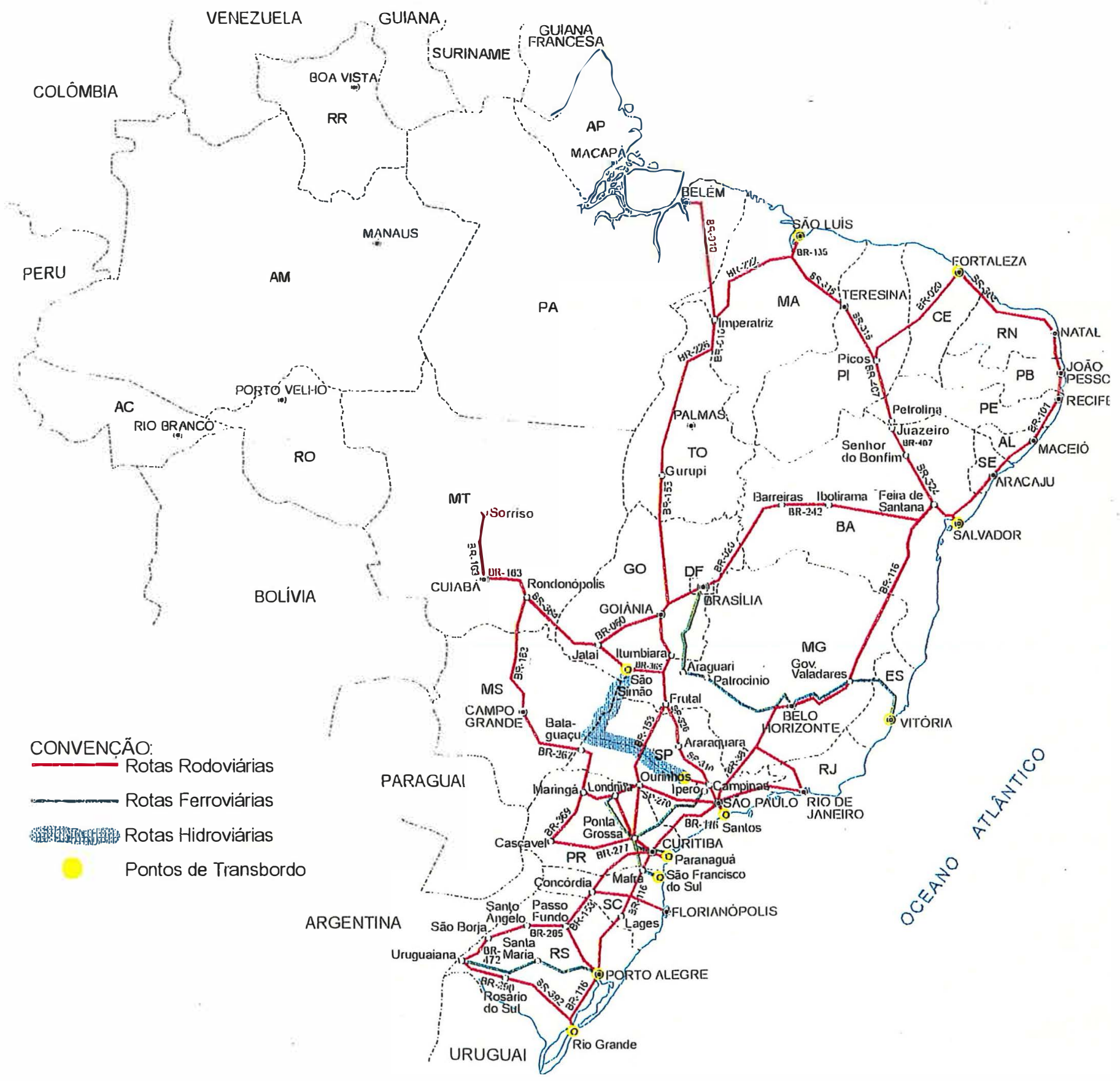

Figura 8 - Principais Rotas utilizadas para movimentação de grãos em 1995 (Extraído do GEIPOT, 1997, p.303). 


\subsubsection{Obtenção dos custos de transportes entre Pólos e portos}

Devido às dificuldades encontradas para levantar os custos de transportes referentes ao ano de 1995 entre os Pólos de oferta e demanda, adotou-se a equação estimada por Oliveira (1996, p.97) para o cálculo dos custos de transportes (Anexo 2). A equação estimada por Oliveira (1996) expressa a relação entre o valor do frete rodoviário (em US\$/t) com a distância $(\mathrm{km})$ para os produtos soja, milho e farelo de soja, transportados no período de outubro de 1993 a outubro de 1996, conforme apresentado na equação (16).

FRETE $=2,375982+0,032202 \times$ distância $-0,000004029 \times$ distância $^{2}$

Nos custos de transportes referentes aos portos de Paranaguá e Santos e São Francisco do Sul estão adicionados os custos referentes às tarifas portuárias praticadas nos referidos portos. As tarifas portuárias representam uma parcela significativa nos custos da soja a ser exportada, sendo que seu valor - US $\$ 10,00$, US\$ 7,50 e US $\$ 1,30$, para os portos de Santos, Paranaguá e São Francisco do Sul, respectivamente (GEIPOT, 1997), - influenciam no processo de tomada de decisão por parte do exportador.

Vale notar que a análise da estrutura portuária em seus vários aspectos, apesar de possuir um importante significado no processo de tomada de decisão pela escolha deste ou daquele porto, foge ao escopo do presente trabalho.

\subsubsection{Preços nas regiões de oferta e demanda}

Segundo Marques \& Mello (1997, p.48), existem três tipos de preços praticados 
no mercado brasileiro de soja, a nível de produção, sendo eles:

“(i) Disponível, preço para entrega imediata e pagamento efetivo à vista. Geralmente, prevalece para pequenos produtores individuais.

(ii) Lote, pagamento à vista mediante entrega de grandes volumes (3 a 6 mil sacas). Este preço é mais elevado do que o "no disponível" e geralmente, é o preço pago para grandes produtores ou cooperativas que negociam com processadoras grandes volumes de seus cooperados.

(iii) A fixar ou balcão, quando o produtor entrega a soja bruta nos armazéns para recebimento posterior. A qualquer momento, o produtor pode solicitar a realização do negócio, recebendo um valor onde foram descontados custos de secagem, armazenamento, etc".

Os preços de mercado da soja, utilizados no presente trabalho, são os de Lote, os quais foram obtidos através da Agência Safras \& Mercados (1997). A cotação dos preços fornecidos pela Agência Safras \& Mercados é feita por praças dentro de cada Estado. Isto significa que nem todos os Pólos possuem cotação própria de preços. Neste caso adotou-se o preço do Pólo mais próximo, menos o custo de transporte. Na Tabela 3.3 são apresentados os preços médios de mercado referentes aos Pólos produtores/exportadores de soja, para o ano de 1995, em US\$ por tonelada.

Deve-se ressaltar que a soja brasileira é colhida entre os meses de janeiro a maio de cada ano, sendo que neste período os preços sofrem redução, atingindo menores valores nos meses de março e abril. Nos meses de junho a dezembro (entressafra), os preços tendem a se elevar, sofrendo pequenas oscilações. Tais oscilações ocorrem em função do comportamento da safra norte-americana (que ocorre na entressafra brasileira): se a cotação da safra norte-americana atingir os patamares desejados ou superá-los, os 
preços no Brasil reduzem-se, e vice-versa. Essa sazonalidade ao longo do ano traz características próprias para cada região (Pólo), influenciando na contabilização do preço médio anual.

Tabela 3.3 - Preços médio de mercado por Pólo, para a soja no ano de 1995 (em US\$/t).

\begin{tabular}{|c|c|c|}
\hline Cidade & Pólo & Preço (US\$/t) \\
\hline Herval D'Oeste - SC & HOSC & 187,35 \\
\hline Lages - SC & LASC & 189,51 \\
\hline Porto União - SC & PUSC & 186,58 \\
\hline Xanxerê - SC & XASC & 180,92 \\
\hline Florianópolis - SC & FLSC & 194,69 \\
\hline São Francisco do Sul - SC & SFSC & 203,13 \\
\hline Curitiba - PR & CUPR & 195,37 \\
\hline Cascavel - PR & CAPR & 186,04 \\
\hline Guarapuava - PR & GUPR & 187,96 \\
\hline Londrina - PR & LOPR & 188,04 \\
\hline Ponta Grossa - PR & PGPR(CIF) & 195,54 \\
\hline Paranaguá - PR & PGUA(CIF) & 200,61 \\
\hline Bauru - SP & $\mathrm{BASP}(\mathrm{CIF})$ & 177,04 \\
\hline Ourinhos - SP & OUSP(CIF) & 183,60 \\
\hline Presidente Prudente - SP & $\operatorname{PPSP}(\mathrm{CIF})$ & 175,10 \\
\hline Ribeirão Preto - SP & $\mathrm{RPSP}(\mathrm{CIF})$ & 173,46 \\
\hline São José do Rio Preto - SP & SJSP(CIF) & 172,46 \\
\hline Campinas - SP & CASP(CIF) & 183,27 \\
\hline São Paulo - SP & $\operatorname{SPSP}(\mathrm{CIF})$ & 188,79 \\
\hline Santos - SP & SANT(CIF) & 193,46 \\
\hline Uberlândia - MG & UBMG(CIF) & 177,70 \\
\hline Varginha - MG & VAMG(CIF) & 177,92 \\
\hline Patos de Minas - MG & PMMG(CIF) & 168,83 \\
\hline Cuiabá - MT & CUMT & 150,97 \\
\hline Rondonópolis - MT & ROMT & 160,20 \\
\hline Sorriso - MT & SOMT & 138,95 \\
\hline Barra do Garças - MT & BGMT & 168,52 \\
\hline Campo Grande - MS & CGMS(CIF) & 172,03 \\
\hline Dourados - MS & DOMS & 171,03 \\
\hline Três Lagoas - MS & TLMS & 175,10 \\
\hline Goiânia - GO & GOGO & 150,80 \\
\hline Brasília - GO & BRGO & 144,94 \\
\hline Rio Verde - GO & RVGO & 160,70 \\
\hline
\end{tabular}

Fonte: dados coletados através da agência Safras \& Mercados (1997). 


\subsubsection{Elasticidades-preço de oferta e demanda}

Devido às dificuldades encontradas para levantar as elasticidades-preço de oferta e demanda para a soja que abrangesse o ano de 1995, deverão ser utilizadas as elasticidades-preço de oferta e demanda referente ao período compreendido entre 1970 a 1993, estimadas por Tôsto (1995). As elasticidades-preço de oferta e demanda estimadas

pelo autor, 0,60 e -0,19, respectivamente, constituem-se num único valor para o País como um todo, devendo ser aplicadas dessa forma homogênea aos Pólos considerados neste trabalho.

\subsection{Função de demanda}

Considerando o modelo de competição perfeita proposto, a função de demanda é definida como quantidade demandada em função do preço. Portanto, para estimar os coeficientes da função de demanda, para cada Pólo, foram utilizados, as quantidades demandadas em cada Pólo, preço de mercado por Pólo consumidor e a elasticidade preço de demanda, construindo-se uma relação de demanda linear com preço dependente, conforme as funções (2), (8) e (9) do ítem 3.3. Os coeficientes estimados apresentam-se na Tabela 3.4 . 
Tabela 3.4 - Coeficientes utilizados nas funções de demanda de soja em grão, 1995.

\begin{tabular}{lrcccc}
\hline Pólo & $\begin{array}{c}\text { Quantidade } \\
(\mathbf{1 0 0 0} \mathbf{t})\end{array}$ & Preço (US\$/t) & Elasticidade & $\begin{array}{c}\beta \\
\text { (coef. } \\
\text { angular) }\end{array}$ & $\begin{array}{c}\boldsymbol{\alpha} \\
\text { (intercepto) }\end{array}$ \\
\hline XASC & 22,51 & 180,9 & $-0,19$ & 0,02 & 26,13 \\
FLSC & 240,33 & 194,7 & $-0,19$ & 0,23 & 285,11 \\
SFSC & 94,47 & 203,1 & $-0,19$ & 0,09 & 112,75 \\
CUPR & 435,63 & 195,4 & $-0,19$ & 0,42 & 517,70 \\
LOPR & $2.793,31$ & 188,0 & $-0,19$ & 2,82 & $3.323,47$ \\
PGPR & $2.566,74$ & 195,5 & $-0,19$ & 2,49 & $3.053,54$ \\
PGUA & $1.165,30$ & 200,6 & $-0,19$ & 1,10 & $1.385,96$ \\
BASP & 137,09 & 177,0 & $-0,19$ & 0,15 & 163,64 \\
OUSP & 134,62 & 183,6 & $-0,19$ & 0,14 & 160,32 \\
PPSP & 827,87 & 175,1 & $-0,19$ & 0,90 & 985,46 \\
RPSP & 708,45 & 173,5 & $-0,19$ & 0,78 & 843,78 \\
SJSP & 335,97 & 172,5 & $-0,19$ & 0,37 & 399,80 \\
CASP & 477,11 & 183,3 & $-0,19$ & 0,49 & 566,93 \\
SPSP & 9,95 & 188,8 & $-0,19$ & 0,01 & 11,84 \\
SANT & $1.014,01$ & 193,5 & $-0,19$ & 1,00 & $1.207,51$ \\
UBMG & 288,08 & 177,7 & $-0,19$ & 0,31 & 343,17 \\
CUMT & $1.761,83$ & 150,9 & $-0,19$ & 2,22 & $2.096,83$ \\
ROMT & 783,80 & 160,2 & $-0,19$ & 0,93 & 932,79 \\
CGMS & $1.901,05$ & 172,0 & $-0,19$ & 2,10 & $2.262,25$ \\
TLMS & 502,81 & 175,1 & $-0,19$ & 0,55 & 599,12 \\
GOGO & 86,87 & 150,8 & $-0,19$ & 0,11 & 103,46 \\
BRGO & 29,96 & 144,9 & $-0,19$ & 0,04 & 35,76 \\
RVGO & 304,87 & 160,7 & $-0,19$ & 0,36 & 362,72 \\
\hline
\end{tabular}

\subsection{Função de oferta}

Semelhantemente à função de demanda, os coeficientes da função de oferta $(\phi \mathrm{e}$ 7), conforme a equação (10) apresentada no item 3.3, podem ser estimados utilizando-se a quantidade de soja ofertada, os preços de mercado em cada Pólo e a elasticidade-preço de oferta. Os coeficientes estimados podem ser visualizados na Tabela 3.5. 
Tabela 3.5 - Coeficientes utilizados nas funções de oferta de soja em grão, 1995.

\begin{tabular}{|c|c|c|c|c|c|}
\hline Pólo & $\begin{array}{l}\text { Quantidade } \\
(1000 \mathrm{t})\end{array}$ & Preço (US\$/t) & Elasticidade & $\begin{array}{c}\gamma \\
\text { (coef. } \\
\text { angular) }\end{array}$ & $\begin{array}{c}\phi \\
\text { (intercepto) }\end{array}$ \\
\hline HOSC & 22,50 & 187,4 & 0,6 & 0,07 & 9,39 \\
\hline LASC & 64,30 & 189,5 & 0,6 & 0,20 & 26,40 \\
\hline PUSC & 76,90 & 186,6 & 0,6 & 0,25 & 30,25 \\
\hline XASC & 279,70 & 180,9 & 0,6 & 0,93 & 111,44 \\
\hline FLSC & 0,70 & 194,7 & 0,6 & 0,00 & 0,70 \\
\hline CUPR & 93,60 & 195,4 & 0,6 & 0,29 & 36,94 \\
\hline CAPR & $3.104,50$ & 186,0 & 0,6 & 10,01 & $1.242,24$ \\
\hline GUPR & 856,10 & 187,7 & 0,6 & 2,73 & 342,97 \\
\hline LOPR & $1.413,30$ & 188,0 & 0,6 & 4,51 & 565,24 \\
\hline PGPR & 567,20 & 195,5 & 0,6 & 1,74 & 226,96 \\
\hline BASP & 31,80 & 177,0 & 0,6 & 0,11 & 12,33 \\
\hline OUSP & 275,50 & 183,6 & 0,6 & 0,90 & 110,26 \\
\hline PPSP & 16,70 & 175,1 & 0,6 & 0,06 & 6,19 \\
\hline RPSP & 537,80 & 173,5 & 0,6 & 1,86 & 215,16 \\
\hline SJSP & 92,70 & 172,5 & 0,6 & 0,32 & 37,51 \\
\hline CASP & 54,30 & 183,3 & 0,6 & 0,18 & 21,30 \\
\hline UBMG & 629,00 & 177,7 & 0,6 & 2,12 & 252,28 \\
\hline VAMG & 12,60 & 177,9 & 0,6 & 0,04 & 5,48 \\
\hline PMMG & 381,10 & 168,8 & 0,6 & 1,36 & 151,49 \\
\hline ROMT & $1.725,60$ & 160,2 & 0,6 & 6,46 & 690,71 \\
\hline CUMT & 446,80 & 150,9 & 0,6 & 1,78 & 178,07 \\
\hline SOMT & $2.825,80$ & 138,9 & 0,6 & 12,20 & $1.130,61$ \\
\hline BGMT & 493,20 & 168,5 & 0,6 & 1,76 & 196,60 \\
\hline CGMS & 616,20 & 172,0 & 0,6 & 2,15 & 246,33 \\
\hline DOMS & $1.100,40$ & 171,0 & 0,6 & 3,86 & 440,22 \\
\hline TLMS & 566,90 & 175,1 & 0,6 & 1,94 & 227,21 \\
\hline GOGO & 317,00 & 150,8 & 0,6 & 1,26 & 126,99 \\
\hline BRGO & 128,60 & 144,9 & 0,6 & 0,53 & 51,78 \\
\hline RVGO & $1.549,90$ & 160,7 & 0,6 & 5,79 & 619,45 \\
\hline
\end{tabular}

Os coeficientes estimados para as funções de oferta e demanda, assim como os custos de transportes, foram as variáveis exógenas consideradas no modelo computacional apresentado no Anexo 3, cujos resultados são analisados e discutidos no capitulo seguinte. 


\subsection{Considerações finais}

Neste capítulo foram apresentados o modelo de equilíbrio espacial e os dados relacionados às variáveis referentes à estrutura matemática do modelo. Os dados, após serem processados, deverão ter seus resultados avaliados com o intuíto de se verificar se os mesmos refletem a situação atual ou não. Sendo assim, no próximo capítulo será apresentado o processo de verificação e validação do modelo de equilíbrio espacial, assim como a análise dos resultados fornecidos pelo modelo. 


\section{ANÁLISE E DISCUSSÃO DOS RESULTADOS}

Neste capítulo, primeiramente serão apresentados os resultados obtidos através dos dados coletados e processados de acordo com o modelo proposto no capítulo 3 . Numa segunda etapa será procedida a validação do modelo. Na terceira etapa serão apresentadas as análises de sensibilidades, e, finalmente, será feita a discussão dos resultados.

\subsection{Fluxo de soja por Estado}

A movimentação da soja brasileira tem ocorrido de uma forma desordenada entre a região de produção e o consumidor final, quer seja para processamento pelas indústrias, quer seja para exportação. É comum, por exemplo, uma região como a de São José do Rio Preto, no Estado de São Paulo, enviar soja para o mercado externo, via porto de Santos, percorrendo uma distância de aproximadamente 530 quilômetros, e importar soja de Cuiabá, no Mato Grosso, cuja distância é mais que o dobro. Ou ainda, como é o caso da soja originada em Sorriso no Mato Grosso, com destino ao porto de Paranaguá, percorrendo aproximadamente 2.300 quilômetros, por rodovia, a um custo de US\$ 54,92 por tonelada.

Diante deste cenário, uma opção logística para distribuição da soja brasileira, que implique menores custos, torna-se necessária. Sendo assim, nas Tabelas 4.1 a 4.7 são apresentados os fluxos de soja ocorridos na área de abrangência deste estudo em 1995, 
com origem por Estado. Ao mesmo tempo é apontado um caminho alternativo a ser percorrido pela soja, resultante do processamento do modelo de equilibrio espacial, que implica uma distribuição ótima por uma rota de menor custo. Portanto, procura-se comparar o fluxo observado empiricamente (Real) e o fluxo simulado pelo modelo de equilíbrio espacial (M).

Tabela 4.1 - Comparação do fluxo de soja por origem para o Estado de Santa Catarina em 1995 (1000 t).

\begin{tabular}{|c|c|c|c|c|c|c|c|c|c|c|}
\hline \multirow[b]{3}{*}{ ORIG. } & \multicolumn{8}{|c|}{ DESTINO } & \multirow{2}{*}{\multicolumn{2}{|c|}{ FLUXO TOTAL }} \\
\hline & \multicolumn{2}{|c|}{ XASC } & \multicolumn{2}{|c|}{ FLSC } & \multicolumn{2}{|c|}{ SFSC } & \multicolumn{2}{|c|}{ PGUA } & & \\
\hline & $\mathbf{R}^{\mathbf{2}}$ & $\mathbf{M}^{\mathbf{b}}$ & $\mathbf{R}$ & $\mathbf{M}$ & $\mathbf{R}$ & $\mathbf{M}$ & $\mathbf{R}$ & $\mathbf{M}$ & $\mathbf{R}$ & $\mathbf{M}$ \\
\hline$\overline{\mathrm{HOSC}}$ & 22,5 & 0 & 2,6 & 0 & 0 & 22,0 & 3,5 & 0 & 28,6 & 22,0 \\
\hline LASC & 0 & 0 & 47,4 & 69,5 & 1,7 & 0 & 0,5 & 0 & 49,5 & 69,5 \\
\hline PUSC & 0 & 0 & 50,8 & 0 & 1,5 & 0 & 9,5 & 76,1 & 61,8 & 76,1 \\
\hline XASC & 0 & 22,5 & 0 & 175,6 & 8,3 & 73,0 & 0,2 & 4,7 & 8,6 & 275,8 \\
\hline FLSC & 0 & 0 & 0 & 0,7 & 0 & 0 & 0 & 0 & 0 & 0,7 \\
\hline LOPR & 0 & 0 & 58,1 & 0 & 0 & 0 & 0 & 0 & 58,1 & 0 \\
\hline PGPR & 0 & 0 & 81,5 & 0 & 0 & 0 & 0 & 0 & 81,5 & 0 \\
\hline TOTAL & 22,5 & 22,5 & 240,4 & 245,8 & 11,5 & 95,0 & 13,7 & $\mathbf{8 0 , 8}$ & 288,1 & 444,1 \\
\hline
\end{tabular}

Tabela 4.2 - Comparação do fluxo de soja por origem para o Estado do Paraná, em 1995 $(1000 \mathrm{t})$.

\begin{tabular}{|c|c|c|c|c|c|c|c|c|c|c|c|c|c|c|c|c|}
\hline \multirow[b]{3}{*}{ ORIG. } & \multicolumn{16}{|c|}{ DESTINO } \\
\hline & \multicolumn{2}{|c|}{ FLSC } & \multicolumn{2}{|c|}{ CUPR } & \multicolumn{2}{|c|}{ LOPR } & \multicolumn{2}{|c|}{ PGPR } & \multicolumn{2}{|c|}{ SFSC } & \multicolumn{2}{|c|}{ PGUA } & \multicolumn{2}{|c|}{ SANT } & \multicolumn{2}{|c|}{ FLUXO TOTAL } \\
\hline & $\mathbf{R}^{*}$ & $\mathbf{M}^{\mathbf{b}}$ & $\mathbf{R}$ & $\mathbf{M}$ & $\mathbf{R}$ & $\mathbf{M}$ & $\overline{\mathbf{R}}$ & $\mathbf{M}$ & $\bar{R}$ & $\mathbf{M}$ & $\overline{\mathbf{R}}$ & $\mathbf{M}$ & $\mathbf{R}$ & $\mathbf{M}$ & $\mathbf{R}$ & $\mathbf{M}$ \\
\hline$\overline{\text { CUPR }}$ & 0 & 0 & 0 & 92.2 & 0 & 0 & 0 & 0 & 0 & 0 & 24,0 & 0 & 0 & 0 & 24,0 & 92,2 \\
\hline CAPR & 0 & 0 & 101.8 & 344,4 & 392,3 & 391,7 & 386,5 & 1183,1 & 14,6 & 0 & 527,6 & 1081,4 & 194,6 & 0 & 1617,4 & 3000,6 \\
\hline GUPR & 0 & 0 & 35,0 & 0 & 47,0 & 0 & 107,1 & 842,1 & 0 & 0 & 66,9 & 0 & 0 & 0 & 256,0 & 842,1 \\
\hline LOPR & 58,1 & 0 & 205,5 & 0 & 0 & 1411,5 & 73,5 & 0 & 30,8 & 0 & 34,2 & 0 & 0 & 0 & 402,1 & 1411,5 \\
\hline PGPR & 81,5 & 0 & 92,3 & 0 & 0 & 0 & 0 & 554,1 & 34,2 & 0 & 61,2 & 0 & 0 & 0 & 269,2 & 554,1 \\
\hline OUSP & 0 & 0 & 0 & 0 & 0 & 140,6 & 0 & 0 & 0 & 0 & 0 & 0 & 0 & 0 & 0 & 140,6 \\
\hline CUMT & 0 & 0 & 0 & 0 & 1499,7 & 0 & 1141,8 & 0 & 0 & 0 & 0 & 0 & 0 & 0 & 2641,5 & 0 \\
\hline ROMI & 0 & 0 & 0 & 0 & 235,7 & 0 & 230,1 & 0 & 0 & 0 & 0 & 0 & 0 & 0 & 465,8 & 0 \\
\hline SOMT & 0 & 0 & 0 & 0 & 0 & 0 & 37,3 & 0 & 0 & 0 & 0 & 0 & 0 & 0 & 37,3 & 0 \\
\hline BGMT & 0 & 0 & 0 & 0 & 230.6 & 0 & 178,7 & 0 & 0 & 0 & 0 & 0 & 0 & 0 & 409,3 & 0 \\
\hline CGMS & 0 & 0 & 10.0 & 0 & 197,2 & 0 & 132,3 & 0 & 0 & 0 & 0 & 0 & 0 & 0 & 339.5 & 0 \\
\hline DOMS & 0 & 0 & 0 & 0 & 49,7 & 11.9 & 84,3 & 0 & 0 & 0 & 0 & 0 & 0 & 0 & 134,0 & 11,9 \\
\hline TLMS & 0 & 0 & 0 & 0 & 13,8 & 0 & 72,0 & 0 & 0 & 0 & 0 & 0 & 0 & 0 & 85,8 & 0 \\
\hline GOGO & 0 & 0 & 0 & 0 & 34,6 & 0 & 0 & 0 & 0 & 0 & 0 & 0 & 0 & 0 & 34.6 & 0 \\
\hline RVGO & 0 & 0 & 0 & 0 & 92,8 & 831,9 & 122,7 & 0 & 0 & 0 & 0 & 0 & 0 & 0 & 215,5 & 831,9 \\
\hline TOTAL & 139,6 & 0 & 444,6 & 436,6 & 2793,4 & 2787,6 & 2566,3 & 2579,3 & 79,6 & 0 & 713,9 & 1081,4 & 194,6 & 0 & 6932,0 & 6884,9 \\
\hline
\end{tabular}

$\mathrm{R}=$ Fluxo Real, $\mathrm{M}=$ Fluxo Simulado.

Fonte: $\quad \mathrm{a}=$ Geipot (1995).

$\mathrm{b}=$ Resultados da pesquisa. 

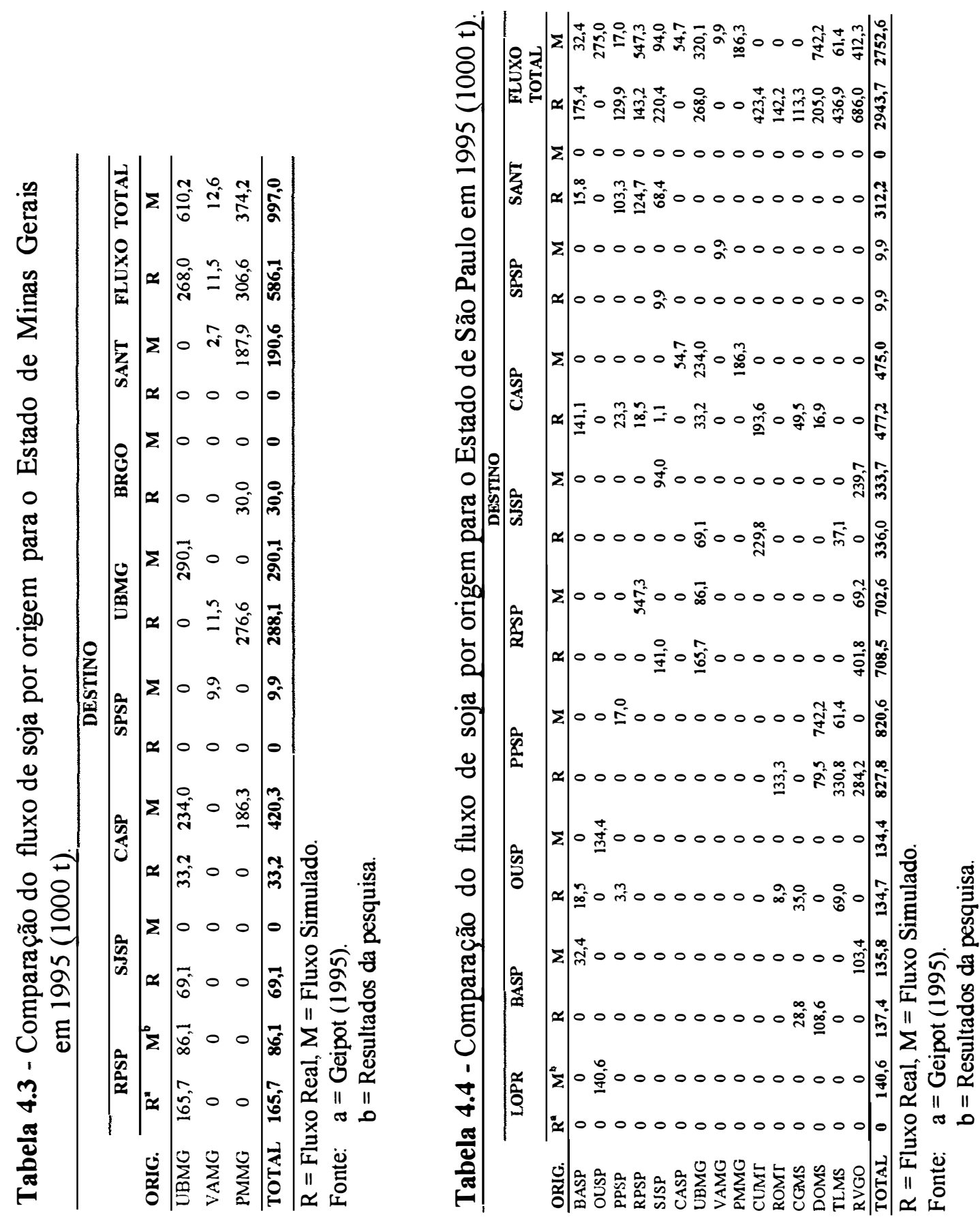

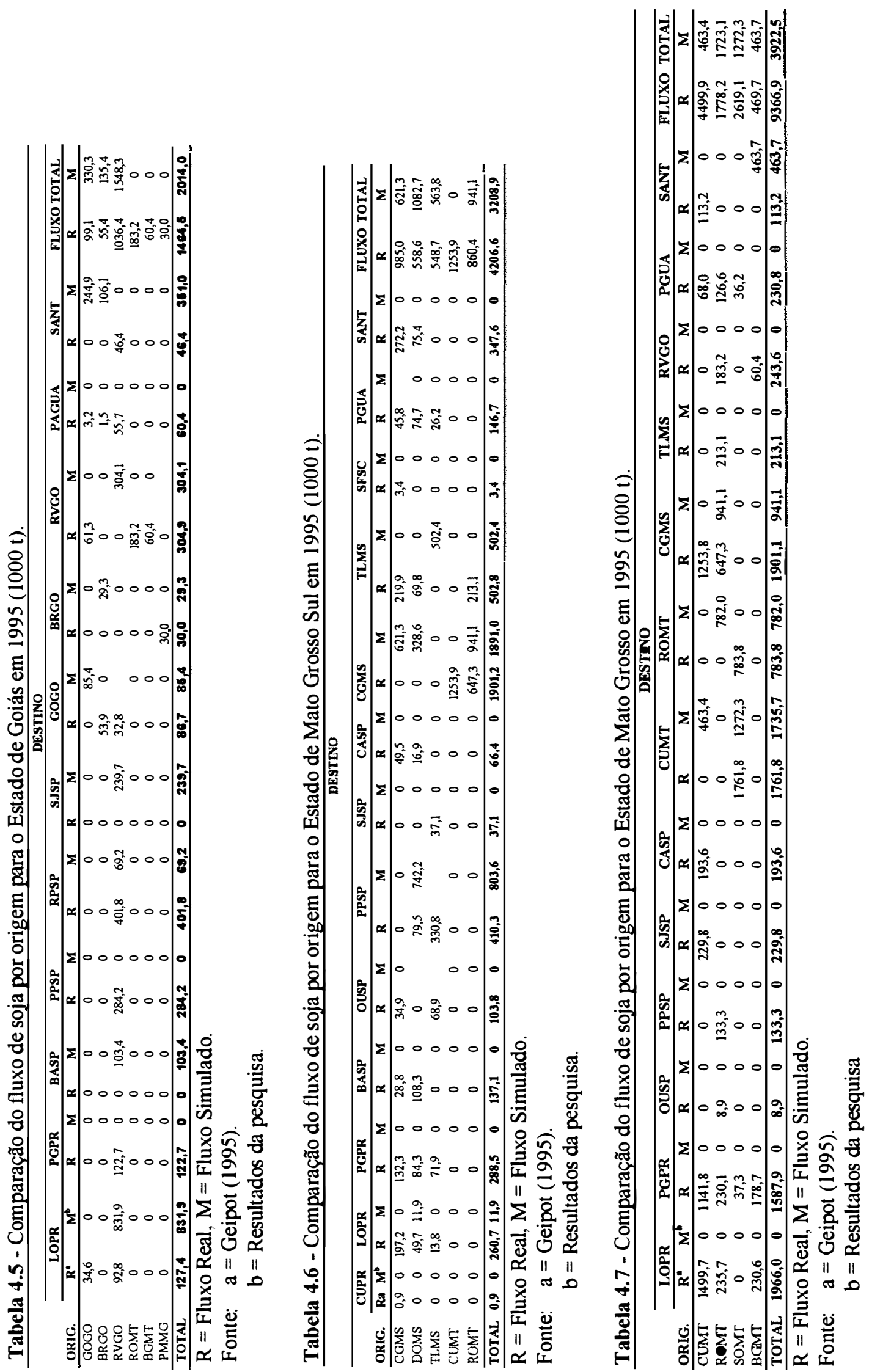
Algumas considerações a respeito do complexo soja devem ser feitas para que se possa avaliar as duas situações (fluxo real e simulado) anteriormente apresentadas. Na realidade, observa-se que alguns Estados apresentam um certo equilíbrio entre a quantidade ofertada e demandada, como é o caso do Paraná e Mato Grosso do Sul (vide Quadros 3.3 e 3.4 do Cap. 3), enquanto outros Estados possuem uma oferta maior do que a demanda, casos de Goiás, Minas Gerais, Santa Catarina e Mato Grosso, que podem ser caracterizados como Estados exportadores. Por outro lado, existem os que possuem a demanda maior que a oferta, caso do Estado de São Paulo, típico importador.

Deve-se ressaltar também que em todos estes Estados existe uma capacidade instalada de moagem, conforme apresentado na Tabela 2.1 do Capítulo 2, o que justifica a demanda interna de cada Estado. Assim sendo, as discrepâncias existentes entre os fluxos observados empiricamente e simulado justificam-se, pois o modelo faz a distribuição ótima de forma racional, combinando os pares de oferta e demanda obedecendo sempre ao menor custo de transporte. Logo, é natural que primeiro serão atendidas as necessidades internas de cada Pólo, para num segundo momento serem exportados os excedentes.

Outro fato que deve ser mencionado é que, em certos casos, as quantidades transportadas de uma região para outra são decorrentes de contratos de venda de soja firmados com um determinado prazo para entrega (quatro meses a partir da data de assinatura do contrato, por exemplo). Contudo, nesse intervalo o vendedor não necessariamente fica com a soja armazenada aguardando o vencimento do contrato para efetuar a entrega, podendo eventualmente, a seu risco, antecipar a comercialização da soja. Em vista disso, na ocasião do vencimento do contrato a soja não está mais disponível, o que obriga o vendedor a importar o grão de outras regiões, sem levar em consideração a distância e os custos a ela relacionados. 


\subsection{Fluxo de soja destinado aos portos de Paranaguá e Santos}

Situação semelhante à descrita anteriormente ocorre com os portos de Paranaguá e Santos, ou seja, a soja tem percorrido distâncias que variam de 90 até 2300 quilômetros, com custos de transportes oscilando entre US\$ 5,24 e US\$ 54,92/t, sem contar as péssimas condições de infra-estrutura viária e lentidão para percorrer o trajeto da origem até o destino (região de produção até o porto, no caso).

Para que se tenha uma melhor noção sobre a origem da soja exportada via porto de Paranaguá e Santos, na Tabela 4.8 são apresentados os fluxos de soja, real e simulado, para os mesmos. O porto de São Francisco do Sul, apesar de não fazer parte dos objetivos do presente trabalho, não deve ser desconsiderado na análise pois, embora possua pouca movimentação de soja (95 mil toneladas aproximadamente no ano de 1995), está localizado nas imediações do porto de Paranaguá (100 quilômetros, aproximadamente), "desviando" algumas cargas destinadas ao porto de Paranaguá. 
Tabela 4.8 - Fluxo de soja para os portos de Paranaguá e Santos em 1995 (1000 t):

\begin{tabular}{|c|c|c|c|c|c|c|c|c|}
\hline \multirow[b]{3}{*}{ ORIG. } & \multicolumn{8}{|c|}{ DESTINO } \\
\hline & \multicolumn{2}{|c|}{ SFSC } & \multicolumn{2}{|c|}{ PGUA } & \multicolumn{2}{|c|}{ SANT } & \multicolumn{2}{|c|}{ FLUXO TOTAL } \\
\hline & $\mathbf{R}^{2}$ & $\mathbf{M}^{\mathbf{b}}$ & $\mathbf{R}$ & $\mathbf{M}$ & $\mathbf{R}$ & $\mathbf{M}$ & $\mathbf{R}$ & $\mathbf{M}$ \\
\hline$\overline{\mathrm{HOSC}}$ & 0 & 22,0 & 3,4 & 0 & 0 & 0 & 3,4 & 22,0 \\
\hline LASC & 1,7 & 0 & 0,5 & 0 & 0 & 0 & 2,2 & 0 \\
\hline PUSC & 1,5 & 0 & 9,8 & 76,1 & 0 & 0 & 11,3 & 76,1 \\
\hline XASC & 8,3 & 73,0 & 0 & 4,7 & 0 & 0 & 8,3 & 77,7 \\
\hline CUPR & 0 & 0 & 24,0 & 0 & 0 & 0 & 24,0 & 0 \\
\hline CAPR & 14,6 & 0 & 527,6 & 1081,4 & 194,6 & 0 & 736,8 & 1081,4 \\
\hline GUPR & 0 & 0 & 66,9 & 0 & 0 & 0 & 66,9 & 0 \\
\hline LOPR & 30,8 & 0 & 34,2 & 0 & 0 & 0 & 65,0 & 0 \\
\hline PGPR & 34,2 & 0 & 61,2 & 0 & 0 & 0 & 95,4 & 0 \\
\hline BASP & 0 & 0 & 0 & 0 & 15,8 & 0 & 15,8 & 0 \\
\hline PPSP & 0 & 0 & 0 & 0 & 103,3 & 0 & 103,3 & 0 \\
\hline RPSP & 0 & 0 & 0 & 0 & 124,7 & 0 & 124,7 & 0 \\
\hline SJSP & 0 & 0 & 0 & 0 & 68,4 & 0 & 68,4 & 0 \\
\hline VAMG & 0 & 0 & 0 & 0 & 0 & 2,7 & 0 & 2,7 \\
\hline PMMG & 0 & 0 & 0 & 0 & 0 & 187,9 & 0 & 187,9 \\
\hline CUMT & 0 & 0 & 68,0 & 0 & 113,2 & 0 & 181,2 & 0 \\
\hline ROMT & 0 & 0 & 126,6 & 0 & 0 & 0 & 126,6 & 0 \\
\hline SOMT & 0 & 0 & 36,2 & 0 & 0 & 0 & 36,2 & 0 \\
\hline BGMT & 0 & 0 & 0 & 0 & 0 & 463,7 & 0 & 463,7 \\
\hline CGMS & 3,4 & 0 & 45,8 & 0 & 272,2 & 0 & 321,4 & 0 \\
\hline DOMS & 0 & 0 & 74,5 & 0 & 75,5 & 0 & 150,0 & 0 \\
\hline TLMS & 0 & 0 & 26,2 & 0 & 0 & 0 & 26,2 & 0 \\
\hline GOGO & 0 & 0 & 3,2 & 0 & 0 & 244,9 & 3,2 & 244,9 \\
\hline BRGO & 0 & 0 & 1,5 & 0 & 0 & 106,1 & 1,5 & 106,1 \\
\hline RVGO & 0 & 0 & 55,7 & 0 & 46,4 & 0 & 102,1 & 0 \\
\hline TOTAL & 94,5 & 95,0 & 1165,3 & 1162,2 & 1014,1 & 1005,3 & 2273,9 & 2262,5 \\
\hline
\end{tabular}

$\mathrm{R}=$ Fluxo Real, $\mathrm{M}=$ Fluxo Simulado.

Fonte: $\quad a=$ Geipot (1995).

$\mathrm{b}=$ Resultados da pesquisa.

Ao examinar a Tabela 4.8, observa-se que na situação real o porto de São Francisco do Sul movimentou 94,5 mil toneladas de soja em 1995, das quais 1,7 mil toneladas foram oriundas de Lages (LASC), 1,5 mil toneladas de Porto União (PUSC), 8,3 mil toneladas de Xanxerê (XASC), 14,6 mil toneladas de Cascavel (CAPR), 30,8 mil toneladas de Londrina (LOPR), 34,2 mil toneladas de Ponta Grossa (PGPR) e 3,4 mil toneladas de Campo Grande (CGMS). No caso da soja oriunda de Campo Grande, esta percorre aproximadamente 1233 quilômetros. No entanto, a solução ótima obtida para suprir a demanda do porto de São Francisco do Sul implica em 22,0 mil toneladas 
oriundas de Herval D'Oeste (HOSC) e 73,0 mil toneladas de Xanxerê (XASC) no Estado de Santa Catarina.

Com relação ao porto de Paranaguá, verifica-se que na situação real o Estado do Paraná contribui com $61,26 \%$ da soja destinada ao mesmo, ficando os Estados de Santa Catarina com 1,18\%, Mato Grosso do Sul com 12,57\%, Mato Grosso com 19,81\% e Minas Gerais com 5,18\%. Este cenário deixa claro a participação da região Sul, $62,44 \%$, em relação à região Centro-Oeste, $37,56 \%$, no fluxo de soja destinado ao porto de Paranaguá.

Dos 1,18\% (13,7 mil toneladas) correspondentes ao Estado de Santa Catarina, 3,4 mil toneladas tiveram origem no Pólo de Herval D’Oeste (HOSC), 0,5 mil toneladas no Pólo de Lages (LASC) e 9,8 mil toneladas em Porto União (PUSC).

Os $61,26 \%$ (713,9 mil toneladas) correspondentes ao Estado do Paraná, tiveram origem em todos os Pólos do Estado, isto é, 24,0 mil toneladas de Curitiba (CUPR), 527,6 mil toneladas de Cascavel (CAPR), 66,9 mil toneladas de Guarapuava (GPVA), 34,2 mil toneladas de Londrina (LOPR) e, finalmente, 61,2 mil toneladas de Ponta Grossa (PGPR).

Os $37,56 \%$ (437,7 mil toneladas) oriundos do Centro-Oeste, possuem as seguintes origens: (a) no Mato Grosso 230,8 mil toneladas, sendo 68,0 mil toneladas de Cuiabá (CUMT), 126,6 mil toneladas de Rondonópolis (ROMT) e 36,2 mil toneladas de Sorriso (SOMT); (b) no Mato Grosso do Sul 146,5 mil toneladas, das quais 45,8 mil toneladas de Campo Grande (CGMS), 74,5 mil toneladas de Dourados (DOMS) e 26,2 mil toneladas de Três Lagoas (TLMS); e (c) Goiás 60,4 mil toneladas, sendo 3,2 mil toneladas de Goiânia (GOGO), 1,5 mil toneladas de Brasilia (BRGO) e 55,7 mil toneladas de Rio Verde (RVGO). 
Ao realizar-se a análise do fluxo simulado, observa-se que a soja destinada ao porto de Paranaguá origina-se totalmente na região Sul do País, com 93,0\% (1081,4 mil toneladas) correspondentes ao Pólo de Cascavel (CAPR) no Paraná e 7,0\% correspondentes aos Pólos de Porto União (PUSC), 76,1 mil toneladas, e ao Pólo de Xanxerê (XASC), 4,7 mil toneladas, no Estado de Santa Catarina.

Torna-se necessário ressaltar que tanto na situação real quanto na simulada o maior volume de soja transportada ao porto de Paranaguá, 527,6 e 1081,4 mil toneladas respectivamente, corresponderam ao Pólo de Cascavel (CAPR). Este fato confirma o que ocorre na prática, principalmente, com relação a soja oriunda do Paraguai e destinada ao porto de Paranaguá via Pólo de Cascavel. Cabe ressaltar também que, nem na situação real nem na simulada, ocorreram fluxos dos Estados de São Paulo e Minas Gerais para o porto de Paranaguá.

No que se diz respeito ao volume de soja escoado via porto de Santos, na situação real verifica-se que 30,79\% (312,2 mil toneladas) tiveram origem no Estado de São Paulo, 19,19\% (194,6 mil toneladas) no Estado do Paraná, 11,16\% (113,2 mil toneladas) no Estado do Mato Grosso, 34,28\% (347,7 mil toneladas) no Estado do Mato Grosso do Sul e 4,58\% (46,4 mil toneladas) no Estado de Goiás.

As 194,6 mil toneladas oriundas do Paraná corresponderam ao Pólo de Cascavel (CAPR). Já com relação às 312,2 mil toneladas do Estado de São Paulo, 15,8 mil toneladas corresponderam ao Pólo de Bauru (BASP), 103,3 mil toneladas ao Pólo de Presidente Prudente (PPSP), 124,7 mil toneladas ao Pólo de Ribeirão Preto (RPSP) e 68,4 mil toneladas correspondentes a São José do Rio Preto (SJSP).

Com relação às 113,2 mil toneladas do Mato Grosso, estas corresponderam ao Pólo de Cuiabá (CUMT); já das 347,7 mil toneladas do Mato Grosso do Sul, 272,2 mil corresponderam ao Pólo de Campo Grande (CGMS) e 75,5 mil toneladas ao Pólo de 
Dourados (DOMS). Finalmente, as 46,4 mil toneladas de Goiás, corresponderam ao Pólo de Rio Verde (RVGO).

O fluxo simulado para o porto de Santos indicou que toda a soja escoada por este porto tem como origem a região Centro Oeste, sendo 2,7 mil toneladas do Pólo de Varginha (VAMG) e 187,9 mil toneladas de Patos de Minas (PMMG) no Estado de Minas Gerais; 463,7 mil toneladas do Pólo de Barra do Garças (BGMT) no Mato Grosso e, finalmente, 244,9 mil toneladas do Pólo de Goiânia (GOGO) e 106,1 mil toneladas do Pólo de Rio Verde (RVGO).

\subsection{Preços}

Com relação aos preços, praticamente não houve discrepâncias entre o real e o simulado, salvo nos Pólos de BASP, PPSP, RPSP, CUMT, SOMT, GOGO e BRGO onde o modelo apresentou os preços com um nível um pouco mais elevado do que o praticado no mercado (vide Tabela 4.9). Já para os Pólos de CAPR, UBMG e BGMT, os preços apresentados pelo modelo foram mais baixo que o preço real. Estas diferenças, aliadas à redução de custos de transportes, podem resultar em ganhos que o produtor pode auferir, caso opte pela comercialização da soja através do fluxo simulado pelo modelo.

$\mathrm{Na}$ Tabela 4.9, são apresentados o preço atual e o fornecido pelo modelo. $\mathrm{Na}$ coluna referente ao preço fornecido pelo modelo encontram-se dois preços: um caso a região atuasse como ponto de origem do fluxo e outro, caso a região atuasse como ponto

de destino do fluxo. Na realidade estes preços deveriam ser apenas um, o preço de mercado em cada Pólo. No entanto, a diferença entre eles (US\$ 2,38) corresponde ao valor do frete para a comercialização que viesse a ocorrer internamente ao Pólo (distância 
percorrida aproximadamente igual a zero) que é representado pelo coeficiente linear da equação pela qual foram estimados os custos de transportes (equação 16, Capítulo 3).

Tabela 4.9 - Preços de mercado para a soja (atual e fornecido pelo modelo) para o ano de 1995, em US\$/t.

\begin{tabular}{lcc|c}
\hline Pólo & \multicolumn{2}{c|}{ Preço Modelo (US\$/t) } & Preço Atual (US\$/t) \\
& Origem & 182,75 & \\
\hline HOSC & 180,37 & 189,87 & 187,40 \\
LASC & 187,49 & 185,61 & 189,50 \\
PUSC & 183,23 & 179,14 & 186,60 \\
XASC & 176,76 & 196,60 & 180,90 \\
FLSC & 194,22 & 193,07 & 194,70 \\
CUPR & 190,69 & 178,04 & 195,40 \\
CAPR & 175,66 & 185,22 & 186,00 \\
GUPR & 182,84 & 190,01 & 187,70 \\
LOPR & 187,63 & 190,42 & 188,00 \\
PGPR & 188,04 & 185,13 & 195,50 \\
BASP & 182,75 & 185,40 & 177,00 \\
OUSP & 183,02 & 183,16 & 183,60 \\
PPSP & 180,78 & 180,95 & 175,10 \\
RPSP & 178,57 & 178,80 & 173,50 \\
SJSP & 176,42 & 187,78 & 172,50 \\
CASP & 185,40 & 171,21 & 183,30 \\
UBMG & 168,83 & 181,51 & 177,70 \\
VAMG & 179,13 & 166,13 & 177,90 \\
PMMG & 163,75 & 162,66 & 168,80 \\
CUMT & 160,28 & 162,18 & 150,90 \\
ROMT & 159,80 & 149,91 & 160,20 \\
SOMT & 147,53 & 154,15 & 138,90 \\
BGMT & 151,77 & 176,79 & 168,50 \\
CGMS & 174,41 & 168,81 & 172,00 \\
DOMS & 166,43 & 175,88 & 171,00 \\
TLMS & 173,50 & 163,80 & 175,10 \\
GOGO & 161,42 & 160,23 & 150,80 \\
BRGO & 157,85 & 162,81 & 144,90 \\
RVGO & 160,43 & 190,00 & 160,70 \\
SPSP & 187,62 & 197,44 & 188,80 \\
SFSC & 195,06 & 203,41 & 203,10 \\
PGUA & 201,03 & 202,14 & 200,60 \\
SANT & 199,76 & 193,50 \\
\hline & & & \\
\hline
\end{tabular}




\subsection{Validação}

Para Mitchell (1993) e Gass \& Harris (1996), a validação é utilizada para testar se os resultados obtidos através do modelo proposto representam uma alternativa viável para a reprodução da situação atual. Já para Ignizio \& Cavalier (1994), a validação de um modelo é freqüentemente feita para ser refletida unicamente na sua habilidade para produzir o comportamento do problema que foi modelado. Contudo, Ehrlich (1988) menciona que o problema da validação de um modelo é extremamente complexo, sendo que esse processo toca no problema do conhecimento e na possibilidade da ciência chegar à verdade.

Segundo Caixeta Filho (1996, p.4), "apesar da dificuldade para a validação de modelos, sempre haverá uma indicação do nível de sucesso do processo de modelagem, o que estará intimamente ligado à eventual reprodução da verdade em investigação. Por outro lado, tais verdades podem ser reproduzidas mas sem necessariamente representar um estado de entropia desejável".

Um método comum para testar a validade de um modelo, de acordo com Taha (1987), é comparar seus resultados com os dados da situação atual. Logo, poder-se-á proceder a validação do modelo comparando os resultados fornecidos pelo modelo de equilíbrio espacial com os dados observados na situação atual.

Sendo assim, pode-se testar a hipótese nula de que os valores dos resultados fornecidos pelo modelo de equilíbrio espacial e os dados da situação atual sejam iguais. Devido ao pequeno conjunto de dados utilizado para realizar o trabalho, testes estatísticos não-paramétricos serão adotados para validar o modelo. 
Segundo Campos (1983), um método não-paramétrico é aquele cujo modelo não específica condições sobre os parâmetros da população da qual a amostra foi obtida. Mesmo quando existem certas pressuposições, estas são mais brandas que aquelas associadas aos teste paramétricos. Seu emprego constitui uma valiosíssima ferramenta de trabalho, devido à sua grande simplicidade e versatilidade.

Os métodos não-paramétricos selecionados para realizar o teste da hipótese nula foram o teste de Kolmogorov-Smirnov e o teste de Wilcoxon.

O teste de Kolmogorov-Smimov é aplicado para verificar se os valores de uma amostra $\mathrm{F}_{0}(\mathrm{X})$ - resultados obtidos através do modelo - podem ser considerados como provenientes de uma população com distribuição teórica pré-estabelecida $F(X)$ ( $X$ é uma amostra particular) - derivado dos dados observados - sob uma hipótese de nulidade $\left(\mathrm{H}_{0}\right)$.

Segundo Campos (1983), o teste de Kolmogorov-Smirnov confronta duas distribuições de frequeência acumulada, uma $\mathrm{F}(\mathrm{X})$, teórica, e outra $\mathrm{F}_{0}(\mathrm{X})$, derivada dos dados amostrais. A maior diferença entre $\mathrm{F}(\mathrm{X})$ e $\mathrm{F}_{0}(\mathrm{X}),(D)$, é confrontada com o valor crítico, (d), tabelado, podendo a hipótese ser rejeitada ou não, de acordo com o nível de significância estabelecido. $\mathrm{O}$ valor de $D$ é obtido através da fórmula:

$$
D=\left|F(X)-F_{0}(X)\right|
$$

De acordo com Peters \& Summers (1973), o teste avaliará se as diferenças máximas observadas são bastante grandes para refutar a hipótese de que aquelas distribuições amostrais são fontes de ambas as séries de dados.

O teste de Wilcoxon, denominado de Teste da Soma das Ordens, também aplicase no caso de amostras independentes. De acordo com Siegel (1975) o teste de Wilcoxon 
utiliza informações sobre o sentido da diferença dentro de cada par de observações (dados observados e resultados fornecidos pelo modelo), sendo extremamente útil para os cientistas do comportamento. Com os dados sobre o comportamento, no caso comportamento dos fluxos observado e fornecido pelo modelo, pode-se fazer o julgamento do tipo "maior que" entre os resultados $D$ ( $D$ é a diferença entre os valores observados e fornecidos pelo modelo) e qualquer par, bem como, pode-se fazer esse julgamento em relação às diferenças relativas a dois pares quaisquer.

Para realizar os testes propostos foi utilizado o software Statistica (1997). As variáveis utilizadas para a realização dos testes foram o fluxo de soja total por Estado, fluxo de soja total ocorrido dentro dos Estados, fluxo de soja ocorrido entre os Estados e os portos e os preços de mercado.

No caso dos fluxos (real e simulado), o teste poderia ter sido aplicado utilizandose os fluxos por origem/destino para cada Pólo. Porém, esta prática esbarra no fato de determinados fluxos entre a situação real e simulada não coincidirem para alguns Pólos, por motivos já mencionados anteriormente, resultando, muitas vezes, em uma única observação. Tal situação inviabiliza a aplicação do teste, que exige no mínimo dois pares de observações (no caso específico, um par é formado por um valor da situação real e um valor simulado por origem/destino).

Deve-se ressaltar que os fluxos de soja total internos aos Estados foram utilizados somente para aqueles Estados que não receberam soja de outros Estados, casos de Minas Gerais e Mato Grosso. Como para aplicar o teste necessita-se de no mínimo dois pares de observações, a solução encontrada foi unir os referidos Estados (Anexo 4, Tabela A4.4). $\mathrm{Na}$ realidade, a comparação entre o fluxo de soja total (dentro e fora) do Estado é outra maneira de se aplicar o teste (Anexo 4, Tabela A4.5). As Tabelas referentes aos testes realizados encontram-se no Anexo 4. 
Os resultados obtidos pelos testes Kolmogorov-Smirnov e Wilcoxon, através do software estatístico, encontram-se na Tabela 4.10. Valores de $P$ (D) maiores que 0,05 e 0,10 para as probabilidades de Kolmogorov-Smirnov e Wilcoxon, respectivamente, indicam que os fluxos e preços simulados podem representar os fluxos e preços atuais, ao nível de significância de 5\%. Assim sendo, os resultados obtidos indicam que o modelo de equilíbrio espacial proposto pode ser utilizado satisfatoriamente para investigar o movimento de soja destinado aos portos de Paranaguá e Santos.

Tabela 4.10 - Resultados obtidos pelos testes estatísticos não-paramétricos.

\begin{tabular}{lc|c}
\hline Variáveis & $\begin{array}{c}\text { Probabilidade Kolmogorov- } \\
\text { Smirnov }(\boldsymbol{P}(\mathbf{D}))\end{array}$ & $\begin{array}{c}\text { Probabilidade Wilcoxon } \\
(\boldsymbol{P}(\mathbf{D}))\end{array}$ \\
\hline Santa Catarina & 0,10 & 1,00 \\
Paraná & 0,10 & 0,78 \\
São Paulo & 0,10 & 0,86 \\
Mato Grosso do Sul & 0,10 & 1,00 \\
Goiás & 0,10 & 0,72 \\
Paranaguá & 0,10 & 0,50 \\
Santos & 0,10 & 1,00 \\
São Francisco do Sul & 0,10 & 0,72 \\
Mina Gerais e Mato Grosso & 0,10 & 1,00 \\
Preços Destino & 0,10 & 0,85 \\
Preços Origem & 0,10 & 0,85 \\
Fluxo Total (dentro e fora do Estado) & 0,10 & 1,00 \\
\hline
\end{tabular}

\subsection{Análises de sensibilidade}

No presente trabalho as quantidades ofertadas, demandadas e os preços são variáveis endógenas. Por outro lado, as elasticidades-preço de oferta e demanda, assim como os custos de transportes são variáveis exógenas. Sendo assim, alterações nestes valores, quer seja por melhorias em infra-estrutura no setor de transportes ou 
$\operatorname{portuários}^{10}$, quer seja por um incremento tecnológico tanto por parte do produtor quanto por parte do setor processador da soja brasileira, poderão alterar as quantidades e, até mesmo o sentido do fluxo da soja.

Diante disso, oito cenários foram criados variando-se os valores das elasticidadespreço de oferta e das elasticidades-preço de demanda em $50 \%$, sendo eles: elevação e redução da elasticidade-preço de oferta, mantida a elasticidade-preço de demanda constante; elevação e redução da elasticidade-preço de demanda, mantida a elasticidadepreço de oferta constante; elevação das elasticidades-preço de oferta e demanda no mesmo sentido; redução das elasticidades-preço de oferta e de demanda no mesmo sentido; elevação da elasticidade-preço de oferta e redução da elasticidade-preço de demanda e, finalmente, redução da elasticidade-preço de oferta e elevação da elasticidade-preço de demanda. Como as variações foram realizadas em sentido opostos, o que implicou, na maioria dos casos, em resultados inversos, dos oito cenários serão reproduzidos somente quatro. Com relação aos custos de transportes, simulou-se a situação em que estes fossem reduzidos em $20 \%$ do seu valor original.

\subsubsection{Análise de sensibilidade das elasticidades-preço}

As elasticidades-preço, tanto de oferta quanto de demanda, são utilizadas para descrever os relacionamentos existentes entre as quantidades ofertadas e as demandadas em resposta a alterações nos preços do produto, em termos percentuais. De forma geral, as quantidades ofertadas e demandadas de soja são inelásticas, isto é, a variação percentual nas quantidades ofertadas e demandadas são menores que a variação percentual nos preços.

\footnotetext{
${ }^{10}$ Deve-se ressaltar que nos custos de transportes estão incluídos os custos portuários.
} 
$\mathrm{O}$ acréscimo de $50 \%$ nas elasticidades-preço de oferta e demanda tem como objetivo avaliar o comportamento das quantidades demandadas nos portos de Paranaguá e Santos, assim como o comportamento dos preços. Os resultados encontrados com as variações nas referidas elasticidades são apresentadas a seguir. A comparação é feita com relação ao fluxo simulado com as elasticidades originais, em termos percentuais.

a) elevação da elasticidade-preço de demanda (de $-0,19$ para $-0,28)$, mantido constante a elasticidade-preço de oferta $(0,60)$.

Ao elevar-se a elasticidade-preço de demanda, verifica-se uma mudança no comportamento das quantidades direcionadas aos portos, sem porém acarretar mudanças na direção do fluxo. As diferenças mais significativas com relação ao porto de Paranaguá são: um aumento de $114,9 \%$ da soja transportada do Pólo de Xanxerê (XASC) e uma redução de $0,6 \%$ na quantidade de soja transportada do Pólo de Cascavel (CAPR).

Com relação ao porto de Santos, observaram-se as seguintes modificações: redução de 33,3\% da soja transportada de Varginha (VAMG); aumento de $44,9 \%$ da soja transportada de Patos e Minas (PMMG) e redução de $82,2 \%$ da soja oriunda de Rio Verde (RVGO).

No porto de São Francisco do Sul, houve um aumento de $0,4 \%$ em relação à quantidade transportada de Xanxerê (XASC). Já com relação aos preços, estes sofreram pequenas variações no sentido negativo.

b) elevação da elasticidade -preço de oferta (de 0,60 para 0,90), mantida constante a elasticidade-preço de demanda $(-0,19)$. 
Com a elevação da elasticidade-preço de oferta, o fluxo relacionado ao porto de Paranaguá sofreu redução de $100 \%$ da quantidade transportada do Pólo de Xanxerê (XASC) e 0,4\% de elevação de fluxo com relação ao Pólo de Cascavel (CAPR).

No que se diz respeito ao porto de Santos, observou-se uma redução de $22,2 \%$, 0,6\% e 2,7\% da soja originada em Varginha (VAMG), Patos de Minas (PMMG) e Barra do Garças (BGMT), e uma elevação de 3,5\% e 4,3\% da soja oriunda de Goiânia (GOGO) e Brasília (BRGO), respectivamente.

Com relação ao porto de São Francisco do Sul, o fluxo teve um aumento de 0,9\% da soja oriunda de Herval D'Oeste (HOSC), e uma redução de $0,3 \%$ na quantidade de soja vinda de Xanxerê (XASC). No caso dos preços, a mudança principal ocorreu com relação aos Pólos de Cuiabá (CUMT) e Sorriso (SOMT), cuja variação foi decrescente, isto é, $-2,6 \%$ para ambos os Pólos. Os demais Pólos sofreram pequenos acréscimos de preço.

c) elevação da elasticidade -preço oferta (de 0,60 para 0,90) e redução da elasticidade preço de demanda (de $-0,19$ para $-0,09)$.

A alteração do comportamento dos fluxos quando se eleva a elasticidade-preço de oferta e reduz-se a elasticidade-preço de demanda reflete-se mais na soja destinada ao porto de Santos. O porto de Paranaguá sofreu apenas um aumento de $17,0 \%$ na quantidade de soja vinda de Xanxerê (XASC).

Quanto ao porto de Santos, a quantidade exportada teve um aumento de $43,7 \%$ e 3,3\% da soja oriunda de Patos de Minas (PMMG) e Goiânia (GOGO), respectivamente. 
Por outro lado, a soja originada de Varginha (VAMG), Barra do Garças (BGMT) e de Brasília (BRGO) tiveram uma redução de 55,6\%, 2,5\% e 68,3\%, respectivamente.

Os fluxos destinados ao porto de São Francisco do Sul sofreram uma redução de 0,3\% na quantidade de soja vinda de Xanxerê (XASC) e uma aumento de $0,9 \%$ na quantidade de soja oriunda de Herval D'Oeste (HOSC). Com relação aos preços os Pólos de Sorriso (SOMT) e Cuiabá (CUMT) sofreram variações negativas de $-2,1 \%$, respectivamente. Os demais Pólos tiveram pequenas variações positivas.

d) elevação da elasticidade-preço de oferta e elasticidade-preço de demanda (de 0,60 para 0,90 e $-0,19$ para $-0,28)$.

Elevando-se a elasticidade-preço de oferta e elasticidade-preço de demanda ao mesmo tempo, as quantidades de soja de Xanxerê (XASC) destinadas ao porto de Paranaguá tiveram um aumento de $12,8 \%$, enquanto que as quantidades transportadas de Porto União (PUSC) e Cascavel (CAPR) tiveram uma redução de $0,4 \%$ e $0,3 \%$, respectivamente.

A soja destinada ao porto de Santos sofreu as seguintes alterações: elevação de 3,4\% e 4,7\% referente aos Pólos de Goiânia (GOGO) e Brasília (BRGO), respectivamente. Por outro lado, sofreu redução de 55,6\% de Varginha (VAMG), 2,3\% de Patos de Minas (PMMG) e 2,8\% de Barra do Garças (BGMT) em relação à situação original.

Com relação ao porto de São Francisco do Sul, houve um aumento de $0,9 \%$ no fluxo da soja oriunda do Pólo de Herval D'Oeste (HOSC). Quanto aos preços observaram-se pequenas variações crescentes em praticamente todos os Pólos, com 
exceção dos Pólos de Sorriso (SOMT) e Cuiabá (CUMT), que sofreram reduções de $-3,0 \%$, respectivamente.

\subsubsection{Efeito da redução no custo de transporte}

Os custos de transportes e portuários são fatores de suma importância no processo de comercialização da soja, os quais encarecem sobremaneira o preço final da soja, assim como diminui sua competitividade no mercado internacional. Sendo assim, uma redução nos custos de transportes, ou portuários, ou em ambos, poderá tornar a soja mais competitiva, uma vez que diminui seu custo final.

A análise do efeito de uma redução de $20 \%$ nos custos de transportes, devido a uma melhoria na infra-estrutura de transporte tais como: construção de pontes, duplicação de rodovia, construção de terceira faixa, recapeamento, entre outros, visa observar o comportamento dos fluxos, assim como dos preços da soja para o mercado brasileiro.

Na Tabela 4.11 são apresentados os fluxos real (R), Simulado pelo Modelo (M) e Simulado via redução de custos de transportes (S). Ao observar-se a Coluna "S" percebe-se que não houve mudança de fluxo em relação à rota originalmente simulada. Isto permite inferir que esta continua sendo a melhor opção para a distribuição ótima da soja. No entanto, houve modificações nas quantidades transportadas, bem como variações nos preços.

Com relação ao porto de Paranaguá, a redução do custo de transporte em $20 \%$ provocou um decréscimo de 0,5 mil toneladas oriundas de Porto União (PUSC), 2,7 mil 
toneladas do Pólo de Xanxerê (XASC) e um aumento de 9,9 mil toneladas do Pólo de Cascavel (CAPR).

Quanto ao porto de Santos os fluxos de Varginha (VAMG) e Patos de Minas (PMMG) sofreram uma redução na ordem de 0,1 e 6,7 mil toneladas, respectivamente. Por outro lado, os fluxos de Barra do Garças (BGMT), Goiânia (GOGO) e Brasília (BRGO), sofreram uma elevação de 7,6, 3,3 e 1,7 mil toneladas, respectivamente. 
Tabela 4.11 - Fluxo de soja real, simulado e com custos de transportes reduzidos em $20 \%$.

\begin{tabular}{|c|c|c|c|c|c|c|c|c|c|c|c|c|}
\hline \multirow[b]{3}{*}{ ORIG. } & \multicolumn{12}{|c|}{ DESTINO } \\
\hline & \multicolumn{3}{|c|}{ SFSC } & \multicolumn{3}{|c|}{ PGUA } & \multicolumn{3}{|c|}{ SANT } & \multicolumn{3}{|c|}{ FLUXO TOTAL } \\
\hline & $\mathbf{R}$ & $\mathbf{M}$ & $\mathbf{S}$ & $\mathbf{R}$ & $\mathbf{M}$ & $\mathbf{S}$ & $\mathbf{R}$ & $\mathbf{M}$ & $\mathbf{S}$ & $\mathbf{R}$ & $\mathbf{M}$ & $\bar{S}$ \\
\hline HOSC & 0 & 22,0 & 21,9 & 3,4 & 0 & 0 & 0 & 0 & 0 & 3,4 & 22,0 & 21,9 \\
\hline LASC & 1,7 & 0 & 0 & 0,5 & 0 & 0 & 0 & 0 & 0 & 2,2 & 0 & 0 \\
\hline PUSC & 1,5 & 0 & 0 & 9,8 & 76,1 & 75,6 & 0 & 0 & 0 & 11,3 & 76,1 & 75,6 \\
\hline XASC & 8,3 & 73,0 & 73,5 & 0 & 4,7 & 2,0 & 0 & 0 & 0 & 8,3 & 77,7 & 75,5 \\
\hline CUPR & 0 & 0 & 0 & 24,0 & 0 & 0 & 0 & 0 & 0 & 24,0 & 0 & 0 \\
\hline CAPR & 14,6 & 0 & 0 & 527,6 & 1081,4 & 1091,3 & 194,6 & 0 & 0 & 736,8 & 1081,4 & 1091,3 \\
\hline GUPR & 0 & 0 & 0 & 66,9 & 0 & 0 & 0 & 0 & 0 & 66,9 & 0 & 0 \\
\hline LOPR & 30,8 & 0 & 0 & 34,2 & 0 & 0 & 0 & 0 & 0 & 65,0 & 0 & 0 \\
\hline PGPR & 34,2 & 0 & 0 & 61,2 & 0 & 0 & 0 & 0 & 0 & 95,4 & 0 & 0 \\
\hline BASP & 0 & 0 & 0 & 0 & 0 & 0 & 15,8 & 0 & 0 & 15,8 & 0 & 0 \\
\hline PPSP & 0 & 0 & 0 & 0 & 0 & 0 & 103,3 & 0 & 0 & 103,3 & 0 & 0 \\
\hline RPSP & 0 & 0 & 0 & 0 & 0 & 0 & 124,7 & 0 & 0 & 124,7 & 0 & 0 \\
\hline SJSP & 0 & 0 & 0 & 0 & 0 & 0 & 68,4 & 0 & 0 & 68,4 & 0 & 0 \\
\hline VAMG & 0 & 0 & 0 & 0 & 0 & 0 & 0 & 2,7 & 2,6 & 0 & 2,7 & 2,6 \\
\hline PMMG & 0 & 0 & 0 & 0 & 0 & 0 & 0 & 187,9 & 181,2 & 0 & 187,9 & 181,2 \\
\hline CUMT & 0 & 0 & 0 & 68,0 & 0 & 0 & 113,2 & 0 & 0 & 181,2 & 0 & 0 \\
\hline ROMT & 0 & 0 & 0 & 126,6 & 0 & 0 & 0 & 0 & 0 & 126,6 & 0 & 0 \\
\hline SOMT & 0 & 0 & 0 & 36,2 & 0 & 0 & 0 & 0 & 0 & 36,2 & 0 & 0 \\
\hline BGMT & 0 & 0 & 0 & 0 & 0 & 0 & 0 & 463,7 & 471,3 & 0 & 463,7 & 471,3 \\
\hline CGMS & 3,4 & 0 & 0 & 45,8 & 0 & 0 & 272,2 & 0 & 0 & 321,4 & 0 & 0 \\
\hline DOMS & 0 & 0 & 0 & 74,5 & 0 & 0 & 75,5 & 0 & 0 & 150,0 & 0 & 0 \\
\hline TLMS & 0 & 0 & 0 & 26,2 & 0 & 0 & 0 & 0 & 0 & 26,2 & 0 & 0 \\
\hline GOGO & 0 & 0 & 0 & 3,2 & 0 & 0 & 0 & 244,9 & 248,2 & 3,2 & 244,9 & 248,2 \\
\hline BRGO & 0 & 0 & 0 & 1,5 & 0 & 0 & 0 & 106,1 & 107,8 & 1,5 & 106,1 & 107,8 \\
\hline RVGO & 0 & 0 & 0 & 55,7 & 0 & 0 & 46,4 & 0 & 0 & 102,1 & 0 & 0 \\
\hline TOTAL & 94,5 & 95,0 & 95,4 & 1165,3 & 1162,2 & 1168,9 & 1014,1 & 1005,3 & 1011,1 & 2273,9 & 2262,5 & 2275,4 \\
\hline
\end{tabular}

$\mathrm{R}=$ Fluxo Real, $\mathrm{M}=$ Fluxo Modelo, $\mathrm{S}=$ Fluxo Simulado com Redução de $20 \%$ no CT.

Com relação ao comportamento dos preços, devido à alteração de $20 \%$ nos custos de transporte, estes sofreram redução inferior a 2,96\%, exceto para os Pólos de Uberlandia (UBMG), Patos de Minas (PMMG), Rondonópolis (ROMT), Sorriso (SOMT), Barra do Garças (BGMT), Dourados (DOMS), Goiânia (GOGO), Brasilia (BRGO) e Rio Verde (RVGO) que tiveram elevação nos preços. Para estes Pólos, a variação mais significativa foi para Barra do Garças, com uma elevação de $2,80 \%$ no preço. Já para os Pólos de Patos de Minas, Rondonópolis, Sorriso, Goiânia, Brasília e 
Rio Verde a variação ficou entre $1,16 \%$ e $1,64 \%$. Para os Pólos de Uberlândia e Dourados a variação foi inferior a $1,0 \%$, ou seja, $0,25 \%$ e $0,82 \%$, respectivamente (vide Tabela 4.12).

Tabela 4.12 - Comportamento dos preços da soja com a redução de $20 \%$ nos custos de transportes, em US\$ por tonelada, para o ano de 1995.

\begin{tabular}{|c|c|c|c|}
\hline \multirow[b]{2}{*}{ Pólo } & \multicolumn{2}{|c|}{ Preço Simulado } & \multirow{2}{*}{$\begin{array}{c}\text { Variação } \\
\text { Percentual }\end{array}$} \\
\hline & Sem Redução & Com Redução & \\
\hline HOSC & 182,75 & 181,33 & $-0,78$ \\
\hline LASC & 189,87 & 187,03 & $-1,50$ \\
\hline PUSC & 185.61 & 183.62 & $-1,07$ \\
\hline XASC & 179,14 & 177,97 & $-0,65$ \\
\hline FLSC & 196,60 & 191,94 & $-2,37$ \\
\hline CUPR & 193,07 & 189,12 & $-2,05$ \\
\hline CAPR & 178,04 & 177,56 & $-0,26$ \\
\hline GUPR & 185,22 & 183,32 & 1,03 \\
\hline LOPR & 190,01 & 186,67 & $-1,76$ \\
\hline PGPR & 190,42 & 187,00 & $-1,80$ \\
\hline BASP & 185,13 & 182,77 & $-1,27$ \\
\hline OUSP & 185,40 & 182,98 & $-1,31$ \\
\hline PPSP & 183,16 & 181,20 & $-1,07$ \\
\hline RPSP & 180,95 & 179,43 & $-0,84$ \\
\hline SJSP & 178,80 & 177,70 & $-0,62$ \\
\hline CASP & 187,78 & 184,89 & $-1,54$ \\
\hline UBMG & 171,21 & 171.63 & 0,25 \\
\hline VAMG & 181,51 & 180,36 & $-0,63$ \\
\hline PMMG & 166,13 & 168,05 & 1,16 \\
\hline CUMT & 162,66 & 161,49 & $-0,72$ \\
\hline ROMT & 162,18 & 164.40 & 1,37 \\
\hline SOMT & 149,91 & 151,76 & 1,23 \\
\hline BGMT & 154.15 & 158,46 & 2,80 \\
\hline CGMS & 176,79 & 176,09 & $-0,40$ \\
\hline DOMS & 168,81 & 170,19 & 0.82 \\
\hline TLMS & 175,88 & 175,37 & $-0,29$ \\
\hline GOGO & 163,80 & 165,71 & 1,17 \\
\hline BRGO & 160,23 & 162,85 & 1,64 \\
\hline RVGO & 162.81 & 164.91 & 1,29 \\
\hline SPSP & 190,00 & 186,67 & $-1,75$ \\
\hline SFSC & 197,44 & 192.61 & $-2,45$ \\
\hline PGUA & 203,41 & 197.39 & $-2,96$ \\
\hline SANT & 202,14 & 196.38 & $-2,85$ \\
\hline
\end{tabular}

* Obs.: Preços no destino. 


\subsection{Discussão dos resultados}

O transporte, no processo de comercialização da soja em grão, pode ser considerado como fator determinante no processo de tomada de decisão, tanto para os produtores como para os consumidores.

O modelo de equilíbrio espacial foi utilizado como um meio de se obter fluxos, quantidades e preços a partir das funções de demanda, oferta e custos de transportes. Através dos resultados apresentados pelo modelo para o fluxo e as quantidades comercializadas entre as regiões produtoras e os portos de Paranaguá e Santos, tornou-se possível uma análise comparativa dos fluxos.

O fluxo simulado mostrou-se diferenciado para algumas regiões, uma vez que o critério adotado pelo modelo é de priorizar as necessidades de consumo de cada Pólo, de acordo com sua capacidade instalada, enquanto o que ocorre na realidade é que algumas regiões, mesmo produzindo para atender a demanda local, exportam sua produção e suprem suas necessidades com soja importada de outras regiões. É possível que este tipo de ação seja justificável, embora possa não parecer coerente, pois cada região produtora visa obter maiores retornos, o que implica comercializar a soja que não será consumida naquele momento com regiões que apresentem preços mais elevados.

Os resultados obtidos para a exportação da soja mostraram que os fluxos devem ser originados daquelas regiões cujas necessidades internas foram satisfeitas e que possuam uma certa proximidade com os portos de exportação. No caso do porto de Paranaguá, a soja por ele escoada teve origem nos Estados do Paraná e Santa Catarina, com fluxos similares aos ocorridos na situação atual, porém com volumes diferentes. Isto é, foi utilizada aquela rota que apresentou um menor custo, dentre aquelas que vinham sendo observadas na prática, com a máxima alocação possível, inclusive considerando a soja oriunda do Paraguai. 
Com relação ao porto de Santos, a soja exportada simulada pelo modelo não apresentou o mesmo comportamento da situação atual, onde praticamente todos os Pólos do Estado de São Paulo exportavam a soja produzida por este porto. Os resultados mostraram que é mais viável os Pólos do Estado de São Paulo consumirem a produção local, de acordo com sua capacidade de industrialização, que exportar, uma vez que se destinar sua produção ao mercado externo, terá que importar de outros Estados para suprir suas necessidades de processamento, o que por sinal vem sendo observado ultimamente. Assim, a soja destinada ao porto de Santos, de acordo com a solução ótima, deve ter origem nos Estados de Minas Gerais, Goiás e Mato Grosso.

Para melhor caracterizar as rotas apresentadas pelo modelo, para escoamento da soja, via porto de Paranaguá ou Santos, foram simuladas variações nas elasticidadespreço de oferta e elasticidade-preço de demanda e redução de $20 \%$ nos custos de transportes. Os resultados das variações não mudaram o cenário obtido em termos de sentido de fluxo, refletindo somente pequenas variações nos preços e nas quantidades transportadas.

No caso da redução dos custos de transportes, os preços, em sua maioria, sofreram uma variação negativa, oscilando entre $-0,25 \%$ e $-2,96 \%$, o que atesta que a soja poderá tornar-se mais competitiva caso melhorias sejam realizadas no setor de infraestrutura de transportes. 


\section{CONCLUSÕES}

O cultivo da soja no Brasil ocorreu primeiramente na região Sul, deslocando-se posteriormente para a região Central do País. Com o deslocamento do eixo de produção da soja, aumentaram-se as distâncias entre as regiões de produção e os portos de exportação, principalmente, Paranaguá e Santos, implicando em aumentos dos custos de transporte, os quais somados aos altos custos portuários, contribuem para a elevação do preço final da soja, acarretando perda de competitividade junto ao mercado internacional.

Para se analisar a competição entre os portos de Paranaguá e Santos, além de custos de transportes, quantidades transportadas e preços de equilibrio, aspectos como localização, vias de acesso e infra-estrutura fisica tornaram-se necessárias. No que diz respeito à localização, o porto de Santos apresenta menor distância para cargas oriundas da região Centro-Oeste, Minas Gerais e São Paulo, enquanto o porto de Paranaguá está mais próximo para cargas originadas no Paraná, Santa Catarina e Paraguai.

Com relação às vias de acesso da soja aos portos, através do modal rodoviário, um problema comum aos dois portos é a transposição das cidades de Curitiba e São Paulo, onde há conflito de tráfego de caminhões com o tráfego urbano. Contudo, a transposição de Curitiba é menos congestionada que a de São Paulo.

Para o caso do modal ferroviário, o porto de Santos possui uma melhor infra- 
estrutura ferroviária, contando com duas vias de acesso (MRS Logística e Fepasa), sendo que praticamente não há limitações de tráfego. Por outro lado, o porto de Paranaguá possui somente uma via de acesso (FSA), a qual enfrenta limitações de tráfego, principalmente, no trecho Ponta Grossa/Paranaguá.

No caso da infra-estrutura fisica, o porto de Paranaguá apresenta maior capacidade de recepção, armazenamento e embarque, sendo que sua capacidade total de embarque é de 9300 t/h. Por outro lado, o porto de Santos apresenta limitações nesses três setores, sendo que sua capacidade total de embarque corresponde a 32,3\% (3000 t/h) da capacidade total do porto de Paranaguá. Além das limitações de infra-estrutura fisica, o porto de Santos conta ainda com uma tarifa portuária superior à tarifa portuária praticada em Paranaguá.

Sendo assim, a determinação de estratégias no processo de tomada de decisão por parte dos produtores ou comerciantes de soja, diante da opção de utilização do porto de Paranaguá ou Santos para exportação, podem acarretar em maiores ganhos desde que combinações entre custos de transportes e custos portuários sejam feitas de forma eficiente.

Diante desse cenário, o presente estudo foi realizado com o objetivo de analisar a competição entre os portos de Paranaguá e Santos para movimentação de soja, utilizando-se para tal o modelo de equilíbrio espacial, adotando-se o modal rodoviário como sistema de transporte predominante.

Os resultados fornecidos pelo modelo para exportação de soja mostram que os fluxos devem ser originados a partir dos excedentes localizados nas regiões mais próximas aos portos. No caso do porto de Paranaguá, sua demanda para exportação foi suprida pelos excedentes dos Estados do Paraná e Santa Catarina. Já o porto de Santos teve sua demanda suprida pelos Estados de Minas Gerais, Goiás e Mato Grosso, uma vez 
que o Estado de São Paulo não gerou excedente para exportação no período em estudo. Deve-se ressaltar que estes resultados são consistentes com a localização estratégica dos portos descritas anteriormente.

Com o objetivo de melhor caracterizar os fluxos apresentados pelo modelo, foram simuladas variações de $50 \%$ nos valores das elasticidade-preço de oferta e elasticidadepreço de demanda, assim como, variação de $20 \%$ nos custos de transportes. As variações nas elasticidades foram no sentido alternado, isto é, fixava-se a elasticidade-preço de oferta e elevava-se a elasticidade-preço de demanda, e assim sucessivamente.

As simulações realizadas não mudaram o cenário obtido em termos de sentido de fluxo, refletindo somente pequenas variações nos preços e nas quantidades transportadas. O reflexo maior foi com relação à redução nos custos de transportes, a qual resultou, em sua maioria, variações negativas dos preços, cujas oscilações ficaram entre $-0,25 \%$ e $-2,96 \%$, demonstrando, assim, que a soja poderá tornar-se mais competitiva caso melhorias no setor de infra-estrutura de transportes e portuários sejam realizadas.

Deve-se também destacar que as limitações de infra-estrutura e os altos custos portuários, somados aos elevados custos de transportes, acabam por anular a vantagem que o porto de Santos possui sobre o porto de Paranaguá em relação à região CentroOeste, o que contribui para tornar o porto de Paranaguá mais competitivo que o porto de Santos no que se diz respeito à soja oriunda dessa região, e até mesmo da região Sul e Sudoeste de São Paulo, mesmo possuindo maior distância em relação ao porto de Santos.

Deve-se ressaltar ainda que para a realização da análise foram consideradas somente a posição estratégica e infra-estrutura básica (capacidade de recepção, armazenamento e embarque) dos portos, assim como somente o modal rodoviário como meio de transporte. Portanto, para estudos futuros, sugere-se uma análise sobre a infraestrutura portuária como um todo, bem como utilização de alternativas de transporte 
multimodal, envolvendo articulações entre os sistemas rodoviário, ferroviário e hidroviário.

Finalmente, um aspecto importante a ser considerado diz respeito aos preços no mercado de soja. Como no presente estudo foram utilizados os preços médios anuais, sugere-se, para estudos futuros, a utilização de preços médios mensais, para uma melhor visualização das eventuais variações sazonais ocorridas ao longo das safras. 


\section{BIBLIOGRAFIA}

AGUIAR, D.R.D. Formação de preços na indústria brasileira de soja - 1982/1989. Piracicaba, 1990. 140p. Dissertação (M.S.) - Escola Superior de Agricultura "Luiz de Queiroz", Universidade de São Paulo.

A indústria de esmagamento de soja no Brasil: mudança estrutural, conduta e alguns indicadores de desempenho. Revista de Economia e Sociologia Rural, Brasilia, v.32, n.1, p.23-45, jan./mar. 1994.

ALMEIDA, E.; ELSTRODT, H.P.; MARTINS, M. O caminho ideal para a privatização dos portos brasileiros. Conjuntura Econômica. Rio de Janeiro, v. 50, n. 12, p.1922, dez. 1996.

BARROS, G.S.A.C. Economia da comercialização agrícola. Piracicaba. FEALQ, 1987. 306p.

BARROS, G.S.A. C.; MARQUES, P.V.; BACCHI, M.R.P.; CAFFAGNI, L.C. Elaboração de indicadores de preços da soja: um eštudo preliminar. Piracicaba. CEPEA-ESALQ/USP, 1997 (trabalho não publicado). 
BIVINGS, E.L. The Seasonal and Spatial Dimensions of Sorghum Market Liberalization in Mexico. American Journal of Agricultural Economics. v. 79, n. 2, p.383-393, May 1997.

BRASIL, Ministério dos Transportes. Secretaria de Transportes Aquaviários. Departamento de Portos. Anuário estatístico portuário - 1995. Brasília: Ministério dos Transportes, 1997. 266p.

BRESSLER, R.G. Jr.; KING, R.A. Markets, Prices and Interregional Trade. John Wiley \& Sons, New York, 1970.

BROOKE, A.; KENDRICK, D.; MEERRAUS, A. GAMS: A User's Guide, Release 2.25. 1992, The Scientific Press. 289p.

CAIXETA FILHO, J.V. Interstate movements of wheat in Australia: an application of a spatial equilibrium model. Armidale. 1989. 162p. Dissertação (M.S.) - University of New England, Armidale, Australia.

. Transporte e logística no sistema agroindustrial. Preços Agrícolas, Piracicaba, ano 10, n.119, set. 1996a. p. 2-7.

. Pesquisa Operacional Aplicada ao Sistema Agroindustrial. ESALQ, 1996b, 166 p. (Série Didática).

CAMPOS. H. de. Estatística Não-Paramétrica. 4.ed. Piracicaba: ESALQ, 1983. 349p.

CONFEDERAÇÃO NACIONAL DA INDÚSTRIA. Seminário Custo Brasil: Diálogo com o Congresso Nacional. Brasília, 1995. 75p.

Custos Portuários no Brasil: ainda bastante acima da média praticada no 
mercado internacional. Comércio Exterior em Perspectiva. Rio de Janeiro, v.7, n.8, p.1-5, mai. 1998.

COSTA, T.F. II Fórum Cargill de Debates: "Logística e transporte - caminho para o desenvolvimento do agribusiness". Campinas, Fundação Cargill, p.81-89, 1995.

EHRLICH, P.J. Pesquisa Operacional: Curso Introdutório. 6.ed. São Paulo: Atlas, 1988. 316p.

FERGUSON, C.E. Teoria microeconômica; tradução de Almir Guilherme Barbosa e Antonio Pessoa Brandão, revisão técnica de Fernando Lopes de Almeida e Fancisco Rego Chaves Fernandes. 9.ed. Rio de Janeiro: Forense-Universitária, 1986. 610 p.

FERREIRA， L.R.; BURNQUIST, H.L.; AGUIAR, D.R.D. Infraestrutura, comercialização e competitividade da agricultura brasileira. Rio de Janeiro: IPEA, out 1993. 63p. (Texto para Discussão nº 318).

GASS, S.I; HARRIS, C.M. (eds.) Encyclopedia of Operations Research and Managemente Science . Kluwer, Boston, 1996. 753p. 1996.

GEIPOT. Empresa Brasileira de Planejamento de Transportes. Corredores de Transporte: proposta de ações para adequação da infra-estrutura e para racionalização do transporte de graneis agrícolas. Brasilia: Ministério dos Transportes/GEIPOT, 1995. 320p.

Corredores de Transporte: proposta de ações para adequação da infraestrutura e para racionalização do transporte de graneis agrícolas, relatório de atualização. Brasília: Ministério dos Transportes/GEIPOT, 1997. 314p. 
Corredor do Paraná/Santa Catarina. Brasília: Ministério dos Transportes/GEIPOT, 1994a. 70p.

. Corredor de Santos. Brasília: Ministério dos Transportes/ GEIPOT, 1994b. $94 \mathrm{p}$. Transportes/GEIPOT, 1993a. 188p.

O modelo portuário brasileiro. Brasilia: Ministério dos Transportes/GEIPOT, 1993b. 62p.

GUIA RODOVIÁRIO QUATRO RODAS 1997. São Paulo: Editora Abril, 1997, 106p.

HII.LER, F.S.; LIEBERMAN, G.J. Introdução à Pesquisa Operacional. São Paulo, Campus/EDUSP. 1988 (Trad.).

IGNIZIO, J.P.; CAVALIER, T.M. Linear Programming. Prentice Hall, New Jersey, 1994, 666p.

KAWAGUCHI, T.; SUZUKI, N.; KAISER, H.M. A Spatial Equilibrium Model for Imperfectly Competitive Milk Markets. American Journal of Agricultural Economics. v.79, n.3, p.851-859, August 1997.

LÍCIO, A. Os eixos estruturadores e os corredores de transportes. Revista de Política Agrícola, Brasilia: v.9, n.4, p.3-4,out/nov/dez 1995.

LÍCIO, A.; CORBUCCI, R. Agricultura e os corredores de transportes multimodais. Revista de Política Agrícola, Brasília, v.5, n.2, p.22-36, abr/maio/jun. 1996. 
LIMA, E.T.; VELASCO, L.O.M. O sistema portuário brasileiro. Revista do Banco Nacional de Desenvolvimento Econômico e Social, Rio de Janeiro, v.3, n.6, p.115156, dez.1996.

MAGANO, C.E.B., Estruturação dos serviços nos Portos. São Paulo, 1995a. 69p. Dissertação (M.S.) - Escola Politécnica da Universidade de São Paulo. Dpto. de Engenharia de Transportes.

. In: II Fórum Cargill de Debates: "Logística e transporte - caminho para o desenvolvimento do agribusiness". Campinas, Fundação Cargill, p.75-80, 1995 b.

MARQUES, P.V.; AGUIAR, D.R.D. Comercialização de produtos agrícolas. São Paulo: Editora da Universidade de São Paulo, 1993. - (Campi; v. 13), 295p.

MARQUES, P.V.; MELlO, P.C. de. Mercados Futuros de Commodities Agropecuária. Piracicaba. Série Didática 144, DESR/ESALQ, 3 ed, p.24-54, 1997.

MITCHELL, G. The practice of Operational Research. Wiley, Chichester,1993. 235p.

MOREIRA, M. A rede portuária brasileira. Folha de São Paulo, São Paulo, p.1-6, 06 jan.1997.

MWANAUMO, A.; MASTERS, W.A.; PRECKEL, P.V. A Spatial Analysis of Maize Marketing Policy Reforms in Zambia. American Journal of Agricultural Economics, v. 79, n. 2, p.514-523, May 1997.

OLIVEIRA, J.C.V. Análise do Transporte de Soja, Milho e Farelo de Soja na Hidrovia Tietê-Paraná. Piracicaba. 1996. 136p. Dissertação (M.S.). Escola Superior de Agricultura "Luiz de Queiroz"/Universidade de São Paulo. 
PAVAN, R.C. Brasil: na onda verde do progresso. Brasília: Imprensa Oficial do Estado, vol. 1, 1997, 290p.

. É Preciso Mudar. Agroanalysis: a Revista de Economia Agrícola da FGV. Instituto Brasileiro de Economia/Centro de Estudos Agrícolas, v. 18, n.7, p.25-30, jul. 1998.

PETERS, W.S.; SUMMERS, G.W. Análise Estatística e Processo Decisório. Trad. de Nathanael C. Caixeiro. Rio de Janeiro, Fundação Getúlio Vargas, 1973. 868p.

ROESSING, A.C. Situação Mundial das Oleaginosas. Informe Econômico CNPSo. Londrina, v.4, n.1, abr. 1998.

\section{SIEGEL, S. Estatística Não-Paramétrica Para as Ciências do Comportamento. McGraw-Hill, São Paulo, 1975 (Trad.).}

SILVA, A.C.P. Proposta de Preços Mínimos da Safra 96/97: Soja. Coleção Documento de Política Agrícola n. 5. Brasília: Ministério da Agricultura e do Abastecimento/ Companhia Nacional de Abastecimento, p.89-95, jul. 1997.

SOARES, M.G; GALVANI, P.R.C \& CAIXETA FILHO, J.V. Transporte de soja em grãos e farelo de soja no Brasil. Preços Agrícolas, Piracicaba, ano 11, n.126, p.2629, abr. 1997.

SOUSA, I.S.F. Condicionantes da Modernização da Soja no Brasil. Revista de Economia e Sociologia Rural, Brasília, v.28, n.2, p.175-212, abr./mai./jun. 1990.

STATISTICA for Windows, release 5.1, edition 1997, Stat Soft, Inc. 
SUGAI, Y.; VIEIRA, R.C.M.T.; TEIXEIRA FILHO, A.R.; BENEVENUTO, A.; OLIVEIRA, A.J. Um modelo global do setor agrícola: grãos no Brasil. In: VIEIRA, R.C.M.T. Avaliação global do setor agrícola: grãos no Brasil. Brasilia: IPEA/Projeto PNUD, 1994, p. 3-70 (Estudos de Política agrícola, 25).

TAKAYAMA, T.; JUDGE, G.G. Spatial and Temporal Price and Allocation Models. Amsterdam, North-Holland. 1971.

TAHA, H.A. Operations Research: an introduction. New York, Macmillan. 1987.

TOMEK, W.G.; ROBINSON, K.L. Agricultural Product Prices. Cornell University Press. 1972.

TÔSTO. S.G. Mercado interno de grãos de soja: modelos de equilibrio e desequilibrio. Viçosa. 1995. 114p. Dissertação (M.S.). Universidade Federal de Viçosa.

WAQUIL, P.D. Alocação Ótima de Produtos Agropecuários no Mercosul: modelo de equilíbrio espacial com produtos intermediários. Revista de Economia e Sociologia Rural. vol. 34, n. 1 e 2, p.87-109, Jan/Jun 1996.

WRIGHT, C.L. Análise econômica de transporte e armazenagem de grãos: estudo do corredor de exportação de Paranaguá, Brasília, GEIPOT, 1980. 187p. 
A NEXOS 


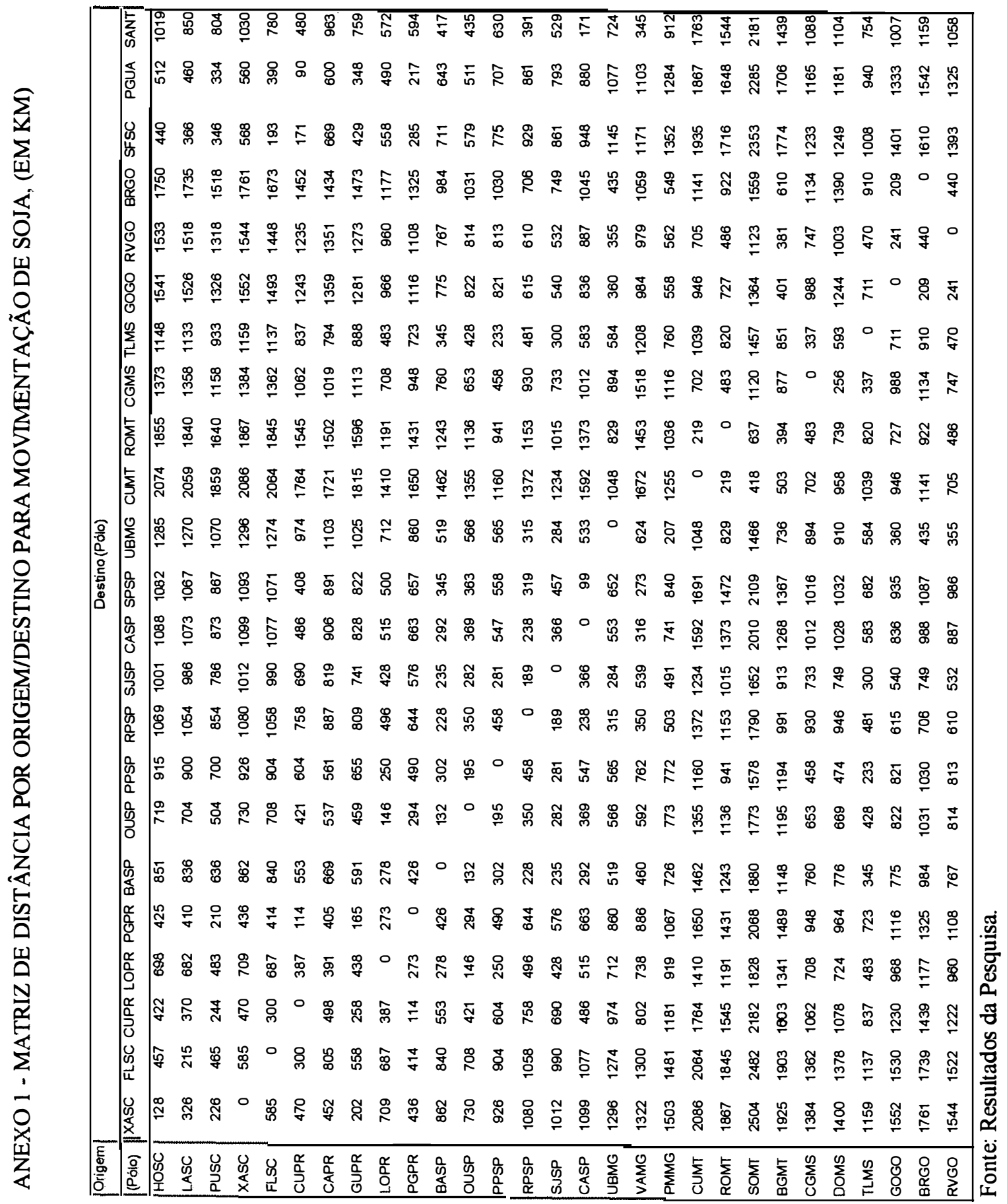




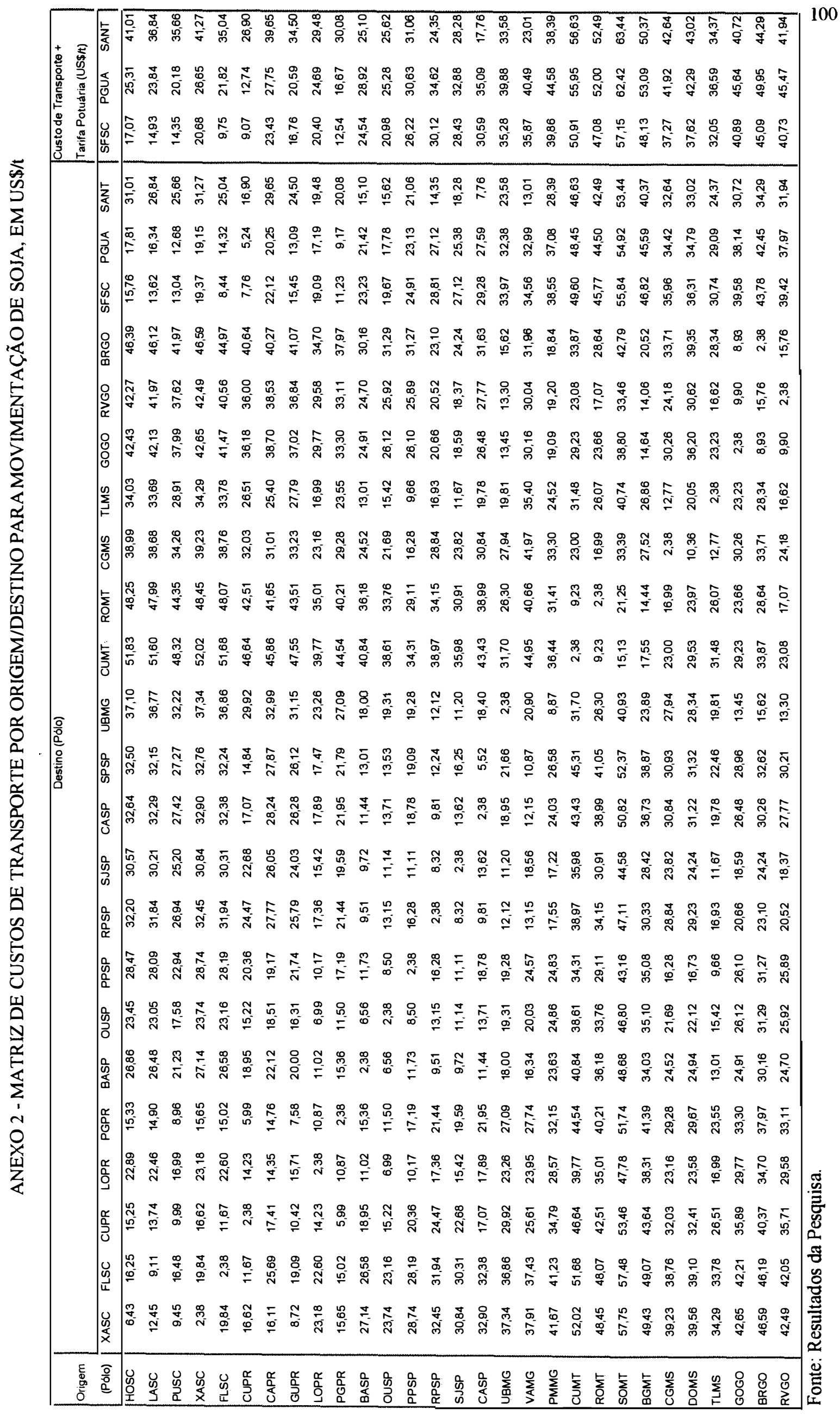


ANEXO 3 - PROGRAMAÇĀO UTILIZADA NO SOFTWARE GAMS PARA DETERMINAÇÃO DOS FLUXOS, QUANTIDADES E PREÇOS

SETS

I regioes de oferta /HOSC, LASC, PUSC, XASC, FLSC, CUPR, CAPR, GUPR, LOPR, PGPR, BASP, OUSP, PPSP, RPSP, SJSP, CASP, UBMG, VAMG, PMMG, CUMT, ROMT, SOMT, BGMT, CGMS, DOMS, TLMS, GOGO, BRGO, RVGO /

J regioes de demanda /XASC, FLSC, CUPR, LOPR, PGPR, BASP, OUSP, PPSP, RPSP, SJSP, CASP, SPSP, UBMG, CUMT, ROMT, CGMS, TLMS, GOGO, BRGO, RVGO, SFSC, PGUA, SANT, FICT / ;

PARAMETERS

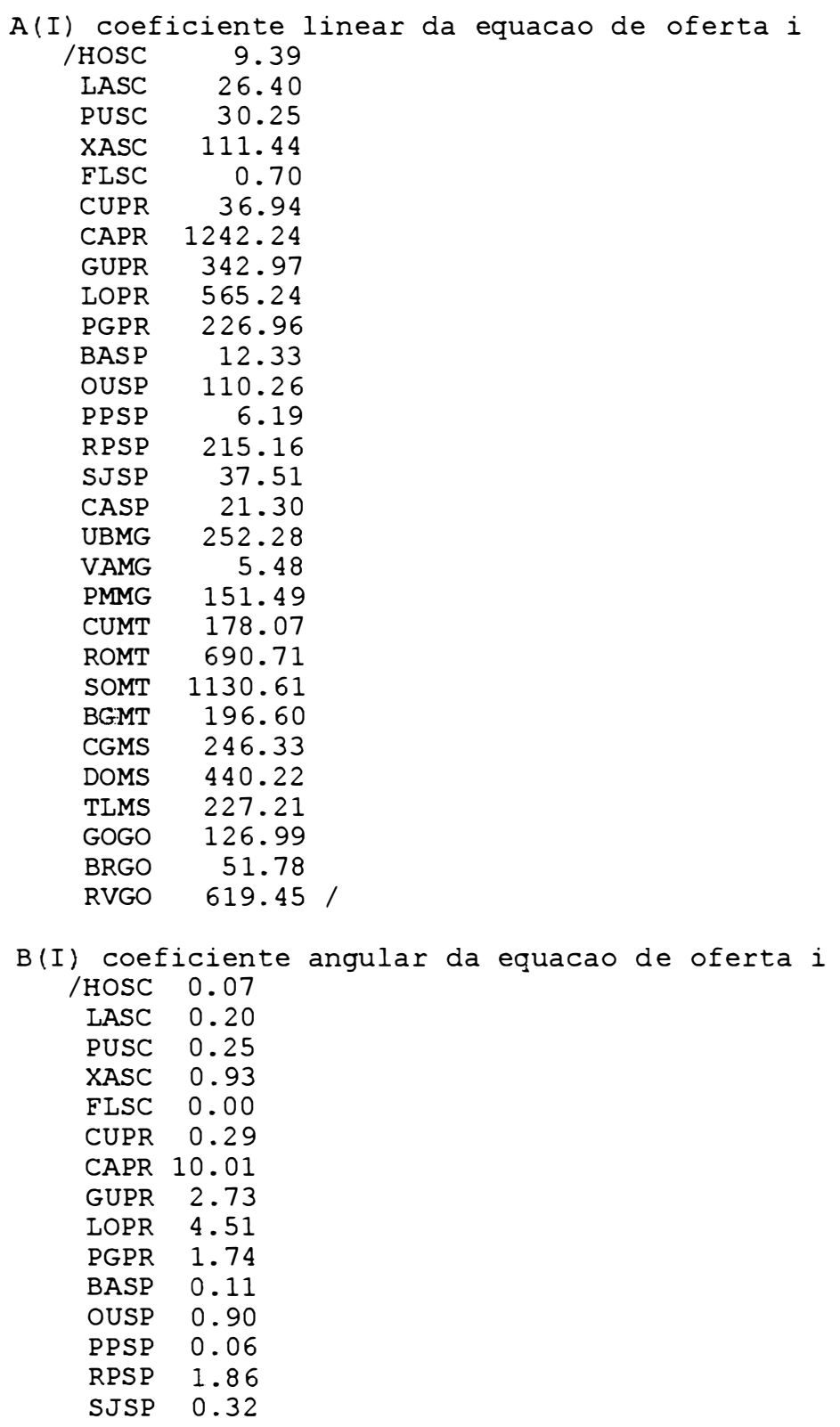




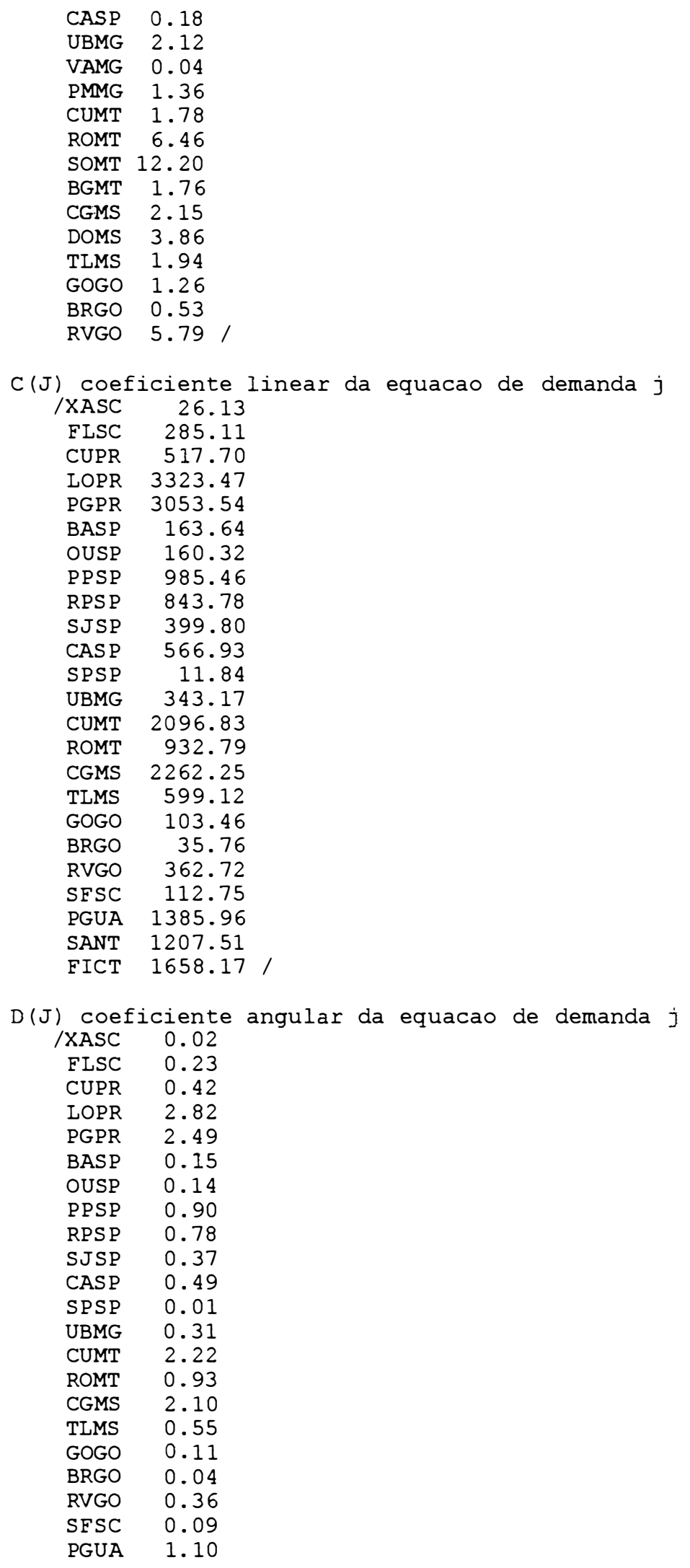




\begin{tabular}{|c|c|c|c|c|c|c|c|c|c|c|c|}
\hline $\begin{array}{l}\text { PSP } \\
\text { ANT }\end{array}$ & & & $\mathrm{MT}$ & MS & $\begin{array}{l}\text { GPR } \\
\text { TLMS }\end{array}$ & $\begin{array}{l}\text { ASP } \\
\text { GOGO }\end{array}$ & $\begin{array}{l}\text { OUSP } \\
\text { BRGO }\end{array}$ & $\begin{array}{l}\text { PPSP } \\
\text { RVGO }\end{array}$ & $\begin{array}{l}\text { RPS P } \\
\text { SFSC }\end{array}$ & $\begin{array}{l}\text { SJSP } \\
\text { PGUA }\end{array}$ & ASP \\
\hline $\begin{array}{l}105 C \\
2.50 \\
1.01\end{array}$ & $\begin{array}{c}6.431 \\
37.10^{1}\end{array}$ & $\begin{array}{c}16.25{ }^{1} \\
51.83^{1}\end{array}$ & $\begin{array}{c}15.25 \\
48.25^{2}\end{array}$ & $\begin{array}{c}22.89 \\
38.99^{1}\end{array}$ & $\begin{array}{c}15.33 \\
34.03^{2}\end{array}$ & $\begin{array}{c}26.86{ }^{2} \\
42.43^{2}\end{array}$ & $\begin{array}{c}3.45 \\
46.39\end{array}$ & $\begin{array}{c}28.47{ }^{3} \\
42.27\end{array}$ & $\begin{array}{c}32.20{ }^{3} \\
17.07\end{array}$ & $\begin{array}{c}30.57 \\
25.31\end{array}$ & 32.64 \\
\hline $\begin{array}{l}\text { IASC } \\
32.15 \\
36.84\end{array}$ & $\begin{array}{c}12.45 \\
36.77\end{array}$ & $\begin{array}{l}9.11 \\
51.60\end{array}$ & $\begin{array}{c}13.74 \\
47.99\end{array}$ & $\begin{array}{r}22.46 \\
38.68\end{array}$ & $\begin{array}{r}14.90 \\
33.69\end{array}$ & $\begin{array}{r}26.48 \\
42.13\end{array}$ & $\begin{array}{l}23.05 \\
46.12\end{array}$ & $\begin{array}{c}28.09 \\
41.97\end{array}$ & $\begin{array}{c}31.84 \\
14.93\end{array}$ & $\begin{array}{c}30.21 \\
23.84\end{array}$ & 32.29 \\
\hline $\begin{array}{l}\text { PUSC } \\
27.27 \\
35.66\end{array}$ & $\begin{array}{c}9.45{ }^{1} \\
32.22\end{array}$ & $\begin{array}{r}16.48 \\
48.32\end{array}$ & $\begin{array}{c}9.99 \\
44.35\end{array}$ & $\begin{array}{r}16.99 \\
34.26\end{array}$ & $\begin{array}{c}8.96 \\
28.91\end{array}$ & $\begin{array}{c}21.23 \\
37.99^{1}\end{array}$ & $\begin{array}{c}17.58 \\
41.97^{2}\end{array}$ & $\begin{array}{c}22.942 \\
37.82\end{array}$ & $\begin{array}{c}26.94{ }^{2} \\
14.35\end{array}$ & $\begin{array}{c}25.20 \\
20.18\end{array}$ & 27.42 \\
\hline $\begin{array}{l}C \\
76 \\
27\end{array}$ & $\begin{array}{c}2.38{ }^{1} \\
37.34\end{array}$ & $\begin{array}{c}19.84{ }^{1} \\
52.02\end{array}$ & $\begin{array}{c}16.62 \\
48.45\end{array}$ & $\begin{array}{c}23.181 \\
39.23\end{array}$ & $\begin{array}{c}15.65 \\
34.29\end{array}$ & $\begin{array}{c}27.142 \\
42.65\end{array}$ & $\begin{array}{c}3.742 \\
46.59\end{array}$ & $\begin{array}{c}28.74{ }^{3} \\
42.49^{3}\end{array}$ & $\begin{array}{c}32.45 \\
20.68\end{array}$ & $\begin{array}{c}30.84 \\
26.65\end{array}$ & 90 \\
\hline $\begin{array}{l}\text { FLSC } \\
32.24 \\
35.04\end{array}$ & $\begin{array}{r}19.84 \\
36.86\end{array}$ & $\begin{array}{l}2.38 \\
51.68\end{array}$ & $\begin{array}{c}11.67 \\
48.07\end{array}$ & $\begin{array}{l}22.60 \\
38.76\end{array}$ & $\begin{array}{c}15.02 \\
33.78\end{array}$ & $\begin{array}{c}26.58 \\
41.47\end{array}$ & $\begin{array}{r}23.16 \\
46.19\end{array}$ & $\begin{array}{c}28.19 \\
40.56\end{array}$ & $\begin{array}{r}31.94 \\
9.75\end{array}$ & $\begin{array}{c}30.31 \\
21.82\end{array}$ & 32.38 \\
\hline $\begin{array}{l}R \\
84 \\
90\end{array}$ & $\begin{array}{r}16.62 \\
29.92\end{array}$ & $\begin{array}{c}11.67 \\
46.64\end{array}$ & $\begin{array}{l}2.38 \\
42.51\end{array}$ & $\begin{array}{c}14.23 \\
32.03\end{array}$ & $\begin{array}{l}5.99 \\
26.51\end{array}$ & $\begin{array}{r}18.95 \\
35.89\end{array}$ & $\begin{array}{r}15.22 \\
40.37\end{array}$ & $\begin{array}{c}20.36 \\
35.71\end{array}$ & $\begin{array}{r}24.47 \\
9.07\end{array}$ & $\begin{array}{l}22.68 \\
12.74\end{array}$ & .7 .07 \\
\hline $\begin{array}{l}\text { CAPR } \\
27.87 \\
39.65\end{array}$ & $\begin{array}{c}16.11 \\
32.99\end{array}$ & $\begin{array}{c}25.69 \\
45.86\end{array}$ & $\begin{array}{c}17.41 \\
41.65\end{array}$ & $\begin{array}{c}14.35 \\
31.01\end{array}$ & $\begin{array}{l}14.76 \\
25.40\end{array}$ & $\begin{array}{r}22.12 \\
38.70\end{array}$ & $\begin{array}{c}18.51 \\
40.27\end{array}$ & $\begin{array}{c}19.17 \\
38.53\end{array}$ & $\begin{array}{c}27.77 \\
23.43\end{array}$ & $\begin{array}{c}26.05 \\
27.75\end{array}$ & 28.24 \\
\hline $\begin{array}{l}\mathrm{R} \\
12 \\
50\end{array}$ & $\begin{array}{c}8.72 \\
31.15^{1}\end{array}$ & $\begin{array}{c}19.09{ }^{1} \\
47.55^{1}\end{array}$ & $\begin{array}{c}10.421 \\
43.51\end{array}$ & $\begin{array}{r}15.71 \\
33.23\end{array}$ & $\begin{array}{c}7.58 \\
27.79\end{array}$ & $\begin{array}{c}20.00{ }^{1} \\
37.02^{1}\end{array}$ & $\begin{array}{c}16.31{ }^{2} \\
41.07\end{array}$ & $\begin{array}{c}21.74{ }^{2} \\
36.84^{2}\end{array}$ & $\begin{array}{c}25.79{ }^{2} \\
16.76^{2}\end{array}$ & $\begin{array}{c}24.03{ }^{2} \\
20.59^{2}\end{array}$ & 26.28 \\
\hline $\begin{array}{l}R \\
47 \\
48\end{array}$ & $\begin{array}{l}23.18 \\
23.26\end{array}$ & $\begin{array}{c}22.60 \\
39.77\end{array}$ & $\begin{array}{c}14.23 \\
31.01\end{array}$ & $\begin{array}{l}8 \\
16\end{array}$ & $\begin{array}{l}7 \\
99\end{array}$ & $\begin{array}{c}11.02 \\
29.77\end{array}$ & & $\begin{array}{l}17 \\
.58\end{array}$ & $\begin{array}{l}17.36 \\
20.40\end{array}$ & $\begin{array}{r}15.42 \\
24.69\end{array}$ & 17.89 \\
\hline $\begin{array}{l}\mathrm{R} \\
79 \\
08\end{array}$ & $\begin{array}{c}15.65 \\
27.09\end{array}$ & $\begin{array}{c}15.02 \\
44.54\end{array}$ & $\begin{array}{l}39 \\
21\end{array}$ & $\begin{array}{r}10 \\
2\end{array}$ & 85 & $\begin{array}{l}36 \\
30\end{array}$ & & $\begin{array}{l}19 \\
11\end{array}$ & $\begin{array}{r}21 \\
1\end{array}$ & $\begin{array}{c}19.59 \\
16.67\end{array}$ & 95 \\
\hline $\begin{array}{l}\text { BASP } \\
13.01 \\
25.10\end{array}$ & $\begin{array}{r}27.14 \\
18.00\end{array}$ & $\begin{array}{c}26.58 \\
40.84\end{array}$ & $\begin{array}{r}18 \\
36\end{array}$ & $\begin{array}{r}11 \\
2\end{array}$ & $\begin{array}{r}15 \\
1\end{array}$ & $\begin{array}{l}38 \\
.91\end{array}$ & & $\begin{array}{r}11 \\
2\end{array}$ & & $\begin{array}{l}9.72 \\
28.92\end{array}$ & 44 \\
\hline $\begin{array}{l}\text { OUSP } \\
13.53 \\
25.62\end{array}$ & $\begin{array}{c}23.74 \\
19.31\end{array}$ & $\begin{array}{l}23.16 \\
38.61\end{array}$ & 15. & $\begin{array}{l}99 \\
.69\end{array}$ & $\begin{array}{r}11 \\
15\end{array}$ & $\begin{array}{l}6.56 \\
26.12\end{array}$ & & & $\begin{array}{r}13.15 \\
20.98\end{array}$ & $\begin{array}{c}11.14 \\
25.28\end{array}$ & 71 \\
\hline $\begin{array}{l}\text { PPSP } \\
19.09 \\
31.06\end{array}$ & $\begin{array}{c}28.74 \\
19.28\end{array}$ & $\begin{array}{c}28.19 \\
34.31\end{array}$ & $\begin{array}{r}20 \\
20\end{array}$ & 1 & $\begin{array}{r}17.19 \\
9.66\end{array}$ & $\begin{array}{l}73 \\
.10\end{array}$ & & & $\begin{array}{c}16.28 \\
26.22\end{array}$ & $\begin{array}{c}11.11 \\
30.63\end{array}$ & 18.78 \\
\hline $\begin{array}{l}\text { RPSP } \\
12.24 \\
24.35\end{array}$ & $\begin{array}{r}32.45 \\
12.12\end{array}$ & $\begin{array}{c}31.94 \\
38.97\end{array}$ & $\begin{array}{r}24 . \\
34\end{array}$ & $\begin{array}{r}17 \\
2\end{array}$ & $\begin{array}{r}21 \\
1\end{array}$ & $\begin{array}{l}9.51 \\
20.66\end{array}$ & $\begin{array}{r}13.15 \\
23.10\end{array}$ & $\begin{array}{l}16.28 \\
20.52\end{array}$ & $\begin{array}{l}2.38 \\
30.12\end{array}$ & $\begin{array}{l}8.32 \\
34.62\end{array}$ & .81 \\
\hline $\begin{array}{l}\text { SJSP } \\
16.25 \\
28.28\end{array}$ & $\begin{array}{c}30.84 \\
11.20\end{array}$ & $\begin{array}{c}30.31 \\
35.98\end{array}$ & $\begin{array}{r}22.68 \\
30.91\end{array}$ & $\begin{array}{r}15 \\
2\end{array}$ & $\begin{array}{r}19 \\
1 .\end{array}$ & $\begin{array}{l}9.72 \\
18.59\end{array}$ & $\begin{array}{r}11 \\
2\end{array}$ & $\begin{array}{r}11 \\
1\end{array}$ & $\begin{array}{l}8.32 \\
28.43\end{array}$ & $\begin{array}{l}2.38 \\
32.88\end{array}$ & .6 \\
\hline $\begin{array}{l}\text { CASP } \\
5.52 \\
17.76\end{array}$ & $\begin{array}{r}32.90 \\
18.40\end{array}$ & $\begin{array}{r}32.38 \\
43.43\end{array}$ & $\begin{array}{r}17.07 \\
38.99\end{array}$ & $\begin{array}{r}17 \\
3\end{array}$ & $\begin{array}{r}21 \\
1\end{array}$ & $\begin{array}{r}11 \\
2\end{array}$ & $\begin{array}{r}13 \\
3\end{array}$ & $\begin{array}{r}18 \\
2\end{array}$ & $\begin{array}{l}9.81 \\
30.59\end{array}$ & $\begin{array}{c}13.62 \\
35.09\end{array}$ & 2.3 \\
\hline $\begin{array}{l}\text { UBMG } \\
21.66 \\
33.58\end{array}$ & $\begin{array}{r}37.34 \\
2.38\end{array}$ & $\begin{array}{c}36.86 \\
31.70\end{array}$ & $\begin{array}{r}29.92 \\
26.30\end{array}$ & $\begin{array}{r}23.26 \\
27.94\end{array}$ & $\begin{array}{r}27.09 \\
19.81\end{array}$ & $\begin{array}{c}18.00 \\
13.45\end{array}$ & $\begin{array}{r}19.31 \\
15.62\end{array}$ & $\begin{array}{r}19.28 \\
13.30\end{array}$ & $\begin{array}{c}12.12 \\
35.28\end{array}$ & $\begin{array}{c}11.20 \\
39.88\end{array}$ & 9 \\
\hline $\begin{array}{l}\text { VAMG } \\
10.87\end{array}$ & $\begin{array}{r}37.91 \\
20.90\end{array}$ & $\begin{array}{r}37.43 \\
44.95\end{array}$ & $\begin{array}{l}25.61 \\
40.66\end{array}$ & $\begin{array}{c}23.95 \\
41.97\end{array}$ & $\begin{array}{r}27.74 \\
35.40\end{array}$ & $\begin{array}{c}16.34 \\
30.16\end{array}$ & $\begin{array}{c}20.03 \\
31.96\end{array}$ & $\begin{array}{c}24.57 \\
30.04\end{array}$ & $\begin{array}{c}13.15 \\
35.87\end{array}$ & $\begin{array}{r}18.56 \\
40.49\end{array}$ & .15 \\
\hline
\end{tabular}




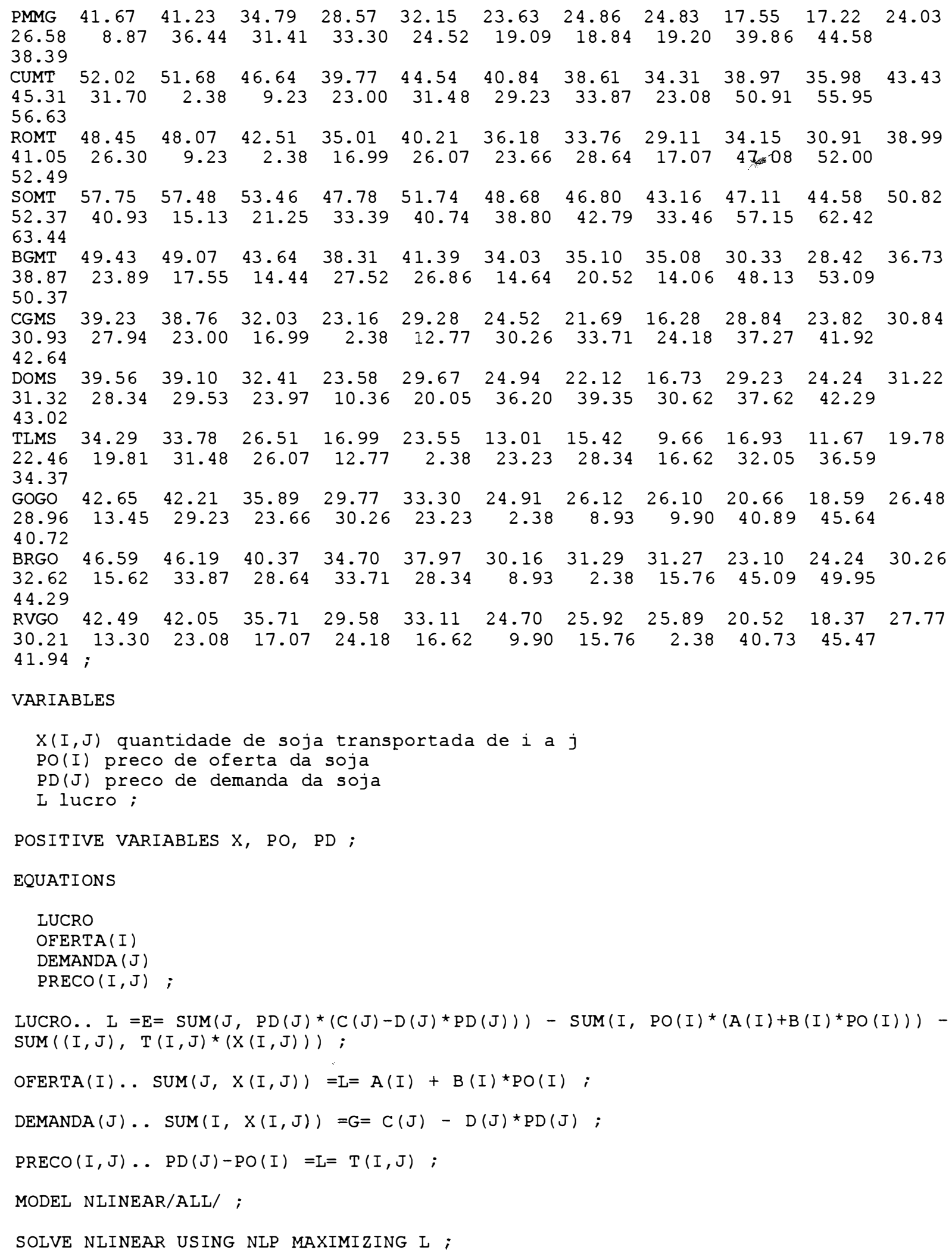


ANEXO 4 - TABELAS REFERENTES AOS TESTES NÃO-PARAMÉTRICOS REALIZADOS PARA O FLUXO DE SOJA POR ESTADO, PARA O FLUXO DE SOJA ENTRE OS ESTADOSE OS PORTOS, PARA OS FLUXOS DE SOJA TOTAL (DENTROE FORA) DO ESTADO E PARA OS PREÇOS

Tabela A4.1 - Fluxo de soja total ocorrido por Estado para Santa Catanina em $1000 \mathrm{t}$.

\begin{tabular}{l|c|c}
\hline Estado & Fluxo Atual & Fluxo Modelo \\
\hline SC & 123,2 & 268,3 \\
PR & 139,6 & 0 \\
\hline Fluxo Total & 262,8 & 268,3 \\
\hline
\end{tabular}

Tabela A4.1.1 - Entrada dos dados para o software Statistica.

\begin{tabular}{c|c|cc}
\hline \multicolumn{2}{c|}{ Kolmogorov-Smimov } & \multicolumn{2}{c}{ Wilcoxon } \\
\hline G1 & SC & V1 & SC \\
\hline 1 & 123,2 & 0 & 268,3 \\
2 & 139,6 & 0 & 0 \\
2 & 268,3 & 123,2 & 0 \\
& 0 & 139,6 & 0 \\
\hline
\end{tabular}

Tabela A4.1.2 - Saída do software Statistica.

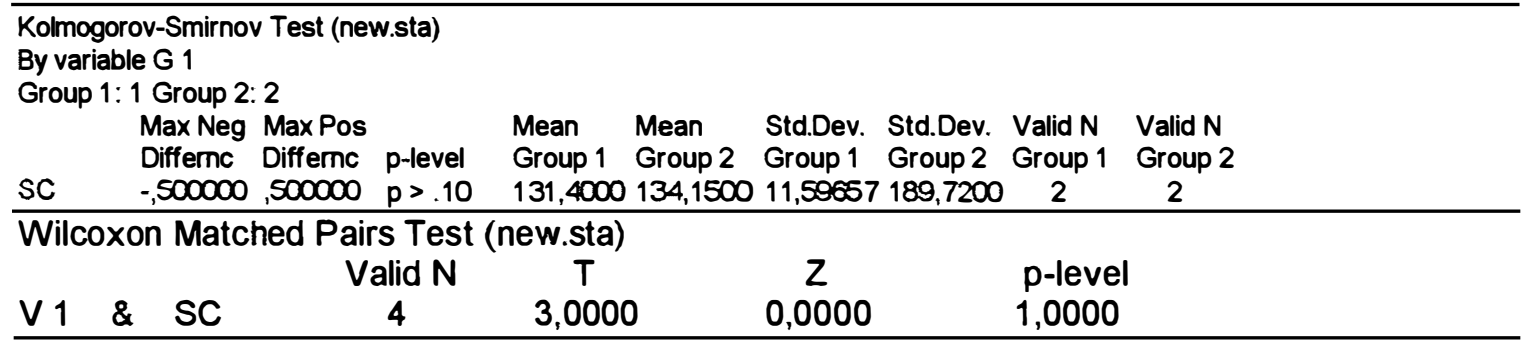

O raciocínio apresentado acima é válido para todos os fluxos e preços desde que os pares sejam iguais ou superiores a dois. Portanto, a demonstração das demais Tabelas para os fluxos e preços toma-se desnecessária e repetitiva. Sendo assim, as Tabelas A4.2 e A4.3 limitar-se-ão a apresentar as saídas obtidas para os testes de Kolmogorov-Smimov e Wilcoxon, respectivamente. Já a Tabela $A 4.4$ refere-se ao teste para os Estados que não possuiram fluxos de outros Estados, bem como a Tabela A4.5 refere-se ao fluxo total ocorrido por Estados. 
Tabela A4.2 - Saída do software Statistica para os fluxos de soja entre os Estados, entre os Estados e os portos e entre os preços.

\begin{tabular}{|c|c|c|c|c|c|c|c|c|c|}
\hline \multicolumn{10}{|c|}{ Kolmogorov-Smimov Test (new.sta) } \\
\hline & Max Neg & Max Pos & & Mean & Mean & Std.Dev. & Std.Dev. & Valid N & Valid N \\
\hline & Differnc & Differnc & p-level & Group 1 & Group 2 & Group 1 & Group 2 & Group 1 & Group 2 \\
\hline$\overline{P R}$ &,- 200000 &, 400000 & $p>.10$ & 1158,960 & 1160,700 & 1445,378 & 2073,618 & 5 & 5 \\
\hline MS &,- 333333 &, 333333 & $p>.10$ & 801,3000 & 1196,700 & 1146,194 & 4361,4796 & 3 & 3 \\
\hline SP &,- 200000 &, 400000 & $p>.10$ & 531,2000 & 522,3590 & 352,9002 & 2350,6268 & 5 & 5 \\
\hline GO &,- 333333 &, 666667 & $p>.10$ & 140,5333 & 139,5009 & 106,9956 & 241,7942 & 3 & 3 \\
\hline PGUA &,- 200000 &,$\infty 00000$ & $p>.10$ & 233,0000 & 232,43909 & 281,3517 & 7475,8710 & 5 & 5 \\
\hline SANT &,- 333333 &, 333333 & $p>.10$ & 169,0167 & 167,5500 & 141,2803 & 3203,0315 & 6 & 6 \\
\hline SFSC &,- 333333 & ,666667 & $p>.10$ & 31,50000 & 31,66667 & 41,85224 & 454,84827 & 3 & 3 \\
\hline Preço D. &,- 212121 &, 060606 & $p>.10$ & 177,5788 & 179,4121 & 15,85416 & 13,64697 & 33 & 33 \\
\hline Preço O. &,- 121212 &, 090009 & $p>.10$ & 177,5788 & 177,0363 & 15,85416 & 6 13,œ3838 & 33 & 33 \\
\hline
\end{tabular}

Tabela A4.3 - Saída do software Statistica para os fluxos de soja entre os Estados, entre os Estados e os portos e entre os preços.

\begin{tabular}{lrrrc}
\multicolumn{5}{l}{ Wilcoxon Matched Pairs Test (new.sta) } \\
& Valid N & $\mathrm{T}$ & $\mathrm{Z}$ & p-level \\
\hline PR & 10 & 16,00000 & 0,28006 & 0,77944 \\
MS & 4 & 5,000000 & 0,00000 & 1,00000 \\
SP & 10 & 21,00000 & 0,17770 & 0,85896 \\
GO & 6 & 4,000000 & 0,36515 & 0,71500 \\
PGUA & 10 & 10,00000 & 0,67612 & 0,49897 \\
SANT & 12 & 18,00000 & 0,00000 & 1,00000 \\
SFSC & 6 & 4,000000 & 0,36515 & 0,71500 \\
Preço D & 66 & 1076,500 & 0,18525 & 0,85303 \\
Preço O & 66 & 1076,500 & 0,18525 & 0,85303 \\
\hline
\end{tabular}

Tabela A4.4 - Fluxo de soja ocorrido dentro dos Estados de Minas Gerais e Mato Grosso em $1000 \mathrm{t}$.

\begin{tabular}{l|c|c}
\hline Estado & Atual & Modelo \\
\hline Minas Gerais & 288,1 & 290,1 \\
Mato Grosso & 2545,6 & 2517,7 \\
\hline Total & 2833,7 & 2807,8 \\
\hline
\end{tabular}

Tabela A4.4.1 - Entrada dos dados para o software Statística.

\begin{tabular}{c|c|c|c}
\hline \multicolumn{2}{c|}{ Entrada Kolmogorov-Smimov } & \multicolumn{2}{|c}{ Entrada Wilcoxon } \\
\hline G9 & MGMT & V9 & MGMT \\
\hline 1 & 288,1 & 0 & 290,1 \\
1 & 2545,6 & 0 & 2517,7 \\
2 & 290,1 & 288,1 & 0 \\
2 & 2517,7 & 2545,6 & 0 \\
\hline
\end{tabular}


Tabela A 4.4.2 - Saída do software Statistica.

Kolmogorov-Smimov Test (new.sta)

By variable $\mathrm{G} 4$

Group 1: 1 Group 2: 2

Max Neg MaxPos Mean Mean Std.Dev. Std.Dev. Valid N Valid N

Differnc Differnc p-level Group 1 Group 2 Group 1 Group 2 Group 1 Group 2

$\begin{array}{llllllllll}\text { MGMT } & -, 500000,500000 & p>.10 & 1416,850 & 1403,900 & 1596,294 & 1575,151 & 2 & 2\end{array}$

Wilcoxon Matched Pairs Test (new.sta)

\begin{tabular}{lllll}
$V 4$ & $\&$ \\
\hline
\end{tabular}

Tabela A4.5 - Fluxo de soja total (dentro e fora) do estado em $1000 \mathrm{t}$.

\begin{tabular}{l|c|c}
\hline Estado & Fluxo Atual & Fluxo Modelo \\
\hline SC & 262,8 & 268,3 \\
PR & 5795,7 & 5803,5 \\
SP & 2631,1 & 2611,8 \\
MS & 2403,9 & 2394,4 \\
GO & 421,5 & 418,8 \\
MG & 288,1 & 290,1 \\
MT & 2545,6 & 2517,7 \\
PGUA & 1159,8 & 1162,2 \\
SANT & 1014,0 & 1005,3 \\
SFSC & 94,5 & 95,0 \\
\hline Fluxo Total & 16617,0 & 16567,1
\end{tabular}

Tabela A4.5.1 - Entrada dos dados para o software Statistica.

\begin{tabular}{cr|c|c}
\hline \multicolumn{2}{c|}{ Entrada Kolmogorov-Smimov } & \multicolumn{2}{|c}{ Entrada Wilcoxon } \\
\hline G 11 & Fluxo & V11 & Fluxo \\
\hline 1 & 262,8 & 0 & 268,3 \\
1 & 5795,7 & 0 & 5803,5 \\
1 & 2631,1 & 0 & 2611,8 \\
1 & 2403,9 & 0 & 2394,4 \\
1 & 421,5 & 0 & 418,8 \\
1 & 288,1 & 0 & 290,1 \\
1 & 2545,6 & 0 & 2517,7 \\
1 & 1159,8 & 0 & 1162,2 \\
1 & 1014,0 & 0 & 1005,3 \\
2 & 94,5 & 0 & 95,5 \\
2 & 268,3 & 262,8 & 0 \\
2 & 5803,5 & 5795,7 & 0 \\
2 & 2611,8 & 2631,1 & 0 \\
2 & 2394,4 & 2403,9 & 0 \\
2 & 418,8 & 421,5 & 0 \\
2 & 290,1 & 288,1 & 0 \\
2 & 2517,7 & 2545,6 & 0 \\
2 & 1162,2 & 1159,8 & 0 \\
2 & 1005,3 & 1014,0 & 0 \\
\hline
\end{tabular}


Tabela A4.5.2 - Saída do software Statistica.

\begin{tabular}{|c|c|c|c|c|c|c|c|c|c|}
\hline $\begin{array}{l}\text { Kolmo } \\
\text { By vari } \\
\text { Group }\end{array}$ & $\begin{array}{l}\text { ov-Smimo } \\
\text { le G } 5 \\
1 \text { Group } 2 \\
\text { Max Neg } \\
\text { Differnc } \\
-, 100000\end{array}$ & $\begin{array}{l}\text { v Test (nev } \\
2 \\
\text { Max Pos } \\
\text { Diffemc } \\
, 100000\end{array}$ & $\begin{array}{l}\text { p-level } \\
p>.10\end{array}$ & $\begin{array}{l}\text { Mean } \\
\text { Group 1 } \\
1661,700\end{array}$ & $\begin{array}{l}\text { Mean } \\
\text { Group 2 } \\
1656,799\end{array}$ & $\begin{array}{l}\text { Std.Dev. } \\
\text { Group } 1 \\
1759,771\end{array}$ & $\begin{array}{l}\text { Std.Dev. } \\
\text { Group } 2 \\
1758,443\end{array}$ & $\begin{array}{c}\text { Valid N } \\
\text { Group } 1 \\
10\end{array}$ & $\begin{array}{l}\text { Valid N } \\
\text { Group 2 } \\
10\end{array}$ \\
\hline \multicolumn{10}{|c|}{ Wilcoxon Matched Pairs Test (new.sta) } \\
\hline V 5 & Fluxo & & $\begin{array}{l}\text { alid } N \\
20\end{array}$ & $\begin{array}{c}T_{105,000} \\
\end{array}$ & & $\underset{0,0000}{Z}$ & & $\begin{array}{l}\text { p-level } \\
1,0000\end{array}$ & \\
\hline
\end{tabular}

